\title{
Preeclampsia : cardiovascular health and renal function
}

Citation for published version (APA):

Spaan, J. J. (2012). Preeclampsia : cardiovascular health and renal function. [Doctoral Thesis, Maastricht University]. Maastricht University. https://doi.org/10.26481/dis.20121026js

Document status and date:

Published: 01/01/2012

DOI:

10.26481/dis.20121026js

Document Version:

Publisher's PDF, also known as Version of record

\section{Please check the document version of this publication:}

- A submitted manuscript is the version of the article upon submission and before peer-review. There can be important differences between the submitted version and the official published version of record.

People interested in the research are advised to contact the author for the final version of the publication, or visit the DOI to the publisher's website.

- The final author version and the galley proof are versions of the publication after peer review.

- The final published version features the final layout of the paper including the volume, issue and page numbers.

Link to publication

\footnotetext{
General rights rights.

- You may freely distribute the URL identifying the publication in the public portal. please follow below link for the End User Agreement:

www.umlib.nl/taverne-license

Take down policy

If you believe that this document breaches copyright please contact us at:

repository@maastrichtuniversity.nl

providing details and we will investigate your claim.
}

Copyright and moral rights for the publications made accessible in the public portal are retained by the authors and/or other copyright owners and it is a condition of accessing publications that users recognise and abide by the legal requirements associated with these

- Users may download and print one copy of any publication from the public portal for the purpose of private study or research.

- You may not further distribute the material or use it for any profit-making activity or commercial gain

If the publication is distributed under the terms of Article $25 \mathrm{fa}$ of the Dutch Copyright Act, indicated by the "Taverne" license above, 
Cardiovascular health

and renal function

\author{
Julia Spaan
}




\section{Preeclampsia}

Cardiovascular health and renal function 


\section{Preeclampsia \\ Cardiovascular health and renal function}

\section{Proefschrift}

ter verkrijging van de graad van doctor aan de Universiteit Maastricht, op gezag van de Rector Magnificus, Prof. dr. Luc Soete volgens het besluit van het College van Decanen, in het openbaar te verdedigen op vrijdag 26 oktober 2012 om 10.00 uur

door

Julia Jeltje Spaan

ISBN/EAN: 978-90-819808-0-7

Grafisch ontwerp proefschrift: Milena Spaan

๑) Julia Spaan, Maastricht 2012 


\section{Promotor:}

Prof. dr. M.E.A. Spaanderman

\section{Copromotor:}

Dr. L.L.H. Peeters

\section{Beoordelingscommissie:}

Prof. dr. P.W. de Leeuw (voorzitter)

Prof. dr. A. Franx (Universiteit Utrecht)

Prof. dr. F.K. Lotgering (Radboud Universiteit)

Prof. dr. J.G. de Mey

Dr. L.J.M. Smits

Het verschijnen van dit proefschrift werd mede mogelijk gemaakt door de steun van de Nederlandse Hartstichting. 


\section{Table of contents}

1. General introduction

Part I: Cardiovascular health

2. Remote hemodynamics and renal function in formerly preeclamptic women

Obstetrics \& Gynecology

3. Markers of cardiovascular disease after hypertension in pregnancy

Journal of Hypertension

4. Insulin resistance relates to microvascular reactivity 23 years after preeclampsia

Microvascular Research

\section{Part II: Renal function}

5. Reduced renal function after preeclampsia does not result from accelerated age-dependent renal function loss Acta Obstetricia et Gynecologica Scandinavica

6. Renal function after preeclampsia: a longitudinal pilot study Nephron Clinical Practice

\section{Part III: Cardiovascular risk management}

7. Cardiovascular risk management following a hypertensive disorder of pregnancy: a review

Hypertension

8. The metabolic syndrome as a risk factor for hypertension after preeclampsia

Obstetrics \& Gynecology

9. General discussion

10. Samenvatting

11. Dankwoord 


\section{Chapter 1}

\section{General introduction}

Emerging evidence has changed our view on preeclampsia from being a syndrome unique and confined to pregnancy to a risk marker for cardiovascular disease. Large epidemiological studies have shown that women with a history of preeclampsia have an increased risk of cardiovascular disease, such as ischemic heart disease, cerebrovascular accidents and venous thromboembolism. ${ }^{1}$ Such studies do not reveal the functional impact of a previous preeclampsia on several organs. This thesis tries to provide insight in long-term cardiovascular health and renal function of women with a history of preeclampsia. Risk factors for the development of chronic hypertension after preeclampsia are evaluated and a clinical strategy for cardiovascular risk management after a hypertensive disorder pregnancy will be proposed.

\section{Clinical picture of preeclampsia}

Pregnancy can be complicated by hypertension, either pre-existent or new-onset during pregnancy (table 1). Preeclampsia is a hypertensive disorder of pregnancy, characterized by new-onset hypertension and proteinuria. Preeclampsia is an important cause of maternal and fetal mortality and morbidity worldwide complicating approximately 2-8\% of all pregnancies. ${ }^{2}$ It is a systemic disorder, in which several organs are involved, such as the liver, kidneys and brain. The role of the placenta is pivotal for the development and progression of the disorder. After delivery the clinical syndrome usually resolves within a couple of days.

\footnotetext{
Table 1: Definitions of hypertension for this thesis.

Hypertensive disorder of pregnancy

- Preeclampsia: a syndrome of pregnancy characterized by new-onset hypertension $(\geq 140 / 90 \mathrm{mmHg})$ and proteinuria $(\geq 300 \mathrm{mg} / 24 \mathrm{hr})$; diagnosed after 20 weeks of gestation.

- Gestational hypertension: new-onset hypertension ( $\geq 140 / 90 \mathrm{mmHg}$ ) in pregnancy; diagnosed after 20 weeks of gestation.

Chronic hypertension

- Pre-existent hypertension: hypertension $(\geq 140 / 90 \mathrm{mmHg})$ and/or usage of antihypertensive drugs before pregnancy; or hypertension $(\geq 140 / 90 \mathrm{mmHg})$ diagnosed before 20 weeks of gestation.

- Hypertension after pregnancy: hypertension $(\geq 140 / 90 \mathrm{mmHg})$ and/or usage of antihypertensive drugs after first completed pregnancy.
} 


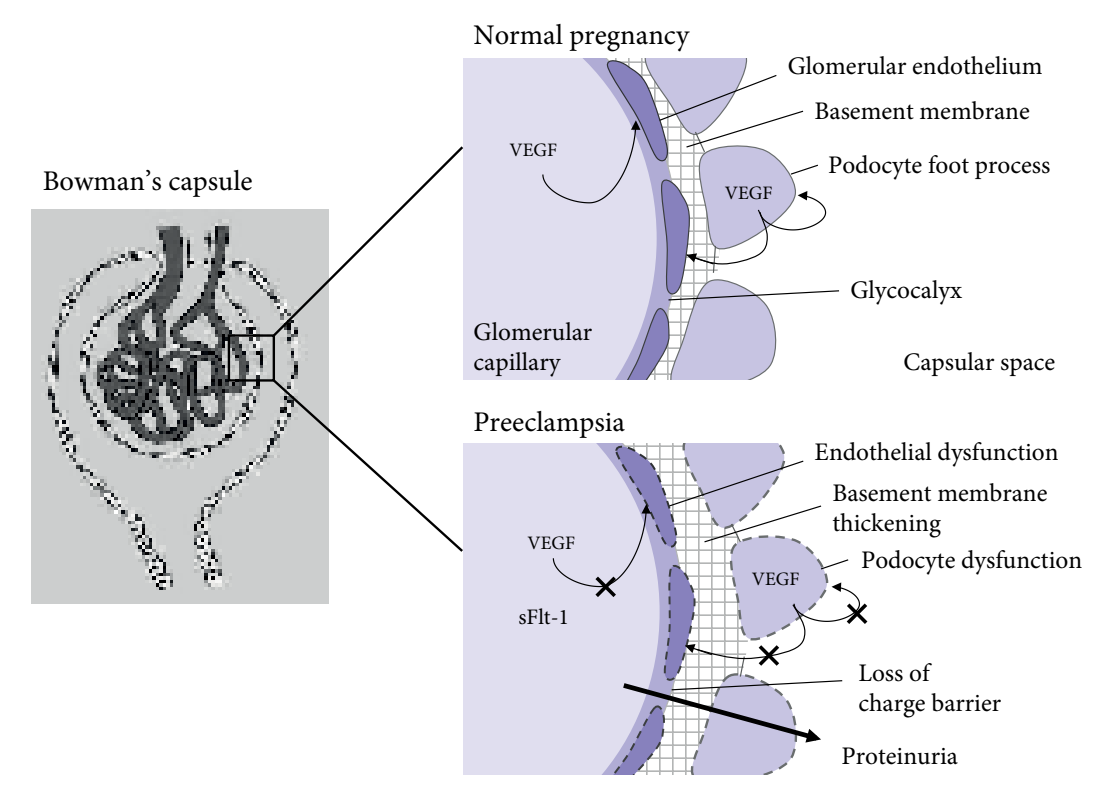

\section{Etiology}

Endothelial dysfunction plays a central role in the etiology of preeclampsia. For many years, the placenta was considered to release an unknown factor $\mathrm{X}$, causing endothelial dysfunction and subsequently leading to damage in a number of target organs. Basic science studies have unravelled several pathophysiological steps that lead to impaired placentation. Nowadays, we consider shallow trophoblast invasion, necessary for remodelling of the spiral arteries, a key feature in preeclampsia. ${ }^{3}$ Moreover, the importance of soluble Flt-1, an antiangiogenic factor, in the pathophysiology of preeclampsia has been established. A normal healthy placenta releases substances such as placental growth factor (PlGF) and vascular endothelial growth factor (VEGF). Receptors for VEGF (such as Flt-1) are present on all endothelial cells and contribute to a healthy endothelium. In preeclampsia, the placenta releases large amounts of soluble Flt-1, a circulating receptor for VEGF, which antagonizes the actions of VEGF by binding it and thus preventing VEGF from interacting with its receptor on the endothelium. ${ }^{3}$ This may result in systemic endothelial dysfunction, triggering the clinical symptoms of preeclampsia.

\section{Preeclampsia and the kidneys}

The kidneys show typical histological features during preeclampsia, called glomerular endotheliosis. The glomerular barrier consists of several layers, which is impermeable for larger molecules such as proteins. ${ }^{4}$ Typical histological findings from kidney biopsies in preeclampsia are thickening and swelling of the glomerular basement membrane and loss of endothelial cell fenestrae. ${ }^{5}$ The glycocalyx, contributing to charge selectivity of the membrane, is also affected. Electron microscopy shows loss of podocyte foot processes, which are crucial to maintain the integrity of the membrane. ${ }^{6}$ All these changes lead to reduced permselectivity of the glomerular barrier and loss of proteins in the urine.

Figure 1: Model of kidney dysfunction in preeclampsia

Figure 1 displays a pathway on how circulating soluble Flt- 1 may cause glomerular endotheliosis in preeclampsia. VEGF is essential for formation of endothelial cell fenestrae and proper functioning of the glomerular endothelium. ${ }^{7}$ The podocytes produce large amounts of VEGF and this local signalling seems critical for their adequate functioning and that of the glomerular endothelium. ${ }^{4,8}$ The blockage of VEGF by circulating soluble Flt-1 leads to detrimental effects on the glomerular filtration barrier. Infusion of soluble Flt-1 in mice or rats leads to rapid glomerular endothelial cell dysfunction and proteinuria. $^{9,10}$

Pregnancy induces renal hyperfiltration, with an increase in glomerular filtration rate of $40-60 \%$, resolving within a few weeks post partum..$^{11}$ During preeclampsia, the glomerular filtration rate is reduced to non-pregnant values, accompanied by a marked fall in glomerular ultrafiltration compared with normal pregnancy. ${ }^{12}$ After pregnancy a fast recovery of kidney function is observed. There is a marked improvement in glomerular filtration capacity in the first month post partum after preeclampsia. ${ }^{11}$ Although proteinuria usually resolves within a couple of months after delivery, microalbuminuria persists in about 30\%. ${ }^{13}$ 
Preeclampsia is associated with a five times increased risk of end-stage renal disease. ${ }^{14}$ Reports on long-term renal function after preeclampsia, especially using accurate methods, are scarce. A few cross-sectional studies evaluating kidney function several years after preeclampsia, did not find any difference in creatinine clearance when measured 3-6 years post partum. ${ }^{15,16} \mathrm{~A}$ gradual decline in renal function with age is observed in the general population from 30 years onwards, reflected by a decrease in glomerular filtration rate of $1 \mathrm{ml} /$ year. $^{17}$

Preeclampsia itself or concomitant risk factors, such as hypertension, could induce kidney damage, making the kidneys prone to accelerated age-related renal function loss.

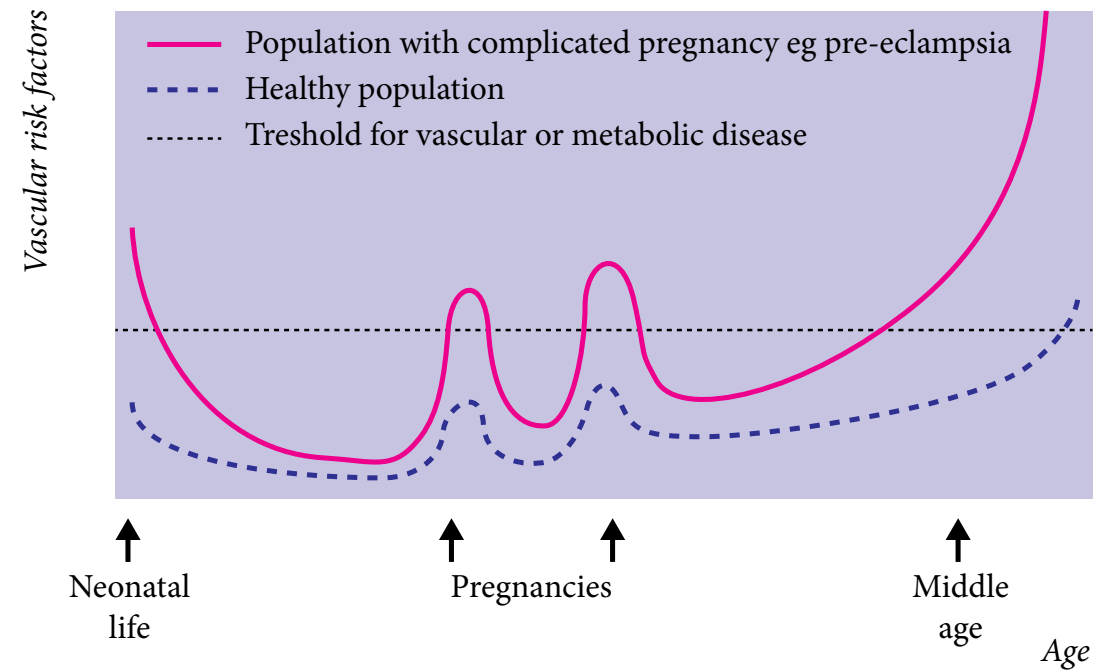

Figure 2: Pregnancy as a stress test

Reproduced with permission from the BMJ Publishing Group Ltd. ${ }^{20}$

\section{Preeclampsia and cardiovascular disease}

Women with a history of preeclampsia have an almost four times higher risk of chronic hypertension and a doubled risk of cardiovascular diseases (table 2). ${ }^{1,18}$ These risks are observed within 10-20 years after pregnancy in relatively young women. The life expectancy is reduced by approximately 6 years, mainly due to cardiovascular death. ${ }^{19}$ Risk factors for preeclampsia show large overlap with classical risk factors for cardiovascular disease, such as obesity, hyperinsulinemia and dyslipidemia. Elaborating on this, Sattar proposed the following theory (figure 2). ${ }^{20}$ Pregnancy can be considered as a stress test for the vascular and metabolic system. Women with a preexisting cardiovascular risk exceed a certain threshold for disease during pregnancy triggering the development of preeclampsia. Later in life, ageing will lead to the development of cardiovascular disease at a younger age than in women who had uneventful pregnancies.

Several reports support the view that pre-existing risk factors contribute to the increased risk of cardiovascular disease after preeclampsia. However, it is still unsettled whether preeclampsia itself has a direct effect contributing to the development of cardiovascular disease. Irrespective of whether this risk profile is pre-existent or induced by pregnancy itself, the occurrence of a hypertensive disorder of pregnancy identifies women at risk for cardiovascular disease. This offers opportunities for prevention of cardiovascular disease in these women. Currently, there is no structured follow-up after a hypertensive disorder of pregnancy and no guidelines for cardiovascular risk management in these women. 


\section{Outline of this thesis}

This thesis focuses on possible underlying mechanisms explaining the increased risk of cardiovascular disease after preeclampsia and the impact on target organs such as the cardiovascular system and kidneys.

Chapter 2 determines the remote impact of preeclampsia on hemodynamic and renal function. A group of women with a history of preeclampsia are studied at middle-age, on average 23 years after pregnancy. Chapter 3 studies cardiovascular risk factors and renal, endothelial and sympathetic function in women with a history of preeclampsia and gestational hypertension about 4 years postpartum. Chapter 4 explores the role of endothelial dysfunction in middleaged women with a history of preeclampsia evaluating microvascular reactivity and its relation with several cardiovascular risk factors.

Chapter 5 elaborates on the hypothesis that women with a history of preeclampsia may have accelerated age-related renal function loss compared to women with a history of normal pregnancies. It compares two different age groups, young and middle-aged women, in a cross-sectional study design. The same question is addressed in Chapter 6, after optimizing the study methods using a longitudinal design and inulin clearances to measure renal function.

Chapter 7 presents a clinical strategy for cardiovascular risk management following a hypertensive disorder of pregnancy. Chapter 8 identifies, within a population of women with a history of preeclampsia, metabolic and obstetric risk factors for the subsequent development of chronic hypertension.

Chapter 9 summarizes the main findings of this thesis. The general discussion highlights the implications of this thesis for future research and ends with the conclusion of this thesis.

\section{References}

1. Bellamy L, Casas JP, Hingorani AD, Williams DJ. Pre-eclampsia and risk of cardiovascular disease and cancer in later life: systematic review and meta-analysis. Bmj. 2007;335:974.

2. Steegers EA, von Dadelszen P, Duvekot JJ, Pijnenborg R. Pre-eclampsia. Lancet. 2010;376:631-44.

3. Karumanchi SA, Maynard SE, Stillman IE, Epstein FH, Sukhatme VP. Preeclampsia: a renal perspective. Kidney Int. 2005;67:2101-13

4. Lindheimer MD, Kanter D. Interpreting abnormal proteinuria in pregnancy: the need for a more pathophysiological approach. Obstet Gynecol. 2010;115:365-75.

5. Packham DK, Mathews DC, Fairley KF, Whitworth JA, Kincaid-Smith PS. Morphometric analysis of preeclampsia in women biopsied in pregnancy and post-partum. Kidney Int. 1988;34:704-11.

6. Aita $\mathrm{K}$, Etoh $\mathrm{M}$, Hamada $\mathrm{H}$, et al. Acute and transient podocyte loss and proteinuria in preeclampsia. Nephron Clin Pract. 2009;112:c65-70.

7. Ballermann BJ. Contribution of the endothelium to the glomerular permselectivity barrier in health and disease. Nephron Physiol. 2007;106:19-25.

8. Eremina V, Baelde HJ, Quaggin SE. Role of the VEGF--a signaling pathway in the glomerulus: evidence for crosstalk between components of the glomerular filtration barrier. Nephron Physiol. 2007;106:32-7.

9. Maynard SE, Min JY, Merchan J, et al. Excess placental soluble fms-like tyrosine kinase 1 (sFlt1) may contribute to endothelial dysfunction, hypertension, and proteinuria in preeclampsia. J Clin Invest. 2003;111:649-58.

10. Sugimoto $\mathrm{H}$, Hamano $\mathrm{Y}$, Charytan D, et al. Neutralization of circulating vascular endothelial growth factor (VEGF) by anti-VEGF antibodies and soluble VEGF receptor 1 (sFlt-1) induces proteinuria. J Biol Chem. 2003;278:12605-8.

1. Hladunewich MA, Myers BD, Derby GC, et al. Course of preeclamptic glomerular injury after delivery. Am J Physiol Renal Physiol. 2008;294:F614-20.

12. Moran P, Baylis PH, Lindheimer MD, Davison JM. Glomerular ultrafiltration in normal and preeclamptic pregnancy. J Am Soc Nephrol. 2003;14:648-52.

13. McDonald SD, Han Z, Walsh MW, Gerstein HC, Devereaux PJ. Kidney disease after preeclampsia: a systematic review and meta-analysis. Am J Kidney Dis. 2010;55:1026-39.

14. Vikse BE, Irgens LM, Leivestad T, Skjaerven R, Iversen BM. Preeclampsia and the risk of end-stage renal disease. N Engl J Med. 2008;359:800-9.

15. Bar J, Kaplan B, Wittenberg C, et al. Microalbuminuria after pregnancy complicated by pre-eclampsia. Nephrol Dial Transplant. 1999;14:1129-32

16. Lampinen KH, Ronnback M, Groop PH, Kaaja RJ. Renal and vascular function in women with previou preeclampsia: a comparison of low- and high-degree proteinuria. Kidney Int. 2006;70:1818-22.

17. Zhou XJ, Rakheja D, Yu X, Saxena R, Vaziri ND, Silva FG. The aging kidney. Kidney Int. 2008;74:710-20 18. McDonald SD, Malinowski A, Zhou Q, Yusuf S, Devereaux PJ. Cardiovascular sequelae of preeclampsia/ eclampsia: a systematic review and meta-analyses. Am Heart J. 2008;156:918-30.

19. Arnadottir GA, Geirsson RT, Arngrimsson R, Jonsdottir LS, Olafsson O. Cardiovascular death in women who had hypertension in pregnancy: a case-control study. Bjog. 2005;112:286-92.

20. Sattar N, Greer IA. Pregnancy complications and maternal cardiovascular risk: opportunities for intervention and screening? Bmj. 2002:325:157-60. 


\section{PART I}

\section{Cardiovascular health}

Julia Spaan, Timo Ekhart, Marc Spaanderman, Louis Peeters

\section{Chapter 2}

Remote hemodynamics and renal function in formerly preeclamptic women

$$
\text { Obstetrics \& Gynecology 2009;113:853-9 }
$$


Objective: Women with a history of preeclampsia have an increased risk of developing chronic hypertension and cardiovascular disease. However, little is known about the mechanism responsible for vascular disease in formerly preeclamptic women. The aim of our study was to test whether preeclampsia predisposes to central hemodynamic and renal impairments 20 years after pregnancy.

Methods: In this cross-sectional study, 22 formerly preeclamptic women and 29 parous controls participated, matched for BMI, age and date of birth. All women delivered in the period of 1979-1987. Measures included automated blood pressure, Doppler echocardiography, microalbuminuria, para-aminohippurate and creatinine clearances. Hypertension was defined as blood pressure at or above 140/90 mmHg, using antihypertensive drugs, or both.

Results: Hypertension was present in $55 \%$ of the formerly preeclamptic women and $7 \%$ of the women in the control group $(\mathrm{p}<.01)$. Mean arterial pressure was higher in the formerly preeclamptic women compared with controls (100 and $88 \mathrm{mmHg}$, respectively, $\mathrm{p}<.01$ ).

Peripheral vascular resistance was about $20 \%$ higher, renal vascular resistance about $30 \%$ higher, and renal blood flow about $15 \%$ lower in the formerly preeclamptic women compared with those in the control group $(\mathrm{p}<.05)$. Similar results were observed after stratification for hypertension in both groups.

Conclusion: Both normotensive and hypertensive middle-aged formerly, formerly preeclamptic women showed impaired central hemodynamic and renal function compared with parous controls.

\section{Introduction}

Preeclampsia, a syndrome of pregnancy characterized by new onset hypertension and proteinuria, affects about $5-8 \%$ of all first pregnancies. ${ }^{1}$ Preeclampsia accounts for considerable maternal and associated fetal morbidity and mortality. Recent epidemiological data have shown an association between preeclampsia and cardiovascular and renal disease in later life. ${ }^{2-4}$ Within 10 to 20 years after a complicated pregnancy, these women have three to fourfold higher risk of developing chronic hypertension and a twofold higher risk of stroke, venous thromboembolism, and ischemic heart disease compared with healthy parous controls. ${ }^{2}$ Later kidney disease, diagnosed by biopsy or the presence of end-stage renal disease, is more prevalent among formerly preeclamptic women compared with controls. ${ }^{5,6}$ Additionally, life expectancy is reduced by 3 to 9 years, with excess mortality mainly as a consequence of cardiovascular disease. ${ }^{7}$

The etiology of preeclampsia is only partly resolved. Impaired earlypregnancy placentation and endothelial dysfunction seem to play a central role. A large body of evidence favors the hypothesis of pregnancy-related hypertensive disease being superimposed upon a preexisting disorder. ${ }^{8-10}$ Underlying pathophysiological phenotypes may be hypertensive (latent or present), metabolic, auto-immunologic, thrombophilic, or any combination of these. ${ }^{10}$ These disorders share the capacity to jeopardize both endothelial and placental function. It has been proposed that preeclampsia relates to later cardiovascular disease because of shared risk factors. ${ }^{11,12}$ However, the exact mechanism underlying the increased cardiovascular disease risk in preeclamptic women has not been unraveled yet. It is well known that aging negatively influences the vascular system. Aging increases vascular stiffness and affects renal function; however, women seem to be protected in the premenopausal phase. ${ }^{13-16}$ Hemodynamic and renal functions have not been previously studied in middle-aged, formerly preeclamptic women. In this study we tested the hypothesis that preeclampsia predisposes to remote central hemodynamic and renal impairments.

\section{Methods}

We performed this cross-sectional study in 22 formerly preeclamptic women and 29 parous controls in the period of 2001 until 2008. Participants were all white and matched for age, BMI and date of birth. Figure 1 illustrates the selection procedure. 


\begin{tabular}{|c|c|}
\hline Control group $n=113$ & PE group $n=67$ \\
\hline & \\
\hline No recent address $n=39(35 \%)$ & No recent address $n=13(20 \%)$ \\
\hline \multirow[t]{2}{*}{ Died n=2 (2\%) } & Died $n=2(3 \%)$ \\
\hline & $\begin{array}{l}\text { Excluded } n=8(12 \%) \\
\text { Renal failure } n=2 \\
\text { Diabetes mellitus } n=2 \\
\text { Others } n=4\end{array}$ \\
\hline \multicolumn{2}{|c|}{ Invited to participate } \\
\hline Control group $n=72$ & $P E$ group $n=44$ \\
\hline Refusal $n=43(60 \%)$ & Refusal $\mathrm{n}=22(50 \%)$ \\
\hline Informed consent $\mathrm{n}=29(40 \%)$ & Informed consent $\mathrm{n}=22(50 \%)$ \\
\hline
\end{tabular}

Figure 1: Flowchart of the selection procedure.

We retrieved clinical information for all women who delivered after a preeclamptic pregnancy in the period between 1979 and 1987 at the Department of Obstetrics of the Academic Hospital of Maastricht in the Netherlands. Preeclampsia was defined according to the criteria of the Report of the National High Blood Pressure Education Program Working Group on High Blood Pressure in Pregnancy. ${ }^{1}$ An uncomplicated pregnancy was defined as a term singleton pregnancy without complications such as fetal growth restriction, pregnancyinduced hypertension or gestational diabetes. For every primiparous preeclamptic woman, we selected chronologically from the birth register the next two matching primiparous women with uncomplicated pregnancies and deliveries. From the women identified, four women died in the period elapsed since their pregnancies; three from cancer, and one formerly preeclamptic woman had had a fatal cardiac event. Eight formerly preeclamptic women were excluded for medical reasons, namely non-insulin-dependent diabetes mellitus $(n=2)$, cancer therapy $(\mathrm{n}=3)$, chronic corticosteroid use $(\mathrm{n}=1)$ and chronic renal failure $(n=2)$ due to nephrosclerosis and chronic pyelonephritis. Eventually, 44 formerly preeclamptic women and 72 parous controls were invited to participate in this study. From these women, 22 formerly preeclamptic women (50\%) and 29 controls (40\%) gave informed consent to participate. Main reasons for refusal were lack of time (45\%), psychological burden (25\%) and invasiveness of measurements $(10 \%)$. The study protocol was approved by the hospital medical ethical committee board.

Hypertension was defined as blood pressure at or above 140/90 $\mathrm{mmHg}$ during the measurement session, using antihypertensive drugs, or both. Women were considered postmenopausal if they had had 1 year without menstrual bleeding. Early-onset preeclampsia was defined as preeclampsia resulting in birth before gestational age of 34 weeks.

All experiments were preceded by 1 week of standardized sodium intake (100 mmol sodium/day), representing the mean sodium intake in our population. Antihypertensive drugs were discontinued 2 weeks prior to the measurements. Participants did not drink caffeine- or alcohol-containing beverages and refrained from smoking and eating for at least 10 hours prior to the experiment. Measurements were performed in standardized conditions in a temperature-controlled room $\left(25-26^{\circ} \mathrm{C}\right)$, with as little external disturbances as possible, in the mid-follicular phase (day $5 \pm 2$ ) of the menstrual period or randomly when postmenopausal. The measurement session started at 8:00 AM with the insertion of a 20-gauge catheter into a vein of the right forearm to enable estimation of renal function as detailed below. A second catheter was inserted into a vein of the contralateral forearm to collect blood samples. Throughout the measurement session, participants were laying on their back on a comfortable bed. After an acclimatization period of 30 minutes, we recorded arterial blood pressure and heart rate in supine position at 3-minute intervals using a semi-automatic oscillometric device (Dinamap Vital Signs Monitor 1846, Critikon, Tampa, FL).

Effective renal plasma flow was measured by continuous infusion of para-aminohippurate sodium (MSD, West Point, PA). We used the creatinine clearance as an estimate for glomerular filtration rate as inulin was not available due to manufactural problems. Both variables were corrected for body surface area and expressed in $\mathrm{ml} / \mathrm{min} / 1.73 \mathrm{~m}^{2}$. Effective renal blood flow was obtained by dividing the effective renal plasma flow by (1-hematocrit). Renal vascular resistance (dyne.s/ $\mathrm{cm}^{5} / 1.73 \mathrm{~m}^{2}$ ) was obtained by dividing mean arterial pressure by effective renal blood flow. At least 2 hours after the initiation of the para-aminohippurate sodium infusion, we collected blood samples 
for the later measurement of the circulating levels of para-aminohippurate and creatinine. Creatinine $(\mu \mathrm{mol} / \mathrm{l})$ was measured by standard chemical techniques. An extra blood sample was obtained to measure hematocrit (volume \%). Creatinine clearance was calculated from the 24-hours creatinine output during the day before measurement. In this collection, we also measured albumin excretion. Microalbuminuria was defined as urinary albumin excretion rate higher than 3.5 g/mol creatinine (BN ProSpec nephelometer).

Echocardiography to assess cardiac function was performed in semileft lateral position after 5 minutes of rest, using a cross-sectional, phased-array echocardiographic Doppler system. ${ }^{17}$ Cardiac output (CO, $1 / \mathrm{min})$ was calculated by multiplying stroke volume $(\mathrm{ml})$ by heart rate. In this formula, heart rate was obtained by taking the reciprocal of the mean of five consecutive R-R intervals on the electrocardiogram. Stroke volume was calculated by multiplying the aortic velocity integral and the aortic area. Aortic flow was measured across the aortic valves from an apical approach. The average area under the aortic velocity curve (aortic velocity integral) of five consecutive ejections was used to calculate stroke volume. Aortic valve diameter, necessary for the calculation of the aortic area, was measured off-line at the orifice during systole using $\mathrm{M}$-mode. Cardiac index (CO,

$1 / \mathrm{min} / \mathrm{m}^{2}$ ) was used to correct for body surface area. Total peripheral vascular resistance was calculated by 80 times mean arterial pressure divided by $\mathrm{CO}$. The value used for mean arterial pressure was obtained by blood pressure measurement during the $\mathrm{CO}$ measurement and was calculated as the mean of three consecutive recordings. An estimate for arterial compliance $(\mathrm{ml} / \mathrm{mmHg})$ was obtained by dividing stroke volume by pulse pressure.

Data distribution was evaluated using histograms and Q-Q plots. Homogeneity of variance was tested by Levene's test. Differences between groups were tested by Student t-test or Mann-Whitney U-test. Binary outcomes were tested by chi-square test. Using both multiple logistic and linear regression analysis, we adjusted for postmenopausal state. We further analyzed our data after stratification for hypertension by one-way analysis of variance followed by Dunnet's test or the Kruskal-Wallis test followed by Dunn's test. A p-value $<.05$ was considered statistically significant. Data are presented as mean with standard deviation or median with interquartile range.
Table 1: Characteristics of the study population.

\begin{tabular}{|l|l|l|l|}
\hline & $\begin{array}{l}\text { Controls } \\
(\mathrm{n}=29)\end{array}$ & $\begin{array}{l}\text { Formerly preeclamptic } \\
(\mathrm{n}=22)\end{array}$ & p-value \\
\hline Age (y) & $49.8 \pm 3.9$ & $49.0 \pm 3.9$ & 0.48 \\
\hline BMI $\left(\mathrm{kg} / \mathrm{m}^{2}\right)$ & $25.5 \pm 3.5$ & $25.0 \pm 3.6$ & 0.63 \\
\hline Smoking, n (\%) & $10(35)$ & $3(14)$ & 0.09 \\
\hline Postmenopausal, n (\%) & $5(17)$ & $8(36)$ & 0.12 \\
\hline Hypertension, n (\%) & $2(7)$ & $12(55)$ & $<0.01$ \\
\hline Stroke, n (\%) & $1(3)$ & $2(9)$ & 0.40 \\
\hline Thrombosis, $\mathrm{n}(\%)$ & $1(3)$ & $3(13)$ & 0.18 \\
\hline GA at birth (wks) & $404 / 7(38-42)$ & $346 / 7(27-43)$ & $<0.01$ \\
\hline Birth weight (g) & $3574(2730-4500)$ & $1801(880-3350)$ & $<0.01$ \\
\hline Early-onset PE, n (\%) & - & $9(41)$ & \\
\hline Parity & $2.2(1-4)$ & $1.7(1-3)$ & 0.04 \\
\hline Recurrent PE, n (\%) & - & $5(23)$ & 0.12 \\
\hline FU (y) & $23(20-28)$ & $23(20-28)$ & \\
\hline
\end{tabular}

Data are detailed as mean $\pm S D$, mean (min-max) or $n(\%)$. BMI, body mass index $G A$, gestational age; $P E$, preeclampsia; $F U$, follow-up time, years elapsed since preeclamptic or control pregnancy.

\section{Results}

Table 1 lists the characteristics of our study population. Both groups were comparable with respect to age, BMI at measurement, and follow-up time. Mean age was 49.8 (range: 42.2-59.0) for controls and 49.0 (range: $42.7-58.1$ ) years for formerly preeclamptic women. Eight formerly preeclamptic women (36\%) and five women in the control group (17\%) were postmenopausal. None of the women used hormone replacement therapy. Twelve formerly preeclamptic women (55\%) and two women in the control group (7\%) had hypertension at the time of measurement (RR 7.9; 95\%CI 2.0-31.8), with nine formerly preeclamptic women using antihypertensive medication at the time of recruitment. We diagnosed hypertension at the time of the measurement session in two women in the control group. Two formerly preeclamptic women and one woman in the control group had a history of stroke. Three formerly preeclamptic women and one woman in the control group had a history of thrombosis. Nine formerly preeclamptic women (41\%) had a history of early-onset preeclampsia, and five (23\%) had recurrent preeclampsia in their subsequent pregnancies. None of the women in the control group had hypertensive complications during subsequent pregnancies. 
Table 2: Cardiovascular and renal variables measured 23 years after pregnancy in formerly preeclamptic women and parous controls.

\begin{tabular}{|c|c|c|c|}
\hline & $\begin{array}{l}\text { Controls } \\
(\mathrm{n}=29)\end{array}$ & $\begin{array}{l}\text { Formerly preeclamptic } \\
(\mathrm{n}=22)\end{array}$ & $\mathrm{p}$-value \\
\hline \multicolumn{4}{|l|}{ Blood pressure (mmHg) } \\
\hline Systolic blood pressure & $117 \pm 15$ & $132 \pm 17$ & 0.001 \\
\hline Diastolic blood pressure & $72 \pm 9$ & $80 \pm 12$ & 0.005 \\
\hline Mean arterial pressure & $88 \pm 10$ & $100 \pm 12$ & 0.001 \\
\hline Pulse pressure & $45 \pm 11$ & $52 \pm 11$ & 0.021 \\
\hline Heart rate (bpm) & $66 \pm 7$ & $69 \pm 8$ & 0.288 \\
\hline \multicolumn{4}{|l|}{ Cardiovascular } \\
\hline Cardiac output (1/min) & $5.0 \pm 0.7$ & $4.8 \pm 0.7$ & 0.268 \\
\hline Cardiac index $\left(1 / \mathrm{min} / \mathrm{m}^{2}\right)$ & $2.8 \pm 0.4$ & $2.8 \pm 0.4$ & 0.583 \\
\hline LV ejection fraction (\%) & $61(58-64)$ & $65(59-66)$ & 0.145 \\
\hline E/A-ratio & $1.1(1.0-1.5)$ & $1.2(1.0-1.5)$ & 0.969 \\
\hline LV mass-index $\left(\mathrm{g} / \mathrm{m}^{2}\right)$ & $76(67-88)$ & $88(72-97)$ & 0.097 \\
\hline TPVR (dyne.s/cm ${ }^{5}$ ) & $14.6 \pm 1.9$ & $17.5 \pm 2.5$ & $<0.001$ \\
\hline Arterial compliance (ml/mmHg) & $1.6 \pm 0.3$ & $1.3 \pm 0.3$ & $<0.001$ \\
\hline \multicolumn{4}{|l|}{ Renal function } \\
\hline Creat Clear $\left(\mathrm{ml} / \mathrm{min} / 1.73 \mathrm{~m}^{2}\right)$ & $100 \pm 19$ & $88 \pm 15$ & 0.023 \\
\hline $\operatorname{ERPF}\left(\mathrm{ml} / \mathrm{min} / 1.73 \mathrm{~m}^{2}\right)$ & $463 \pm 83$ & $399 \pm 61$ & 0.003 \\
\hline $\operatorname{ERBF}\left(\mathrm{ml} / \mathrm{min}^{\prime} 1.73 \mathrm{~m}^{2}\right)$ & $768 \pm 138$ & $675 \pm 103$ & 0.011 \\
\hline $\operatorname{RVR}\left(.100\right.$ dyne.s $\left./ \mathrm{cm}^{5} / 1.73 \mathrm{~m}^{2}\right)$ & $95 \pm 20$ & $122 \pm 28$ & $<0.001$ \\
\hline Microalbuminuria $(>3,5 \mathrm{~g} / \mathrm{mol})$ & $3(10 \%)$ & $2(9 \%)$ & 0.881 \\
\hline
\end{tabular}

Data are presented as mean $\pm S D$, median (IQR) or $n(\%)$. bpm, beats per minute; $L V$ left ventricle; E/A, early and late diastolic peak flow velocity; TPVR, total peripheral vascular resistance; Creat Clear, Creatinine clearance; ERPF, effective renal plasma

flow; ERBF, effective renal blood flow; RVR, renal vascular resistance.

Table 2 lists the cardiovascular and renal variables comparing both study groups. Similar results were found after adjustment for postmenopausal state (not presented). Formerly preeclamptic women had higher systolic, diastolic and mean arterial blood pressure as compared with women in the control group. Cardiac function did not differ between the study groups. Formerly preeclamptic women differed from women in the control group by a $20 \%$ higher total peripheral vascular resistance and a lower arterial compliance. Renal vascular resistance was more than $30 \%$ higher and effective renal plasma flow about $15 \%$ lower in formerly preeclamptic women compared with women in the control group. Creatinine clearance was lowered in formerly preeclamptic women relative to women in the control group. The incidence of microalbuminuria was similar in both groups.
Table 3: Comparison of normotensive and hypertensive formerly preeclamptic (PE) women with parous controls.

\begin{tabular}{|c|c|c|c|}
\hline & $\begin{array}{l}\text { Controls } \\
(\mathrm{n}=29)\end{array}$ & $\begin{array}{l}\text { Normotensive } \\
\operatorname{PE}(n=10)\end{array}$ & $\begin{array}{l}\text { Hypertensive } \\
\text { PE }(\mathrm{n}=12)\end{array}$ \\
\hline \multicolumn{4}{|l|}{ Blood pressure $(\mathrm{mmHg})$} \\
\hline Systolic blood pressure & $117 \pm 15$ & $124 \pm 14$ & $139 \pm 16^{*}$ \\
\hline Diastolic blood pressure & $72 \pm 9$ & $75 \pm 10$ & $84 \pm 12^{\star}$ \\
\hline Mean arterial pressure & $88 \pm 10$ & $95 \pm 11$ & $104 \pm 13^{*}$ \\
\hline Pulse pressure & $45 \pm 11$ & $49 \pm 9$ & $55 \pm 13^{\dagger}$ \\
\hline Heart rate $(\mathrm{bpm})$ & $66 \pm 7$ & $66 \pm 9$ & $71 \pm 6$ \\
\hline \multicolumn{4}{|l|}{ Cardiovascular } \\
\hline Cardiac output (1/min) & $5.0 \pm 0.7$ & $4.6 \pm 0.8$ & $4.9 \pm 0.6$ \\
\hline Cardiac index $\left(1 / \mathrm{min} / \mathrm{m}^{2}\right)$ & $2.8 \pm 0.4$ & $2.7 \pm 0.4$ & $2.8 \pm 0.4$ \\
\hline LV ejection fraction (\%) & $61(58-64)$ & $64(58-67)$ & $65(59-66)$ \\
\hline E/A-ratio & $1.1(1.0-1.5)$ & $1.4(1.1-1.6)$ & $1.1(0.9-1.3)$ \\
\hline LV mass-index $\left(\mathrm{g} / \mathrm{m}^{2}\right)$ & $76(67-88)$ & $79(69-88)$ & $90(79-88)$ \\
\hline TPVR (dyne.s/cm5) & $14.6 \pm 1.9$ & $17.1 \pm 2.5^{\star}$ & $17.9 \pm 2.5^{\star}$ \\
\hline Arterial compliance $(\mathrm{ml} / \mathrm{mmHg})$ & $1.6 \pm 0.3$ & $1.3 \pm 0.2^{\dagger}$ & $1.3 \pm 0.4^{*}$ \\
\hline \multicolumn{4}{|l|}{ Renal function } \\
\hline Creat Clear $\left(\mathrm{ml} / \mathrm{min} / 1.73 \mathrm{~m}^{2}\right)$ & $100 \pm 19$ & $91 \pm 11$ & $86 \pm 18$ \\
\hline $\mathrm{ERPF}\left(\mathrm{ml} / \mathrm{min} / 1.73 \mathrm{~m}^{2}\right)$ & $463 \pm 83$ & $399 \pm 66^{\dagger}$ & $398 \pm 60^{\dagger}$ \\
\hline $\operatorname{ERBF}\left(\mathrm{ml} / \mathrm{min} / 1.73 \mathrm{~m}^{2}\right)$ & $768 \pm 138$ & $671 \pm 122$ & $678 \pm 90$ \\
\hline $\operatorname{RVR}\left(.100\right.$ dyne.s $\left./ \mathrm{cm}^{5} / 1.73 \mathrm{~m}^{2}\right)$ & $95 \pm 20$ & $118 \pm 35^{\dagger}$ & $125 \pm 21^{*}$ \\
\hline Microalbuminuria $(>3,5 \mathrm{~g} / \mathrm{mol})$ & $3(10 \%)$ & $0(-)$ & $2(17 \%)$ \\
\hline \multicolumn{4}{|c|}{$\begin{array}{l}\text { Data are presented as mean } \pm S D \text {, median }(I Q R) \text { or } n(\%) . P E \text {, preeclampsia; bpm, } \\
\text { beats per minute; } L V \text {, left ventricle; E/A, early and late diastolic peak flow velocity; } \\
T P V R, \text { total peripheral vascular resistance; Creat Clear, Creatinine clearance; ERPF, } \\
\text { effective renal plasma flow; ERBF, effective renal blood flow; RVR, renal vascular } \\
\text { resistance. } \\
{ }^{*} p \text {-value }<.01, \text { compared with controls, }{ }^{\dagger} p \text {-value }<.05 \text {, compared with controls. }\end{array}$} \\
\hline
\end{tabular}

Table 3 illustrates the comparison of hemodynamic and renal variables between formerly preeclamptic women, with or without hypertension, and women in the control group. Blood pressure variables and creatinine clearance in normotensive formerly preeclamptic women were intermediate between the values observed in hypertensive formerly preeclamptic women and women in the control group. Like hypertensive formerly preeclamptic women, the normotensive formerly preeclamptic women also differed from controls by higher total peripheral and renal vascular resistance and a lower arterial compliance. Left ventricular mass-index tended to be higher only in hypertensive formerly preeclamptic women. 
Discussion

In this study, we observed differences in central hemodynamics and renal function between formerly preeclamptic women and parous controls 23 years after pregnancy. The hemodynamic pattern we observed in formerly preeclamptic women (high blood pressure, increased peripheral vascular resistance and a normal cardiac output) is consistent with the changes observed in so-called volume-dependent essential hypertension. ${ }^{18,19}$ The kidneys play a central role in this theory because they adjust the setpoint for blood pressure by their effect on sodium homeostasis. The exact pathophysiology of essential hypertension is complex and only partly unraveled. The development of hypertension is the ultimate outcome of activated pathways involving systemic and renal vasoconstriction. These include hyperactivity of the sympathetic nervous system, hyperactivity of the reninangiotensin system and endothelial dysfunction. ${ }^{20}$ Our data suggest that renal vasoconstriction plays a central role in the pathogenesis of hypertension in formerly preeclamptic women. This concept is supported by the raised renal vascular resistance and reduced creatinine clearance in formerly preeclamptic women compared with controls, a difference already detected in normotensive formerly preeclamptic women. The renal impairment observed could be due to lower nephron number and glomerulosclerosis. ${ }^{21,22}$ We observed a low incidence of microalbuminuria in both groups; however, other studies report an increased incidence of microalbuminuria several years after preeclamptic pregnancy. ${ }^{23,24}$

The intermediate position of the group of normotensive formerly preeclamptic women between, on the one hand hypertensive formerly preeclamptic women and, on the other hand, the women in the control group, can be interpreted as prehypertension. The latter is characterized by loss of arterial compliance accompanied by raised systemic and renal vascular resistance and precedes manifest hypertension in high-risk groups such as adolescents of hypertensive parents. ${ }^{25-27}$ Our data suggest that impaired hemodynamic function precedes the onset chronic hypertension in formerly preeclamptic women. However, these data do not exclude the possibility that these impairments reflect an end-stage in the subgroup of normotensive formerly preeclamptic women.

Whether or not the observed changes were present before the preeclamptic pregnancy is obscure. There is increasing evidence for the concept that these women may have an altered vascular function already in their first years of life. During growth and development, genetic factors act in concert with environmental factors to determine the final functional capacity of the vascular system. ${ }^{28,29}$ Low-birth weight, preeclampsia, and essential hypertension seem to share a reduced vascular functional reserve capacity, for example, density of the capillary bed seems to be reduced in those conditions. ${ }^{30-32}$ In this view, preeclamptic women can be considered to represent a subgroup of women predestined to develop hypertension irrespective of pregnancy.

This study has certain limitations. Firstly, the recruitment of the women in the control group may have been hampered by some selection bias because women with certain health problems may have been more eager to participate in this study than their counterparts without any health problems. As the latter could have an attenuating effect on potential differences with formerly preeclamptic women, this effect may only have reduced the already marked differences observed in this study. Secondly, more than 20 years elapsed since either the preeclamptic or uneventful pregnancy. Since then, health in both groups has been influenced by a wide range of demographic and lifestyle factors, which could have had an unknown effect on the variables measured. By matching the controls for age and BMI, we intended to minimize the impact of obesity and its associated metabolic abnormalities, such as insulin resistance and dyslipidemia. A strategy to deal with most shortcomings would be to follow women longitudinally with respect to age-related hemodynamic changes. Preeclampsia may identify a subgroup of women at risk of accelerated aging, enabling exploration of the mechanism of accelerated cardiovascular aging.

In summary, in this cross-sectional study, we found evidence for impaired hemodynamic and renal function in both normotensive and hypertensive middle-aged, formerly preeclamptic women. These data support the view that formerly preeclamptic women would benefit from surveillance of blood pressure. 


\section{References}

1. Report of the National High Blood Pressure Education Program Working Group on High Blood Pressure in Pregnancy. Am J Obstet Gynecol. 2000;183:S1-S22.

2. Bellamy L, Casas JP, Hingorani AD, Williams DJ. Pre-eclampsia and risk of cardiovascular disease and cancer in later life: systematic review and meta-analysis. Bmj. 2007;335:974.

3. Harskamp RE, Zeeman GG. Preeclampsia: at risk for remote cardiovascular disease. Am J Med Sci. 2007;334:291-5

4. Garovic VD, Hayman SR. Hypertension in pregnancy: an emerging risk factor for cardiovascular disease. Nat Clin Pract Nephrol. 2007;3:613-22.

5. Vikse BE, Irgens LM, Leivestad T, Skjaerven R, Iversen BM. Preeclampsia and the risk of end-stage renal disease. N Engl J Med. 2008;359:800-9.

6. Vikse BE, Irgens LM, Bostad L, Iversen BM. Adverse perinatal outcome and later kidney biopsy in the mother. J Am Soc Nephrol. 2006;17:837-45.

7. Arnadottir GA, Geirsson RT, Arngrimsson R, Jonsdottir LS, Olafsson O. Cardiovascular death in wome who had hypertension in pregnancy: a case-control study. Bjog. 2005;112:286-92

8. Dekker GA, de Vries JI, Doelitzsch PM, et al. Underlying disorders associated with severe early-onse preeclampsia. Am J Obstet Gynecol. 1995;173:1042-8.

9. van Pampus MG, Dekker GA, Wolf $\mathrm{H}$, et al. High prevalence of hemostatic abnormalities in women with history of severe preeclampsia. Am J Obstet Gynecol. 1999;180:1146-50.

10. Spaanderman ME, Ekhart TH, van Eyck J, Cheriex EC, de Leeuw PW, Peeters LL. Latent hemodynamic abnormalities in symptom-free women with a history of preeclampsia. Am I Obstet Gynecol. 2000; 182:101-7.

11. Sattar N. Do pregnancy complications and CVD share common antecedents? Atheroscler Suppl. 2004;5:3-7.

12. Sattar N, Ramsay J, Crawford L, Cheyne H, Greer IA Classic and novel risk factor parameters in women with a history of preeclampsia. Hypertension. 2003;42:39-42.

13. Lakatta EG, Levy D. Arterial and cardiac aging: major shareholders in cardiovascular disease enterprises: Part I: aging arteries: a "set up" for vascular disease. Circulation. 2003;107:139-46.

14. Jani B, Rajkumar C. Ageing and vascular ageing. Postgrad Med J. 2006;82:357-62.

5. Berg UB. Differences in decline in GFR with age between males and females. Reference data on clearances of inulin and PAH in potential kidney donors. Nephrol Dial Transplant. 2006;21:2577-82.

16. Baylis $\mathrm{C}$. Changes in renal hemodynamics and structure in the aging kidney; sexual dimorphism and the nitric oxide system. Exp Gerontol. 200540:271-8.

17. Spaanderman ME, Van Beek E, Ekhart TH, et al. Changes in hemodynamic parameters and volume homeostasis with the menstrual cycle among women with a history of preeclampsia. Am J Obstet Gynecol. 2000;182:1127-34

18. Guyton AC, Coleman TG, Cowley AV, Scheel KW, Manning RD, Norman RA. Arterial pressure regulation. Overriding dominance of the kidneys in long-term regulation and in hypertension. Am J Med.

19. Schrier RW. A unifying hypothesis of body fluid volume regulation. The Lilly Lecture 1992. J R Coll Physicians Lond. 1992:26:295-306.

20. Johnson RJ, Feig DI, Nakagawa T, Sanchez-Lozada LG, Rodriguez-Iturbe B. Pathogenesis of essentia hypertension: historical paradigms and modern insights. J Hypertens. 2008;26:381-91.
21. Zhou XJ, Rakheja D, Yu X, Saxena R, Vaziri ND, Silva FG. The aging kidney. Kidney Int. 2008;74:710-20.

2. Keller G, Zimmer G, Mall G, Ritz E, Amann K. Nephron number in patients with primary hypertension. N Engl J Med. 2003;348:101-8.

23. Nisell H, Lintu H, Lunell NO, Mollerstrom G, Pettersson E. Blood pressure and renal function seven years after pregnancy complicated by hypertension. Br J Obstet Gynaecol. 1995:102:876-81.

24. Bar J, Kaplan B, Wittenberg C, et al. Microalbuminuria after pregnancy complicated by pre-eclampsia. Nephrol Dial Transplant. 1999;14:1129-32

25. van Hooft IM, Grobbee DE, Derkx FH, de Leeuw PW, Schalekamp MA, Hofman A. Renal hemodynamics and the renin-angiotensin-aldosterone system in normotensive subjects with hypertensive and normotensive parents. N Engl J Med. 1991;324:1305-11.

26. Mo R, Omvik P, Lund-Johansen P. The Bergen blood pressure study: offspring of two hypertensive parents have significantly higher blood pressures than offspring of one hypertensive and one normotensive parent. J Hypertens. 1995;13:1614-7.

27. Kyvelou SM, Vyssoulis GP, Karpanou EA, et al. Arterial stiffness in offspring of hypertensive parents: A pilot study. Int J Cardiol. 2008;129:438-40.

28. Gluckman PD, Hanson MA, Cooper C, Thornburg KL. Effect of in utero and early-life conditions on adult health and disease. $\mathrm{N}$ Engl J Med. 2008;359:61-73.

29. Barker DJ. Fetal origins of coronary heart disease. Bmj. 1995;311:171-4.

30. le Noble FA, Stassen FR, Hacking WJ, Struijker Boudier HA. Angiogenesis and hypertension. Hypertens. 1998;16:1563-72.

31. Hasan KM, Manyonda IT, Ng FS, Singer DR, Antonios TF Skin capillary density changes in normal pregnancy and pre-eclampsia. J Hypertens. 2002;20:2439-43.

32. Houben AJ, de Leeuw PW, Peeters LL. Configuration of the microcirculation in pre-eclampsia: possible role of the venular system. J Hypertens. 2007;25:1665-70. 


\section{Chapter 3}

\section{Markers of cardiovascular disease risk after hypertension in pregnancy}

George Mangos, Julia Spaan, Saiyini Pirabhahar, Mark Brown Journal of Hypertension 2012;30:351-8

\section{Abstract}

Objective: Women with a history of preeclampsia or gestational hypertension have an increased risk of cardiovascular disease. Underlying cardiovascular risk factors, persistent endothelial dysfunction or sympathetic overactivity may contribute to this risk. We studied markers of cardiovascular disease risk in nonpregnant women with a history of hypertension in pregnancy.

Methods: Women with a history of preeclampsia $(n=39)$, gestational hypertension $(\mathrm{n}=27)$, and normal pregnancies $(\mathrm{n}=35)$ were studied 2-12 years after delivery. Laboratory measures included plasma fasting lipids, glucose, insulin, creatinine and urinary albumin-tocreatinine ratio. Blood pressure was measured by 24 -h ambulatory blood pressure monitoring, endothelial function by flow-mediated dilatation and sympathetic activity by both head-up tilt test and cold pressor test, including the response of the circulating renin-angiotensin system to tilt testing.

Results: Compared with women who had previous normal pregnancies, women with a history of preeclampsia or gestational hypertension have higher ambulatory blood pressure, body mass index and relative insulin resistance. Glomerular filtration rate, albumin-tocreatinine ratio, endothelial function and sympathetic activity was similar between the three groups.

Conclusion: Women with a history of preeclampsia or gestational hypertension have features of the metabolic syndrome which are presumably present already before pregnancy, predisposing them to hypertensive disorders of pregnancy and later cardiovascular risk. In this study, we found no evidence for early renal damage, endothelial dysfunction or sympathetic overactivity in the post partum state. 


\section{Introduction}

About $10 \%$ of all pregnancies are affected by hypertensive disorders worldwide. These include chronic hypertension, gestational hypertension and preeclampsia. Several studies have shown that gestational hypertension and preeclampsia are associated with future cardiovascular and renal disease. ${ }^{1,2}$ The mechanism for this increased risk is unclear; however, hypertension in pregnancy and later vascular disease share common risk factors such as diabetes, dyslipidaemia and obesity.

Women who have had pregnancies complicated by hypertension are at high risk of developing cardiovascular disease. A Norwegian study published in 2001 reported almost three times higher risk of death in general and an eight times higher risk of cardiovascular death in a 26-year follow-up (median 13 year) of women with a history of preeclampsia who delivered preterm, when compared with women who did not have preeclampsia. ${ }^{3}$ The presence of a history of preeclampsia in combination with premature delivery and/or intra-uterine growth restriction is associated with a seven-fold increased risk of future cardio vascular disease. ${ }^{4}$

The persistence of metabolic abnormalities after preeclampsia could be one of the factors contributing to the increased risk of cardiovascular disease in this group of women. ${ }^{4}$ It is not entirely clear whether it is hypertension per se during pregnancy or the more specific placental disorder of preeclampsia that predisposes to later cardiovascular risk. According to Jonsdottir et al., the relative risk of dying from coronary heart disease was significantly higher among women who had eclampsia or preeclampsia than in women with gestational hypertension alone. ${ }^{5}$ Factors common to cardiovascular disease and preeclampsia include obesity, insulin resistance, and inflammation. Elevated fasting insulin and glucose levels have been demonstrated during glucose tolerance tests in women with preeclampsia; ${ }^{6}$ also, women with a history of preeclampsia have higher serum concentrations of fasting lipids, insulin and coagulation factors post partum than do controls matched for body mass index. ${ }^{7-9}$

Several regulatory mechanisms have been implicated in the pathogenesis of preeclampsia. Endothelial dysfunction is a hallmark of the disease and several authors have suggested that persistence of endothelial dysfunction post partum may contribute to their increased cardiovascular disease risk. ${ }^{10-12}$ Sympathetic overactivity is proposed to be one of the contributors to preeclampsia and is one of the mechanisms involved in the development of essential hypertension. ${ }^{13,14}$ Although increasing research has examined the factors involved in the propensity for women with preeclampsia to develop later cardiovascular disease, less work has been conducted in women with a history of gestational hypertension alone and few studies have examined endothelial function or sympathetic nervous system activity in these women.

The aim of this study was, therefore, to test 2-12 years after delivery whether women who had preeclampsia or gestational hypertension during their pregnancy have a greater cluster of cardiovascular risk abnormalities than women who had a normal pregnancy; evidence of endothelial dysfunction, sympathetic (over)activity and/or reninangiotensin system activation; and evidence of subtle abnormalities of renal function.

\section{Methods}

We recruited 101 women who were of 2-12 years postpartum using a database of all pregnant women consulted to our department for management of hypertension or renal disease during pregnancy, maintained since 1988. Twenty seven women had prior gestational hypertension, 39 had prior preeclampsia and 35 had previous normal pregnancies. We excluded women who were pregnant, had diabetes mellitus, prior essential hypertension in pregnancy or renal disease. We used the Australasian Society for the Study of Hypertension in Pregnancy consensus statement criteria for the diagnosis of gestational hypertension and preeclampsia. ${ }^{15}$ Gestational hypertension was defined as new onset of blood pressure $\geq 140 / 90 \mathrm{mmHg}$ after the 20th week of gestation in women with no history of hypertension, renal or cardiovascular disease, with no clinical or laboratory features of preeclampsia. Preeclampsia was defined as new onset of hypertension after the 20th week of gestation with proteinuria confirmed by spot urine protein-to-creatinine ratio $>30 \mathrm{mg} / \mathrm{mmol}$. Normal postpartum women were from the same local community with no history of hypertension, renal disease, preeclampsia or gestational hypertension. Informed written consent was obtained from all women before they commenced the study. The study protocol was approved by the South East Sydney Area Health Human Research Ethics 
Committee-Southern Section (reference number 00/24 Brown). All women came to the research centre on two consecutive days during the follicular phase of their cycle. The study was carried out in a quiet, temperature controlled room.

Day 1: Blood pressure and metabolic measurements

First trimester blood pressure and weight from the index pregnancy were recorded from antenatal records; first trimester data were available in 76 and $60 \%$ of all cases, respectively. Full medical and obstetric histories were taken. These included age, smoking, oral contraceptive use, history of hypertension in subsequent pregnancies and gestation at delivery. Women were asked to fast for 12 hours before the blood collection. Blood was collected for fasting lipids, glucose, insulin and renal function. Homeostasis model assessment (HOMA) score was calculated by fasting insulin times fasting glucose divided by $22.5 .^{16}$ eGFR was estimated using the Cockcroft-Gault formula. Mid stream urine was collected for albumin, protein and creatinine. Urinary calcium and sodium were determined to give an indication of dietary intake. Upper arm circumference was measured and an appropriate blood pressure cuff was used, a 'large' adult cuff was chosen if mid-upper arm circumference $\geq 33 \mathrm{~cm}$. Blood pressure was measured three times after 15 mins sitting with a mercury sphygmomanometer. A 24-h ambulatory blood pressure monitor (Space Lab 90207) was fitted before women left the centre. They were asked to perform their normal activities for the 24 - $h$ period while the machine recorded their blood pressure every $30 \mathrm{~min}$. Their sleep and awake periods were recorded from their diaries.

Day 2: Physiological Studies

Measurement of vascular reactivity by flow mediated dilatation

All studies were carried out in a quiet, temperature-controlled (22-24

${ }^{\circ} \mathrm{C}$ ) room. Women were asked to lay supine during the measurement of forearm blood flow (FBF). We used strain gauge plethysmography to assess blood flow in the forearm resistance arteries. This has been described in detail elsewhere. ${ }^{17,18}$ In brief, the forearm circumference was measured and an appropriate size strain gauge fitted $7 \mathrm{~cm}$ below the olecranon in both forearms. Wrist cuffs were placed to both arms to arrest blood circulation to the hands during the FBF measurements. Upper arm cuffs were placed on both arms and the arms were elevated to $45^{\circ}$ (at the heart level) with the assistance of a heightadjustable table and foam under the elbow. To assess for the changes in systemic parameters, arterial blood pressure was measured every 5 min by a Dinamap Portable Vital Signs Monitor 8100 (Critikon, Tampa, Florida, USA) on the left calf. Two baseline blood flow recordings were performed before the commencement of ischaemia. The baseline blood flow was measured by inflating the wrist cuffs to $30 \mathrm{mmHg}$ above systolic blood pressure for $1 \mathrm{~min}$, followed by venous cuff pressure to $40 \mathrm{mmHg}$. The FBF was then measured for 3 mins and the average of five slopes was recorded as the baseline blood flow. All the cuffs were deflated before ischaemia to achieve complete return of normal circulation. Limb ischaemia was achieved by inflating the venous cuff on the left arm to $40 \mathrm{mmHg}$ above systolic blood pressure for $10 \mathrm{mins}$. At $9 \mathrm{~min}$, both wrist cuffs were inflated to $30 \mathrm{mmHg}$ above systolic blood pressure before the FBF measurement was commenced. FBF was measured for 3 mins after the release of arterial occlusion. Flow-mediated dilatation was measured as the ratio of flow in the ischaemic arm to that of the control arm (right arm), expressed as the percentage of change from baseline. This technique controls for changes in systemic blood flow due to other mechanisms. ${ }^{17,18}$

Tilt table testing: sympathetic activity and renin-aldosterone responses

Hemodynamic and hormonal responses to tilt were assessed by $60^{\circ}$ head-up tilt on a tilt table. Participants were asked to lie supine on a tilt table for 10 mins. A Finapres continuous blood pressure cuff (Ohmeda 2300, Ohio, USA) was placed on the left hand middle finger to monitor changes in mean arterial pressure (MAP) and heart rate (HR) throughout the study. ${ }^{19}$ These data were acquired by a personal computer running Acknowledge for Windows software (Biopac Systems Inc., Goleta, California, USA). The hand was placed at the level of the heart. After 10 mins in supine position, patients were tilted upwards to $60^{\circ}$. The left hand was placed on a height adjustable table to the level of heart. A cannula was placed in a left antecubital vein to collect blood for aldosterone and renin at $8 \mathrm{~min}$ (before tilt up) and at $18 \mathrm{~min}\left(\right.$ at $60^{\circ}$.

Cold pressor test

Women were asked to lie in a supine position for $10 \mathrm{~min}$, then place their right foot in a bucket containing $4^{\circ} \mathrm{C}$ water for $2 \mathrm{~min}$. Four $(17 \%)$ women in the normal pregnancy group and six $(26 \%)$ in the preeclampsia group did not complete the test because of discomfort 
$(\mathrm{p}=0.48)$ and they were excluded from analysis. A Finapres cuff

(Finapres Medical Systems, Amsterdam, the Netherlands) was placed on the left hand middle finger to measure changes in MAP and HR during the cold stimulus. This was done at the end of the study morning

Statistical analysis

Data were expressed as mean and standard deviation or median and interquartile range, unless stated otherwise. Figures show mean and standard error of the mean. Groups were compared using one-way analysis of variance (ANOVA) followed by Dunnett test or KruskalWallis test followed by Mann-Whitney U-test with Bonferroni correction. Categorical data were tested using chi-square test. Adjustments for oral contraceptive pill use were made by multiple linear regression analysis after log transformation of the skewed variables. Repeated measurements were analysed by paired t-test or repeated measures ANOVA as appropriate.

\section{Results}

Baseline characteristics

The baseline characteristics of the women are reported in Table 1.

Women were studied approximately 3-4 years post partum and were of similar age. More women with a history of normal pregnancy or preeclampsia were multiparous compared with women with a history of gestational hypertension. There was no difference between the groups in the proportion of smokers. The women with a history of gestational hypertension were heavier, with a higher body mass index at their post-partum evaluation, compared with the normal group; this was of border significance for women with a history of preeclampsia $(\mathrm{p}=0.09)$. A similar trend was observed for the weight and body mass index in first trimester pregnancy $(\mathrm{p}=0.08$ and $\mathrm{p}=0.10$, respectively). Weight gain was present in all three groups, when studying the difference between current and first trimester weight or body mass index. In the preeclampsia group, $46 \%$ had a history of a delivery before 37 weeks of gestation, $26 \%$ had a pregnancy complicated by intrauterine growth restriction and $38 \%$ of the multiparous women had preeclampsia during more than one pregnancy. In the gestational hypertension group, $60 \%$ of the multiparous women had gestational hypertension during more than one pregnancy. Current oral contraceptive pill use was higher in the gestational hypertension group $(\mathrm{N}=26 \%, \mathrm{PE}=13 \%$ and $\mathrm{GH}=44 \%, \mathrm{p}=0.04)$. None of the women were diabetic or used lipid lowering drugs.
Table 1: Baseline characteristics in women with a history of normal pregnancy, preeclampsia and gestational hypertension.

\begin{tabular}{|c|c|c|c|}
\hline & $N(n=35)$ & PE $(n=39)$ & GH $(n=27)$ \\
\hline Age at study (years) & $38 \pm 6$ & $37 \pm 6$ & $36 \pm 6$ \\
\hline Years postpartum & $4.3(2.8-7.0)$ & $3.8(2.5-5.0)$ & $2.9(2.2-6.0)$ \\
\hline Multiparous, $\mathrm{n}(\%)$ & $30(86)$ & $26(67)$ & $15(56)^{\star}$ \\
\hline$\geq 2$ miscarriages, $\mathrm{n}(\%)$ & $6(17)$ & $6(15)$ & $4(15)$ \\
\hline Delivery <37 weeks, n(\%) & $2(6)$ & $18(46)^{*}$ & $4(15)$ \\
\hline IUGR $<\mathrm{p} 10, \mathrm{n}(\%)$ & $1(3)$ & $10(26)^{*}$ & $3(11)$ \\
\hline Smoking during pregnancy, n(\%) & $2(6)$ & $2(5)$ & $2(7)$ \\
\hline Current smoker, $\mathrm{n}(\%)$ & $2(6)$ & $2(5)$ & $3(11)$ \\
\hline First trimester weight $(\mathrm{kg})$ & $61 \pm 9$ & $65 \pm 14$ & $69 \pm 13$ \\
\hline Current weight (kg) & $64 \pm 9$ & $69 \pm 12$ & $73 \pm 16^{*}$ \\
\hline Difference in weight (kg) & $4 \pm 5^{\dagger}$ & $5 \pm 8^{\dagger}$ & $4 \pm 6^{\dagger}$ \\
\hline First trimester BMI $\left(\mathrm{kg} / \mathrm{m}^{2}\right)$ & $22.1 \pm 2.5$ & $24.1 \pm 5.1$ & $25.0 \pm 4.8$ \\
\hline Current BMI $\left(\mathrm{kg} / \mathrm{m}^{2}\right)$ & $23.7 \pm 2.8$ & $25.6 \pm 4.3$ & $27.1 \pm 5.4^{\star}$ \\
\hline Difference in BMI $\left(\mathrm{kg} / \mathrm{m}^{2}\right)$ & $1.6 \pm 1.9^{\dagger}$ & $2.0 \pm 2.8^{\dagger}$ & $1.3 \pm 2.3^{\dagger}$ \\
\hline Current hypertension, $\mathrm{n}(\%)$ & - & $1(3)$ & $2(7)$ \\
\hline
\end{tabular}

N: normal pregnancy, PE: preeclampsia, GH: gestational hypertension, IUGR: intrauterine growth restriction, $B M I$ : body mass index.

${ }^{*} p<0.05$ versus normal pregnancy, ${ }^{\dagger} p<0.05$ current versus first trimester

Table 2: Metabolic and cardiovascular risk factors in women with a history o normal pregnancy, preeclampsia and gestational hypertension.

\begin{tabular}{|c|c|c|c|}
\hline & $N(n=35)$ & PE $(n=39)$ & GH $(n=27)$ \\
\hline Total-cholesterol (mmol/l) & $4.9 \pm 0.7$ & $5.0 \pm 0.8$ & $5.1 \pm 1.0$ \\
\hline Triglycerides (mmol/l) & $0.8 \pm 0.4$ & $1.0 \pm 0.8$ & $1.1 \pm 0.7$ \\
\hline HDL-cholesterol (mmol/l) & $1.4 \pm 0.3$ & $1.4 \pm 0.3$ & $1.3 \pm 0.3$ \\
\hline LDL-cholesterol (mmol/l) & $3.1 \pm 0.7$ & $3.1 \pm 0.6$ & $3.1 \pm 0.7$ \\
\hline Glucose $(\mathrm{mmol} / \mathrm{l})$ & $4.9 \pm 0.5$ & $4.8 \pm 0.6$ & $5.2 \pm 0.6$ \\
\hline Insulin (mU/l) & $5(4-7)$ & $7(5-11)^{\star *}$ & $7(5-11)^{* *}$ \\
\hline HOMA-score & $1.2(0.9-1.5)$ & $1.5(1.2-2.1)^{*}$ & $1.7(1.1-2.5)^{\star *}$ \\
\hline Potassium (mmol/l) & $4.0 \pm 0.3$ & $3.9 \pm 0.3$ & $4.0 \pm 0.3$ \\
\hline Creatinine $(\mathrm{mmol} / \mathrm{l})$ & $64 \pm 11$ & $67 \pm 10$ & $66 \pm 11$ \\
\hline eGFR (mmol/l) & $109 \pm 25$ & $113 \pm 27$ & $120 \pm 24$ \\
\hline Protein:creatinine (mg/mmol) & $9(7-13)$ & $8(7-10)$ & $10(7-13)$ \\
\hline Albumin:creatinine (mg/mmol) & $1.0(0.6-1.9)$ & $1.0(0.7-1.5)$ & $1.1(0.9-1.6)$ \\
\hline Calcium:creatinine (mmol/l) & 0.28 & 0.21 & 0.20 \\
\hline Sodium:creatinine (mmol/l) & 13 & 11 & 11 \\
\hline \multicolumn{4}{|c|}{$\begin{array}{l}\text { N: normal pregnancy, PE: preeclampsia, GH: gestational hypertension, HDL: high } \\
\text { density lipoprotein, LDL: low density lipoprotein, HOMA: homeostasis model assess- } \\
\text { ment, eGFR: estimated glomerular filtration rate. } \\
\text { p-values presented are corrected for oral contraceptive use. } \\
{ }^{*} p<0.05 \text { versus normal pregnancy, }{ }^{*} p<0.01 \text { versus normal pregnancy }\end{array}$} \\
\hline
\end{tabular}


Metabolic and cardiovascular risk markers

Metabolic and cardiovascular risk factors are presented in table 2 with p-values adjusted for oral contraceptive pill use. No differences in lipid profile were observed among the three groups. In both the gestational hypertension and preeclampsia groups, women were relatively insulin resistant, as demonstrated by higher insulin levels and HOMA scores, compared with the normal group. There was a non-significant accompanying trend in fasting blood glucose. No differences in renal function were present, with similar values for glomerular filtration rate, serum creatinine, potassium and urinary protein- or albumin-to-creatinine ratio. Urinary sodium was similar among groups, whereas the urinary calcium showed a trend to be lower in gestational hypertension and preeclampsia $(\mathrm{p}=0.09)$.

Table 3: Mercury blood pressure and 24-h ambulatory blood pressure monitoring in women with a history of normal pregnancy, preeclampsia and gestational hypertension.

\begin{tabular}{|c|c|c|c|}
\hline & $N(n=35)$ & $\operatorname{PE}(n=39)$ & $\mathrm{GH}(\mathrm{n}=27)$ \\
\hline \multicolumn{4}{|l|}{ Mercury } \\
\hline Current SBP (mmHg) & $115 \pm 12$ & $121 \pm 20$ & $124 \pm 11^{\star}$ \\
\hline Current DBP (mmHg) & $72 \pm 9^{\diamond}$ & $79 \pm 8^{* * 0}$ & $79 \pm 10^{*}$ \\
\hline First trimester SBP (mmHg) & $113 \pm 11$ & $119 \pm 10^{*}$ & $120 \pm 9^{*}$ \\
\hline First trimester DBP $(\mathrm{mmHg})$ & $66 \pm 9$ & $71 \pm 8^{*}$ & $76 \pm 8^{* *}$ \\
\hline \multicolumn{4}{|l|}{$A B P M$} \\
\hline 24-hr average SBP (mmHg) & $111 \pm 9$ & $118 \pm 9^{* *}$ & $120 \pm 9^{* *}$ \\
\hline 24-hr average DBP (mmHg) & $69 \pm 7$ & $74 \pm 7^{\star \star}$ & $76 \pm 7^{* *}$ \\
\hline 24-hr average MAP (mmHg) & $83 \pm 7$ & $89 \pm 8^{\star *}$ & $91 \pm 8^{\star *}$ \\
\hline Awake SBP (mmHg) & $113 \pm 10$ & $120 \pm 11^{\star *}$ & $121 \pm 10^{* *}$ \\
\hline Awake DBP (mmHg) & $71 \pm 8$ & $76 \pm 9^{*}$ & $78 \pm 8^{\star *}$ \\
\hline Awake MAP (mmHg) & $85 \pm 8$ & $91 \pm 9^{*}$ & $93 \pm 9^{* *}$ \\
\hline High Awake ABPM (>135/85 mmHg) & $3(9)$ & $6(15)$ & $7(25)$ \\
\hline Sleep SBP (mmHg) & $102 \pm 10$ & $108 \pm 9^{*}$ & $111 \pm 11^{\star *}$ \\
\hline Sleep DBP (mmHg) & $61 \pm 9$ & $65 \pm 8$ & $68 \pm 10^{* *}$ \\
\hline Sleep MAP (mmHg) & $75 \pm 9$ & $80 \pm 8^{*}$ & $82 \pm 10^{* *}$ \\
\hline High Sleep ABPM (>125/75 mmHg) & $3(9)$ & $4(10)$ & $8(29)^{*}$ \\
\hline Awake-sleep MAP fall (\%) & $12 \pm 11$ & $12 \pm 10$ & $11 \pm 12$ \\
\hline Sleep hours & 7 & 7 & 7 \\
\hline \multicolumn{4}{|c|}{$\begin{array}{l}\text { N: normal pregnancy, PE: preeclampsia, GH: gestational hypertension, ABPM: am- } \\
\text { bulatory blood pressure monitoring, SBP: systolic blood pressure, DBP: diastolic blood } \\
\text { pressure, MAP: mean arterial pressure. } \\
{ }^{\star} p<0.05 \text { versus normal pregnancy, }{ }^{* *} p<0.01 \text { versus normal pregnancy, }{ }^{\circledR} p<0.05 \text { cur- } \\
\text { rent versus first trimester }\end{array}$} \\
\hline
\end{tabular}

Blood pressure

Table 3 shows the blood pressure measurements. First trimester blood pressure was higher in women who had gestational hypertension or preeclampsia in that pregnancy compared with women who had normal pregnancy. These changes persisted postpartum when measured by either mercury sphygmanometry or 24-h ambulatory blood pressure monitoring (ABPM). Both awake and sleep ABPM was higher in women with a history of gestational hypertension or preeclampsia compared with women with normal pregnancies. High blood pressure was present in $9 \%, 15 \%$ and $25 \%$ of all cases diagnosed by awake $\operatorname{ABPM}(>135 / 85 \mathrm{mmHg}, \mathrm{p}=0.15)$ and in $9 \%, 10 \%$ and $29 \%$ of all cases diagnosed by sleep ABPM ( $>125 / 75 \mathrm{mmHg}, \mathrm{p}=0.03)$ in women with a history of normal pregnancies, preeclampsia and gestational hypertension, respectively. Excluding the women with known chronic hypertension $(n=3)$ showed comparable findings for the blood pressure measurements.

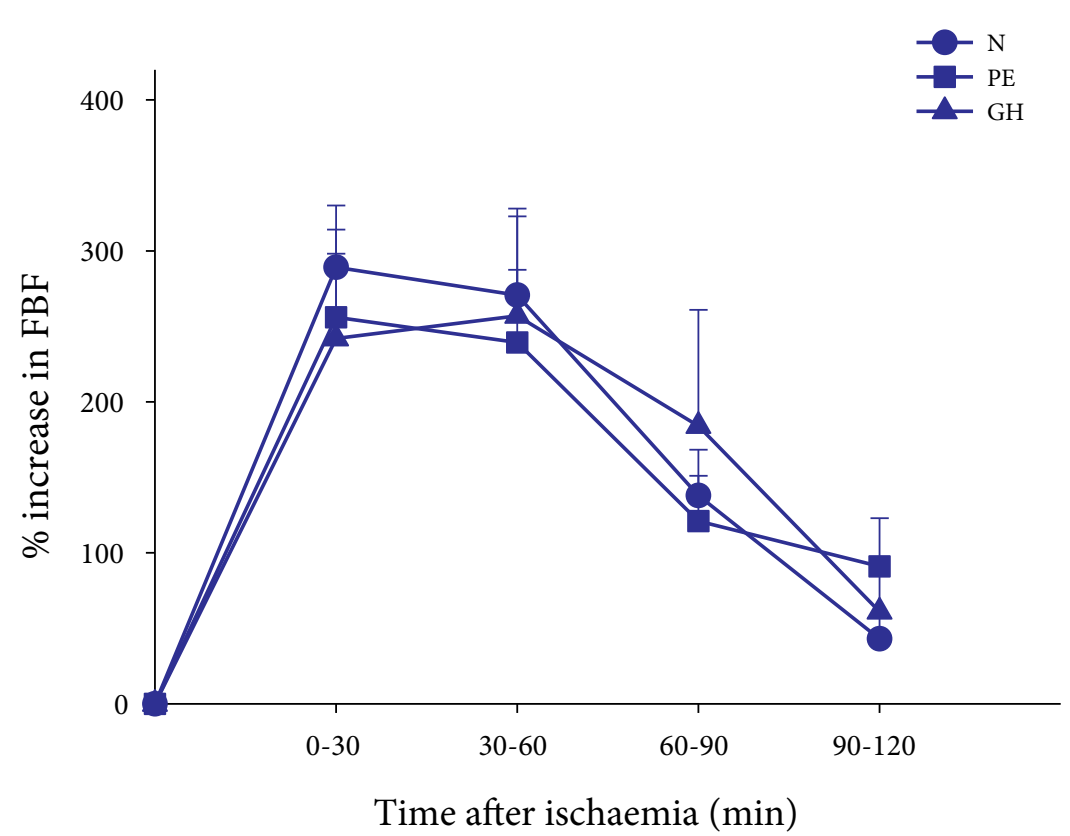

Figure 1: Flow-mediated dilatation

Forearm blood flow $(\mathrm{FBF})$ response to occlusion in women with a history of normal pregnancy $(\mathrm{N}, \mathrm{n}=22)$, preeclampsia $(\mathrm{PE}, \mathrm{n}=23)$ and gestational hypertension $(\mathrm{GH}, \mathrm{n}=15)$. 
Vascular Reactivity

Baseline FBF was 4.33 (3.53-5.31), 4.61 (3.31-5.40) and 4.87 (3.65-7.15) per $100 \mathrm{ml} / \mathrm{min}$ in women with a history of normal pregnancies, preeclampsia and gestational hypertension, respectively $(\mathrm{p}=$ n.s.). After ischaemia, an increase in FBF was observed in each group $(\mathrm{p}<0.001)$ with a peak in the initial $30 \mathrm{~s}$ after occlusion of about $250 \%$ followed by a slow correction over subsequent 2 min (figure 1). There was no difference in FBF response to venous occlusion among the three groups.

Table 4: Plasma aldosterone and renin concentrations before and after tilt testing in women with a history of normal pregnancy, preeclampsia and gestational hypertension.

\begin{tabular}{|c|c|c|c|}
\hline & $N(n=22)$ & $\operatorname{PE}(n=20)$ & $\mathrm{GH}(\mathrm{n}=10)$ \\
\hline Aldosterone basal (pmol/l) & $173(137-310)$ & $191(152-244)$ & $167(119-267)$ \\
\hline $\begin{array}{l}\text { Aldosterone after tilt testing } \\
(\mathrm{pmol} / \mathrm{l})\end{array}$ & $165(126-239)^{\#}$ & $146(122-212)^{\#}$ & $225(133-278)$ \\
\hline Renin basal (mU/l) & $8.1(7.1-12.4)$ & $8.1(6.4-14.9)$ & $7.8(6.1-8.7)$ \\
\hline Renin after tilt testing (mU/l) & $9.8(7.3-13.1)^{\#}$ & $8.9(5.7-16.0)$ & $7.5(5.7-10.6)$ \\
\hline
\end{tabular}

Tilt table testing: sympathetic activity and renin-aldosterone responses

During tilt testing, there was a rise in MAP and HR $(\mathrm{p}<0.001)$ with no differences among the three groups (figure $2 \mathrm{a}$ and $2 \mathrm{~b}$ ). Baseline plasma aldosterone and renin concentration were similar between the groups (table 4). In women with a history of normal pregnancy, the plasma aldosterone concentration decreased and the renin levels increased after tilt testing. This was not observed in women with preeclampsia and gestational hypertension, except for a decrease in aldosterone in preeclampsia. There were no differences among the groups in aldosterone and renin concentration after tilt testing.

\section{Cold pressor test}

MAP and HR increased as a consequence of cold pressor stimulus $(\mathrm{p}<0.001)$, with no differences among the three groups (figure $3 \mathrm{a}$ and $3 b)$.

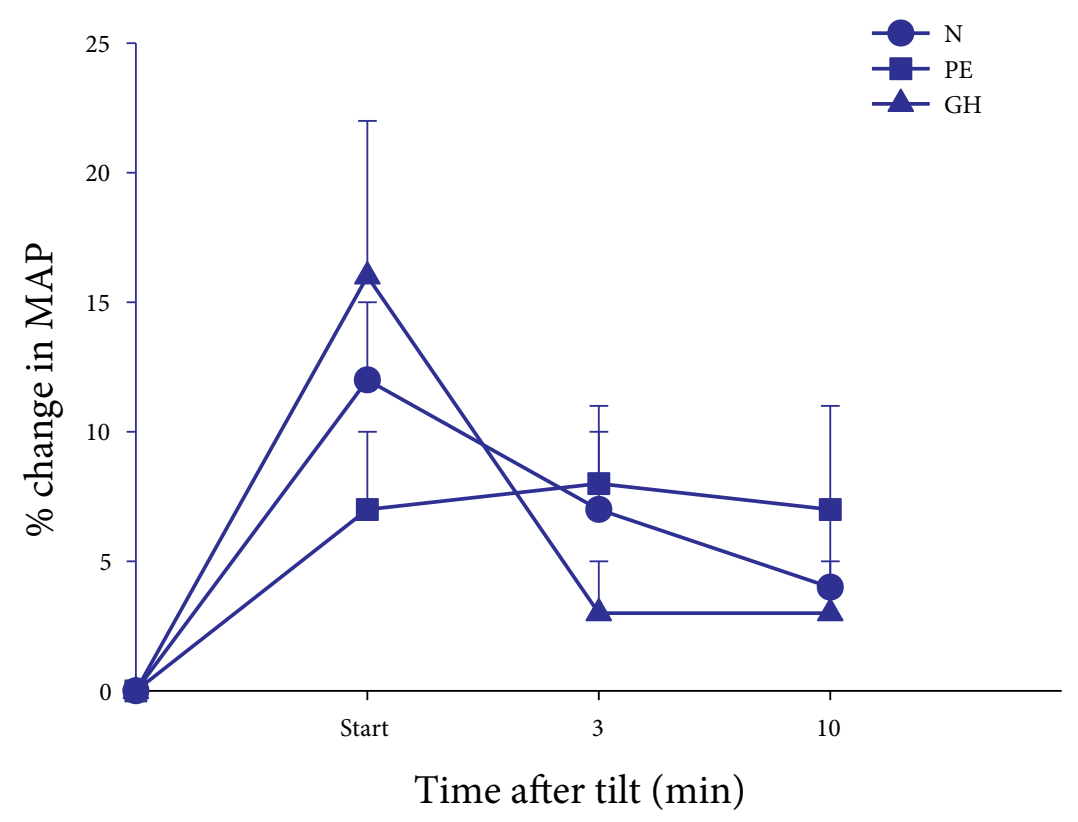

Figure 2: Tilt testing

a) Change in mean arterial pressure (MAP) during tilt testing in women with a history of normal pregnancy $(\mathrm{N}, \mathrm{n}=22)$, preeclampsia $(\mathrm{PE}, \mathrm{n}=22)$ and gestational hypertension $(\mathrm{GH}, \mathrm{n}=16)$.

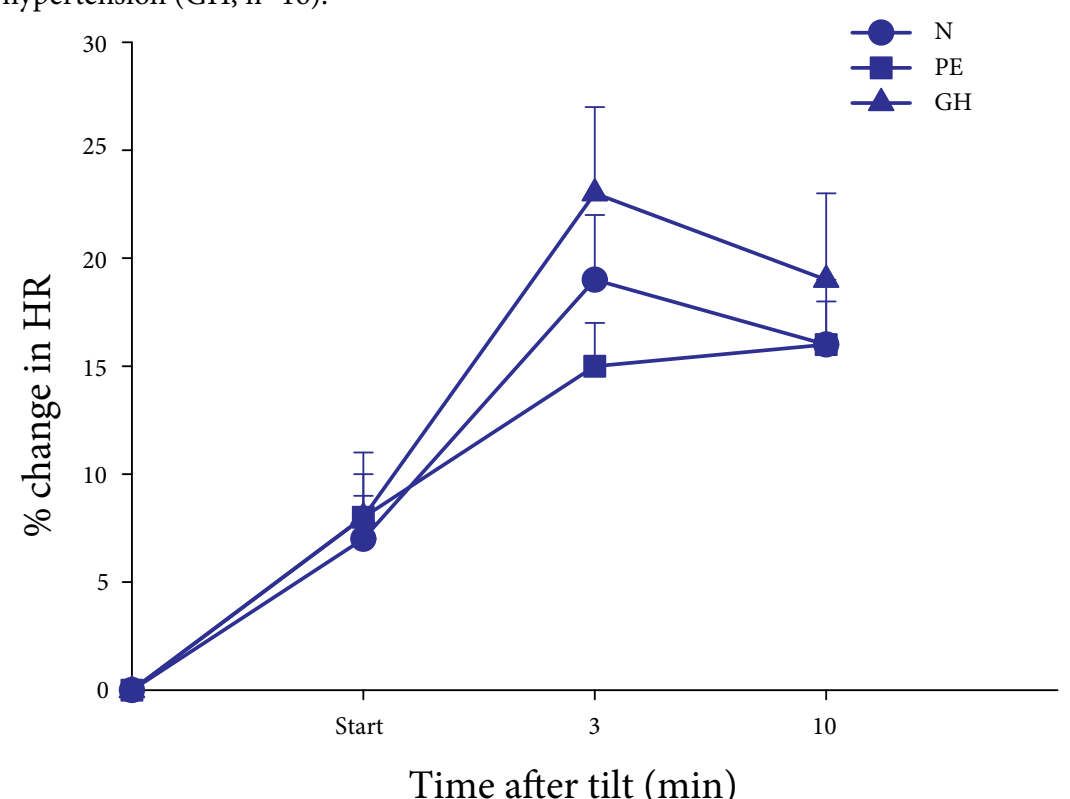

b) Change in heart rate (HR) during tilt testing in women with a history of normal pregnancy $(\mathrm{N}, \mathrm{n}=22)$, preeclampsia $(\mathrm{PE}, \mathrm{n}=22)$ and gestational hypertension $(\mathrm{GH}, \mathrm{n}=16)$. 


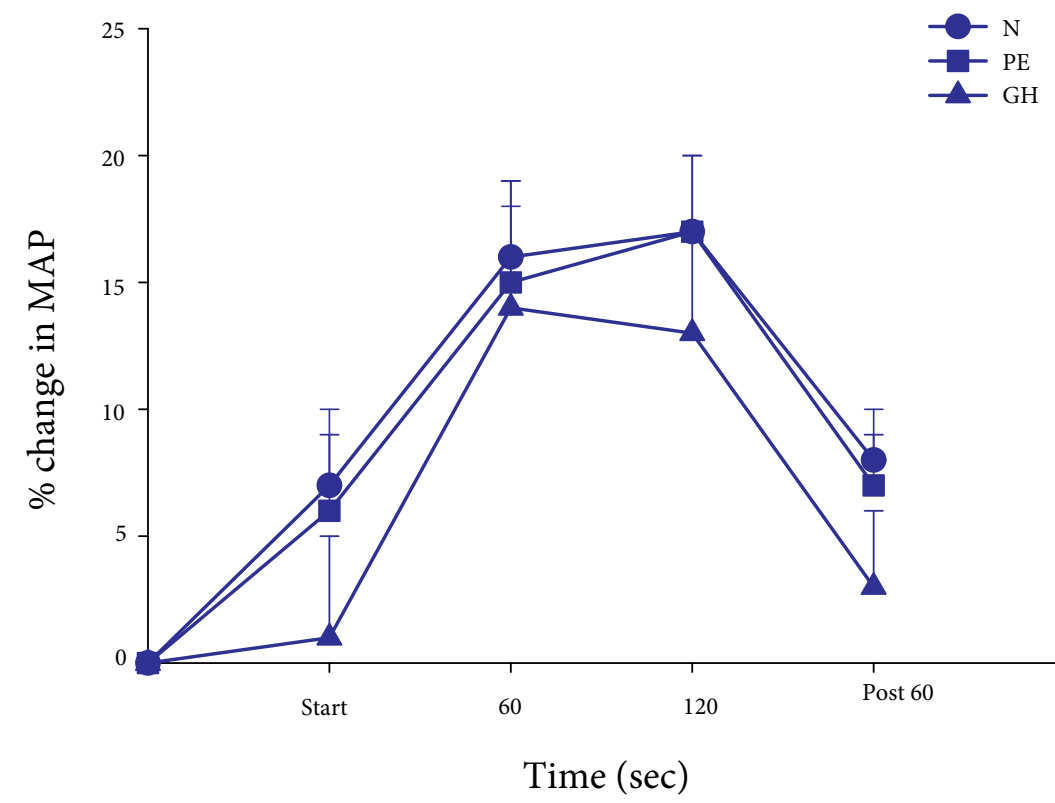

Figure 3: Cold pressor test

a) Change in mean arterial pressure (MAP) during cold pressor test in women with a history of normal pregnancy $(\mathrm{N}, \mathrm{n}=19)$, preeclampsia $(\mathrm{PE}, \mathrm{n}=17)$ and gestational hypertension $(\mathrm{GH}, \mathrm{n}=17)$.

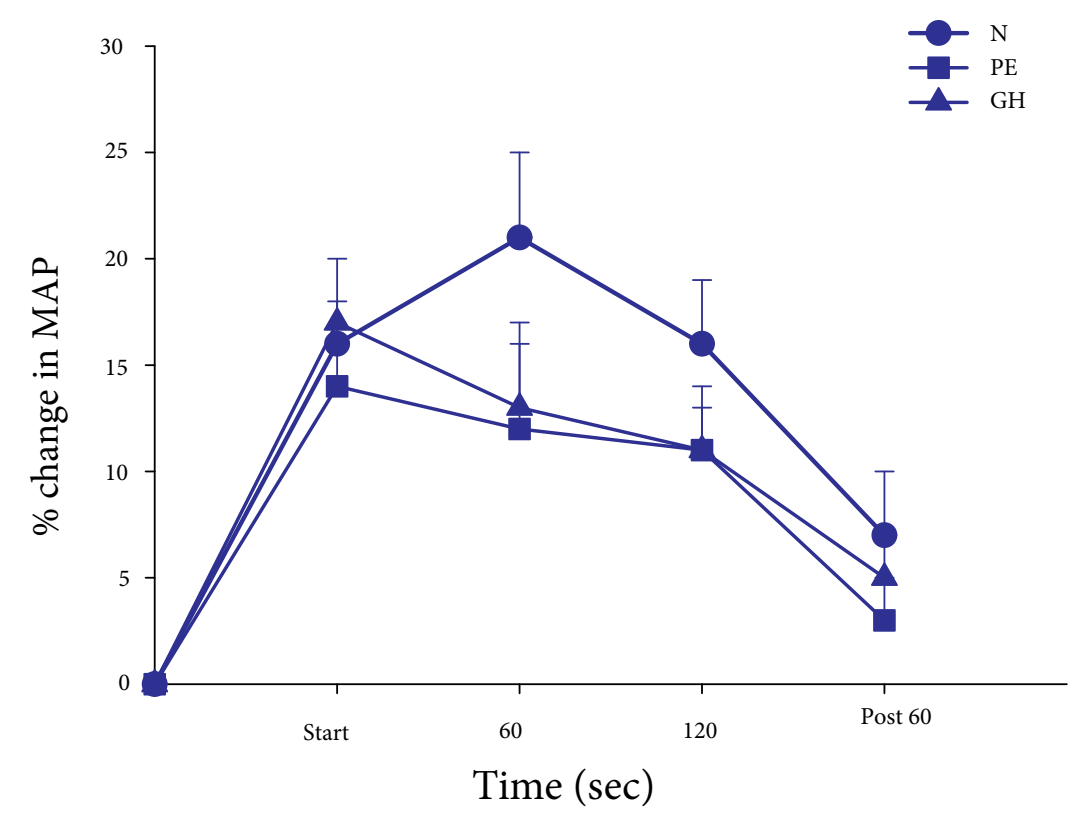

b) Change in heart rate (HR) during cold pressor test in women with a history of normal pregnancy $(N, n=19)$, preeclampsia $(P E, n=17)$ and gestational hypertension $(G H, n=17)$.

\section{Discussion}

This study shows that women who have had preeclampsia or gestational hypertension have greater body mass index, more insulin resistance and higher awake and sleep blood pressures, remote from their pregnancy than do women who have had normal pregnan-

cies. The observation that preeclampsia and gestational hypertension women tended to be heavier and had higher blood pressure (though well within the normal range) at the beginning of their pregnancy supports the hypothesis that these known cardiovascular risk factors (the 'metabolic syndrome') are present before the index pregnancy, and may be then carried through the pregnancy to increase the risk of a hypertensive disorder of pregnancy and in subsequent life to contribute to a higher cardiovascular risk. None of the physiological stress tests of sympathetic nervous system and endothelial function differed among the groups and we found no evidence of renal dysfunction postpartum in this study. Importantly, only three women were aware that they had chronic hypertension, yet between $9 \%$ and $29 \%$ had hypertension by the gold standard of ABPM criteria.

Our finding that women with prior preeclampsia or gestational hypertension were characterised by higher body mass index, blood pressure and relative insulin resistance is relevant as features of the metabolic syndrome have been positively associated with hypertensive disorders of pregnancy by several authors. ${ }^{4,20,21} \mathrm{~A}$ higher blood pressure several years after pregnancy has been observed by others in women with a history of preeclampsia or gestational hypertension; $8,9,22$ and this has been confirmed by our study using 24-h ABPM. We have also shown the novel finding of elevated sleep blood pressure in these women. Using 24-h ABPM, about one in four women with a history of gestational hypertension was classified as high blood pressure, in contrast to about one in 10 with a history of normal pregnancies.

Despite demonstrating higher blood pressure and features suggesting 'early metabolic syndrome', we were unable to demonstrate evidence of renal dysfunction as reflected by estimated glomerular filtration rate or albumin-to-creatinine ratio. We studied women on average 4-5 years after their pregnancy and it is possible that such changes may take longer to develop. On the contrary, others have reported an incidence of microalbuminuria of about $30 \%, 7$ years postpartum after preeclampsia. ${ }^{23}$ 
One of the controversies about the cardiovascular disease risk after preeclampsia has been whether the pregnancy itself programs this risk or whether the risk factors are brought into pregnancy. The fact that insulin resistance can be detected in early pregnancy, before the manifestation of preeclampsia or gestational hypertension supports the latter. ${ }^{24}$ In addition, this study gives some further directions to this question, showing that a higher blood pressure and body mass index were already present in first trimester pregnancy and remain this way on average 4 years postpartum. This is in line with a recent report, showing that the increased blood pressure and body mass index in women with a history of preeclampsia or gestational hypertension can be largely explained by the prepregnancy blood pressure and body mass index values. ${ }^{25}$ Moreover, those women are prone to even more weight gain during the decades that follow, when compared with women who had normotensive pregnancies. ${ }^{26}$ In our study of less follow up, weight gain from early pregnancy to the study measurement was present to a similar extent in all three groups. Lifestyle and dietary habits might contribute to the risk of cardiovascular disease. The trend for lower urinary calcium suggests that women with a history of preeclampsia or gestational hypertension might have a lower dietary calcium intake. Although variations in dietary salt intake contribute to the blood pressure observed in a general population, our study did not show a difference in urinary sodium excretion between groups.

To measure endothelial function, we used a postocclusion test to induce reactive hyperaemia. Similar to a previous report, we found no difference in FBF after occlusion measured by strain gauge plethysmography. ${ }^{27}$ In contrast, others have found reduced vasodilation in women with a history of preeclampsia, when using ultrasound to determine the changes in vessel diameter after occlusion. ${ }^{10,12,22,28}$ Moreover, studies using infusion of vasoactive substances or a mental stress test to induce vasodilation also reported impaired FBF responses in women with a history of preeclampsia. ${ }^{11,29}$ It is possible that the method used to measure endothelial function in our study might not have been sensitive enough to detect these differences among groups. If so, then true differences are likely to be subtle.

In our study, no differences in response to two autonomic function tests were found between women with either a history of preeclampsia, gestational hypertension or normal pregnancy. The head-up table tilt test is an orthostatic challenge test which activates the sympathetic nervous system. Acute standing induces a redistribution of blood flow, leading to a decrease in venous return and cardiac output which activates the baroreflex system. After the initial hemodynamic response, an early phase of stabilization is observed in which blood pressure and HR increases under neurovascular control. ${ }^{30}$ During prolonged orthostasis, after about 5 min of standing, humoral mechanisms such as the renin-angiotensin system contribute to maintaining blood pressure. ${ }^{30,31}$ In our study, the head up table test did show an increase in blood pressure and HR in all groups; however, the response was similar among groups.

Tilt testing activated the renin-angiotensin system in controls as reflected by an increase in renin levels, although without a subsequent rise in aldosterone. During normal pregnancy, plasma renin, aldosterone and angiotensin II levels are increased with reduced vascular response to angiotensin II; in contrast during preeclampsia, plasma renin activity and aldosterone are suppressed, although with higher level of aldosterone for the given level of renin. ${ }^{32}$ During preeclampsia, circulating angiotensin II type 1 autoantibodies are present; those antibodies are also detected 18 months post partum in $17 \%$ of women with previous preeclampsia compared with $3 \%$ of women who had uncomplicated pregnancy. ${ }^{33}$ Even though several components of the renin-angiotensin system seem to be influenced during PE, our study showed no differences among groups in the post partum state in women with a history of preeclampsia, gestational hypertension or normal pregnancy.

The cold pressor test has been used in many studies to evaluate muscle sympathetic activity. ${ }^{34}$ The immersion of a limb into ice cold water activates pain and temperature fibres. The signal, transmitted through the spinothalamic tract, stimulates the sympathetic nervous system. ${ }^{30}$ This response, in contrast to orthostatic stress tests, is not mediated by the baroreflex system. ${ }^{34}$ A study performed early in pregnancy (16-20 weeks of gestation) showed an increased blood pressure response to the cold pressor test in women destined to develop preeclampsia later in the pregnancy. ${ }^{35}$ In third trimester pregnancy, women with preeclampsia have increased muscle sympathetic nerve activity compared with normal pregnant women, when evaluated by intraneural microelectrodes. ${ }^{14}$ We evaluated the cold pressor test in women 3-4 years postpartum and observed a similar response 
of blood pressure and heart rate in women with a history of either preeclampsia, gestational hypertension or normal pregnancy, implying that any changes in sympathetic nervous system activity during preeclampsia are confined to pregnancy.

Although it may be that the functional studies above were underpowered to detect subtle differences in autonomic nervous system function, renin-angiotensin system activity and endothelial function, our results do not suggest any meaningful trends were present in these measurements.

In conclusion, women with a history of preeclampsia or gestational hypertension have higher awake and sleep blood pressure, body mass index and relative insulin resistance compared with women with prior normal pregnancies; it is probable, though not proven conclusively, that those features are already present before pregnancy. In this study, we found no evidence for postpartum renal dysfunction, endothelial dysfunction or sympathetic overactivity. It is important to note that these changes in insulin resistance and blood pressure are subtle and that few, if any, women with a history of preeclampsia or gestational hypertension will have results in the clearly abnormal range. Therefore the strong clinical message is to consider all women with prior preeclampsia or gestational hypertension to carry cardiovascular risk and adopt healthy lifestyle measures accordingly with regular medical follow up.

\section{References}

1. Bellamy L, Casas JP, Hingorani AD, Williams DJ. Pre-eclampsia and risk of cardiovascular disease and cancer in later life: systematic review and meta-analysis. Bmj. 2007;335:974.

2. Vikse BE, Irgens LM, Leivestad T, Skjaerven R, Iversen BM. Preeclampsia and the risk of end-stage renal disease. N Engl J Med. 2008;359:800-9.

3. Irgens HU, Reisaeter L, Irgens LM, Lie RT. Long term mortality of mothers and fathers after pre-eclampsia: population based cohort study. Bmj. 2001;323:1213-7.

4. Rodie VA, Freeman DI, Sattar N, Greer IA. Pre-eclampsia and cardiovascular disease: metabolic syndrome of pregnancy? Atherosclerosis. 2004;175:189-202.

5. Jonsdottir LS, Arngrimsson R, Geirsson RT, Sigvaldason H, Sigfusson N. Death rates from ischemic heart disease in women with a history of hypertension in pregnancy. Acta Obstet Gynecol Scand. 1995;74:772-6.

6. Kaaja R, Laivuori H, Laakso M, Tikkanen MJ, Ylikorkala O. Evidence of a state of increased insulin resistance in preeclampsia. Metabolism. 1999;48:892-6.

7. Wolf M, Hubel CA, Lam C, et al. Preeclampsia and future cardiovascular disease: potential role of altered angiogenesis and insulin resistance. J Clin Endocrinol Metab. 2004;89:6239-43.

8. Sattar N, Ramsay J, Crawford L, Cheyne H, Greer IA. Classic and novel risk factor parameters in women with a history of preeclampsia. Hypertension. 2003;42:39-42.

9. Girouard J, Giguere Y, Moutquin JM, Forest JC. Previous hypertensive disease of pregnancy is associated with alterations of markers of insulin resistance. Hypertension. 2007;49:1056-62.

10. Germain AM, Romanik MC, Guerra I, et al. Endothelial dysfunction: a link among preeclampsia, recurrent pregnancy loss, and future cardiovascular events? Hypertension. 2007;49:90-5.

11. Agatisa PK, Ness RB, Roberts JM, Costantino JP, Kuller LH, McLaughlin MK. Impairment of endothelia function in women with a history of preeclampsia: an indicator of cardiovascular risk. Am J Physiol Heart Circ Physiol. 2004;286:H1389-93.

12. Chambers JC, Fusi L, Malik IS, Haskard DO, De Swiet M, Kooner IS. Association of maternal endothelial dysfunction with preeclampsia. Jama. 2001;285:1607-12.

13. Joyner MJ, Charkoudian N, Wallin BG. A sympathetic view of the sympathetic nervous system and human blood pressure regulation. Exp Physiol. 2008:93:715-24.

14. Schobel HP Fischer T, Heuszer K, Geiger H, Schmieder RE. Preeclampsia -- a state of sympathetic overactivity. N Engl J Med. 1996:335:1480-5.

15. Brown MA, Lindheimer MD, de Swiet M, Van Assche A, Moutquin JM. The classification and diagnosis of the hypertensive disorders of pregnancy: statement from the International Society for the Study of Hypertension in Pregnancy (ISSHP). Hypertens Pregnancy. 2001;20:IX-XIV.

16. Matthews DR, Hosker JP, Rudenski AS, Naylor BA, Treacher DF, Turner RC. Homeostasis model asses ment: insulin resistance and beta-cell function from fasting plasma glucose and insulin concentrations in man. Diabetologia. 1985;28:412-9.

17. Mangos GJ, Walker BR, Kelly JJ, Lawson JA, Webb DJ, Whitworth JA. Cortisol inhibits cholinergic vasodilation in the human forearm. Am J Hypertens. 2000;13:1155-60.

18. Benjamin N, Calver A, Collier J, Robinson B, Vallance P, Webb D. Measuring forearm blood flow and interpreting the responses to drugs and mediators. Hypertension. 1995;25:918-23.

19. Silke B, McAuley D. Accuracy and precision of blood pressure determination with the Finapres: an overview using re-sampling statistics. J Hum Hypertens. 1998;12:403-9. 
20. Stekkinger E Zandstra M, Peeters LL Spaanderman ME Early-onset preeclampsia and the prevalence of postpartum metabolic syndrome. Obstet Gynecol. 2009;114:1076-84.

21. Magnussen EB, Vatten LJ, Lund-Nilsen TI, Salvesen KA, Davey Smith G, Romundstad PR. Prepregnancy cardiovascular risk factors as predictors of pre-eclampsia: population based cohort study. BMJ. 2007;335:978.

22. Hamad RR, Eriksson MJ, Silveira A, Hamsten A, Bremme K. Decreased flow-mediated dilation is present 1 year after a pre-eclamptic pregnancy. J Hypertens. 2007;25:2301-7.

23. McDonald SD, Han Z, Walsh MW, Gerstein HC, Devereaux PJ. Kidney disease after preeclampsia: a systematic review and meta-analysis. Am J Kidney Dis. 2010;55:1026-39.

24. Sierra-Laguado J, Garcia RG, Celedon J, et al. Determination of insulin resistance using the homeostatic model assessment (HOMA) and its relation with the risk of developing pregnancy-induced hypertension. Am J Hypertens. 2007;20:437-42.

25. Romundstad PR, Magnussen EB, Smith GD, Vatten LJ. Hypertension in pregnancy and later cardiovascular risk: common antecedents? Circulation. 2010;122:579-84.

26. Callaway LK, McIntyre HD, O'Callaghan M, Williams GM, Najman JM, Lawlor DA. The association of hypertensive disorders of pregnancy with weight gain over the subsequent 21 years: findings from a prospec-
tive cohort study. Am J Epidemiol. 2007:166:421-8.

27. Lommerse T, Aardenburg R, Houben A, Peeters LL. Endothelium-dependent vasodilatation in formerly preeclamptic women correlates inversely with body mass index and varies independently of plasma volume.
Reprod Sci. 2007:14:765-70.

28. Paez O, Alfie J, Gorosito M, et al. Parallel decrease in arterial distensibility and in endothelium-dependent dilatation in young women with a history of pre-eclampsia. Clin Exp Hypertens. 2009;31:544-52.

29. Lampinen KH, Ronnback M, Kaaja RJ, Groop PH. Impaired vascular dilatation in women with a history of pre-eclampsia. J Hypertens. 2006;24:751-6.

30. Hilz MJ, Dutsch M. Quantitative studies of autonomic function. Muscle Nerve. 2006;33:6-20.

31. Vanderheyden M, Goethals M, Nellens P, Andries E, Brugada P. Different humoral responses during head-up tilt testing among patients with neurocardiogenic syncope. Am Heart J. 1998;135:67-73.

32. Brown MA, Wang J, Whitworth JA. The renin-angiotensin-aldosterone system in pre-eclampsia. Clin Exp Hypertens. 1997;19:713-26.

33. Hubel CA, Wallukat G, Wolf $\mathrm{M}$, et al. Agonistic angiotensin II type 1 receptor autoantibodies in postpartum women with a history of preeclampsia. Hypertension. 2007;49:612-7.

34. Victor RG, Leimbach WN, Jr., Seals DR, Wallin BG, Mark AL. Effects of the cold pressor test on muscle sympathetic nerve activity in humans. Hypertension. 1987;9:429-36.

35. Woisetschlager $\mathrm{C}$, Waldenhofer $\mathrm{U}$, Bur A, et al. Increased blood pressure response to the cold pressor test in pregnant women developing pre-eclampsia. J Hypertens. 2000;18:399-403.

\section{Chapter 4}

\section{Insulin resistance relates to microvascular reactivity 23 years after preeclampsia}

Julia Spaan, Alphons Houben, Angela Musella, Timo Ekhart, Marc Spaanderman, Louis Peeters

Microvascular Research 2010;80:417-21 
Preeclampsia, an endothelial disorder of pregnancy, is associated with an increased risk on cardiovascular diseases. Cardiovascular risk factors may mediate vascular dysfunction both during pregnancy but also later in life. This study aims to investigate microvascular reactivity, and its relationship with several cardiovascular risk factors, in women with a history of preeclampsia and controls. In this crosssectional study we compared women with a history of preeclampsia $(\mathrm{PE}, \mathrm{n}=22)$ with women with uneventful pregnancies only $(\mathrm{CON}$, $\mathrm{n}=29) 23$ years after their first delivery. Participants were matched for BMI, age and date of delivery. We assessed blood concentrations of fasting glucose, HbA1c, insulin, (total, HDL-, LDL-) cholesterol, triglycerides and CRP. Endothelial function was assessed by measurement of skin microcirculatory blood flow by Laser Doppler flowmetry at the dorsal and ventral site of the finger during post-occlusive reactive hyperemia $(\mathrm{PORH})$. $\mathrm{PE}$ had higher fasting insulin levels and HOMA-IR compared with CON. The PORH response was similar in both groups. The area under the curve of PORH correlated with insulin and HOMA-IR at both sites, with BMI, triglycerides at the dorsal site and with CRP at the ventral site of the finger in PE and not in CON. In conclusion, 23 years after pregnancy we did not observe a difference in the microvascular hyperemic response between women with a history of preeclampsia and controls. Meanwhile, the results of our study suggest that insulin resistance and other cardiovascular risk factors are related to microvascular reactivity in middle-aged women with a history of preeclampsia.

\section{Introduction}

Preeclampsia affects about $5-8 \%$ of all first pregnancies and is a major cause of maternal and fetal morbidity and mortality worldwide. ${ }^{1}$

Although the symptoms of preeclampsia typically regress within a few days post partum, women with a history of preeclampsia have a 2 - to 4-fold higher risk of developing chronic hypertension, stroke, venous thromboembolism and ischemic heart disease later in life. ${ }^{2}$

The predisposition to later cardiovascular disease in women with a history of preeclampsia is most likely explained by shared cardiovascular risk factors, such as hypertension, obesity, insulin resistance, hyperlipidemia and chronic low grade inflammation. ${ }^{3-5}$ As a matter of fact, endothelial dysfunction plays a central role in the etiology of both preeclampsia and cardiovascular disease. ${ }^{6,7}$ Moreover, impaired vascular dilatation is still present several years after preeclampsia, ${ }^{8-10}$ suggesting persistent endothelial dysfunction, which may contribute to the development of cardiovascular disease in these women. We hypothesized that women with a history of preeclampsia have a chronically impaired microvascular function. Therefore, the aim of our study was to investigate microvascular reactivity 23 years after pregnancy in women with a history of preeclampsia, using similar observations in women who had uneventful pregnancies only as a reference. We tested microvascular reactivity by Laser Doppler flowmetry of the finger skin during post-occlusive reactive hyperemia (PORH) and its relationship with several cardiovascular risk factors.

\section{Methods}

From January 2001 to July 2008, 22 formerly preeclamptic women (PE) and 29 parous controls (CON) enrolled in this study. All participants were Caucasian and delivered their first child in the period between 1979 and 1987 at the Department of Obstetrics of the University Hospital of Maastricht, the Netherlands. The primiparous subjects were matched for age, BMI and date of delivery. We excluded women with preexistent hypertension, diabetes mellitus, renal disease, current cancer therapy or chronic use of corticosteroid medication. The selection procedure is described in detail elsewhere. ${ }^{11}$ Preeclampsia was defined according to the criteria of the Report of the National High Blood Pressure Education Program Working Group in High Blood Pressure in Pregnancy. ${ }^{1}$ An uneventful pregnancy was defined as a term singleton pregnancy without complications, such as fetal growth restriction, pregnancy-induced hyperten- 
sion or gestational diabetes. The study protocol was approved by the hospital ethical committee board and all participants gave written informed consent.

Measurements were performed in the follicular phase (day $5 \pm 2$ ) of the menstrual period or randomly, when postmenopausal. Antihypertensive drugs were discontinued two weeks prior to the measurements. None of the participants were using cholesterollowering medication. Participants did not drink caffeine- or alcoholcontaining beverages and refrained from smoking and eating for at least 10 hours before the measurements. The measurements were performed in a temperature-controlled room $\left(23-24^{\circ} \mathrm{C}\right)$ with the participant lying on a comfortable bed in supine position. We collected fasting blood samples for the measurement of several cardiovascular risk factors. After an acclimatization period of 30 minutes arterial blood pressure was recorded using a semi-automatic oscillometric device (Dinamap Vital Signs Monitor 1846, Critikon, Tampa, FL, USA). Thereafter, on the opposite arm, basal finger skin blood flow was measured for 3 minutes using laser Doppler flowmetry. Next, arterial occlusion was applied for 5 minutes with a pediatric cuff around the wrist inflated to a pressure of $200 \mathrm{mmHg}$. The post-occlusive reactive hyperemia (PORH) blood flow response following deflation of the cuff, was recorded during 6 minutes. Vascular reactivity as measured by the PORH response reflects endothelial function. ${ }^{12}$

Skin microcirculatory blood flow

Skin microcirculatory blood flow was measured by laser Doppler flowmetry (FloLAB, Moor Instruments, United Kingdom) on the dorsal side of the middle phalanx and the ventral side of the distal phalanx of the third finger on the left hand. This non-invasive method measures skin blood flow by infrared laser light with a wavelength of $780 \mathrm{~nm}$. This light is reflected by skin tissue and scattered by moving red blood cells. Flux values are expressed as arbitrary perfusion units (PU). The laser light penetrates the skin to a depth of $1.0 \mathrm{~mm}$. The laser Doppler flux represents mostly thermoregulatory perfusion. ${ }^{13}$ All measurements were digitalized and analyzed off-line. Biological zero values, obtained during arterial occlusion, were subtracted from all flow values. Mean basal flow was determined as the mean flow during the last minute in rest. Maximum flow, time to maximum, period of hyperemia and the area under the curve (AUC) provided the information needed to quantify the PORH response (figure 1). Maximum flow was defined as

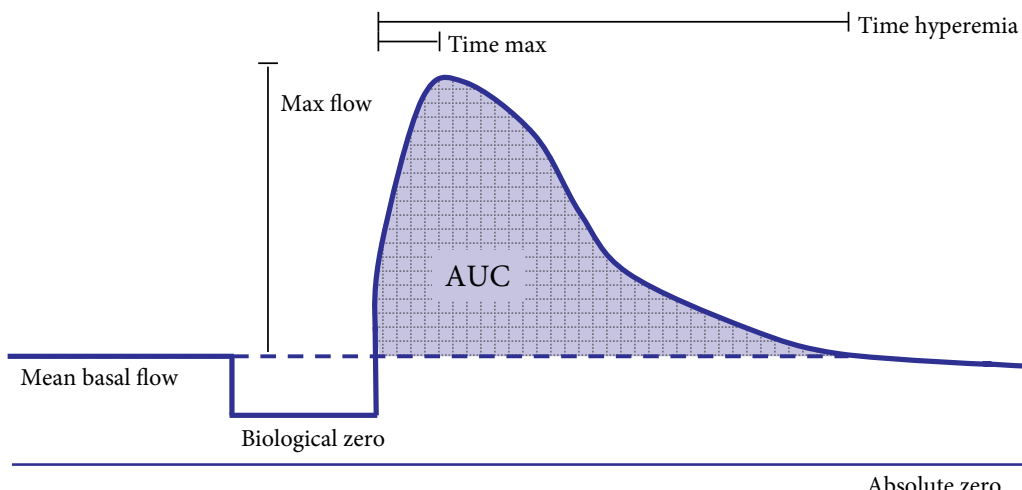

Absolute zero

Figure 1: Determinants of the post-occlusion reactive hyperemia (PORH) response.

the difference between maximum blood flow and the baseline value. The ratio max/basal was calculated by the maximum flow divided by the mean basal flow. To determine the AUC-total we used the period between the start of hyperemia and either the return of the signal to a (new) baseline, or else, until 6 minutes afterwards. The AUC-1min was calculated during the first minute of hyperemia.

Laboratory measurements

Fasting triglycerides, total cholesterol, HDL-cholesterol, glucose and CRP were measured by standard automated laboratory techniques (Beckman Coulter LX20 PRO, Fullerton, USA). LDL-cholesterol was calculated by the Friedewald equation. Plasma insulin concentrations were measured using AutoDelfia time-resolved fluoroimmunoassay. Hyperinsulinemia was considered when plasma insulin levels were equal to or above $15 \mathrm{mU} / \mathrm{l}$. We estimated insulin resistance based on the homeostasis model assessment of insulin resistance (HOMA-IR), using the following formula: HOMA-IR $=$ [fasting serum insulin $(\mathrm{mU} / \mathrm{l}) \times$ fasting plasma glucose $(\mathrm{mmol} / \mathrm{l}] / 22.5{ }^{14}$

Statistical analysis

Data are presented as mean with standard deviation (SD) or median with interquartile range (IQR), unless otherwise specified. Skewed data (insulin, HOMA-IR, AUC) were transformed by square-root transformation. Differences between groups were tested using Student's t-test or Mann-Whitney U-test. To explore the association between variables we used Pearson's correlation or Spearman's rank correlation where appropriate. Multiple regression analysis was used to adjust for possible confounders. A p-value less 0.05 was considered statistically significant. 
Table 1: Characteristics of the study population

\begin{tabular}{|c|c|c|c|}
\hline & $\operatorname{PE}(n=22)$ & $\operatorname{CON}(n=29)$ & p-value \\
\hline Age (years) & $49.0 \pm 3.9$ & $49.8 \pm 3.9$ & 0.48 \\
\hline $\operatorname{BMI}\left(\mathrm{kg} / \mathrm{m}^{2}\right)$ & $25.0 \pm 3.6$ & $25.5 \pm 3.5$ & 0.63 \\
\hline Postmenopausal, n(\%) & $8(36)$ & $5(17)$ & 0.12 \\
\hline $\begin{array}{l}\text { Smoking, } \mathrm{n}(\%) \\
\text { Current } \\
\text { Former } \\
\text { Never }\end{array}$ & $\begin{array}{l}3(14) \\
14(64) \\
5(23)\end{array}$ & $\begin{array}{l}10(35) \\
8(28) \\
11(38)\end{array}$ & $\begin{array}{l}0.09 \\
0.01 \\
0.25\end{array}$ \\
\hline Chronic hypertension, $\mathrm{n}(\%)$ & $11(50)$ & $0(0)$ & $<0.01$ \\
\hline Stroke, $\mathrm{n}(\%)$ & $2(9)$ & $1(3)$ & 0.40 \\
\hline Thrombosis, n(\%) & $3(13)$ & $1(3)$ & 0.18 \\
\hline $\begin{array}{l}\text { Family history of, } \mathrm{n}(\%) \\
\text { Hypertension, } 1 \text { st degree } \\
\text { PE }\end{array}$ & $\begin{array}{l}10(63) \\
3(19)\end{array}$ & $\begin{array}{l}13(48) \\
1(4)\end{array}$ & $\begin{array}{l}0.36 \\
0.09\end{array}$ \\
\hline \multicolumn{4}{|l|}{ Index pregnancy } \\
\hline GA at birth (weeks) ${ }^{a}$ & 34 6/7 (27-43) & $404 / 7(38-42)$ & $<0.01$ \\
\hline Birth weight $(\mathrm{g})^{\mathrm{a}}$ & $1801(880-3350)$ & $3574(2730-4500)$ & $<0.01$ \\
\hline Early-onset PE, n(\%) & $9(41)$ & - & \\
\hline Recurrent PE, n(\%) & $5(23)$ & - & \\
\hline Follow-up time (years) ${ }^{\mathrm{a}}$ & $23(20-28)$ & $23(20-28)$ & 0.12 \\
\hline
\end{tabular}

Table 2: Clinical variables measured in formerly preeclamptic women (PE) and controls (CON).

\begin{tabular}{l|l|l|l|}
\hline Systolic BP (mmHg) & PE $(\mathbf{n}=\mathbf{2 2})$ & CON $(\mathbf{n}=\mathbf{2 9})$ & p-value \\
\hline Diastolic BP (mmHg) & $132 \pm 17$ & $117 \pm 15$ & $<0.01$ \\
\hline MAP (mmHg) & $80 \pm 12$ & $72 \pm 9$ & $<0.01$ \\
\hline Glucose (mmol/l) & $100 \pm 12$ & $88 \pm 10$ & $<0.01$ \\
\hline HbA1c (\%) & $5.0 \pm 0.4$ & $5.0 \pm 0.4$ & 0.65 \\
\hline Insulin (mU/l) & $5.6 \pm 0.4$ & $5.6 \pm 0.3$ & 0.70 \\
\hline HOMA-IR & $8.3(6.8-14.0)$ & $6.4(4.3-9.8)$ & 0.02 \\
\hline Total cholesterol (mmol/l) & $2.0(1.6-3.2)$ & $1.4(1.0-2.3)$ & 0.01 \\
\hline HDL-cholesterol (mmol/l) & $5.94 \pm 0.95$ & $5.59 \pm 1.02$ & 0.22 \\
\hline LDL-cholesterol (mmol/l) & $1.49 \pm 0.47$ & $1.48 \pm 0.38$ & 0.95 \\
\hline Triglycerides (mmol/l) & $3.81 \pm 0.69$ & $3.68 \pm 0.89$ & 0.54 \\
\hline CRP (mg/l) & $1.33 \pm 0.81$ & $1.00 \pm 0.42$ & 0.06 \\
\hline $\begin{array}{l}\text { BP: blood pressure, MAP: } \text { mean arterial pressure, HbA1c: } \text { glycosylated hemoglobin } \\
\text { type A1c, HOMA-IR: homeostasis model assessment of insulin resistance, HDL: high } \\
\text { density lipoprotein, LDL: low density lipoprotein, CRP: C-reactive protein. }\end{array}$
\end{tabular}

Results

Table 1 lists the characteristics of the study population. Median follow-up time since preeclampsia or uneventful pregnancy was 23 years. Both groups were comparable with respect to age, BMI and family history of preeclampsia and hypertension. Although at the time of measurements, the women in PE tended to smoke less often than those in CON (14 vs. 35\%), a larger fraction of the women in $\mathrm{PE}$ was former smoker. At the time of measurement 8 (36\%) PE and 5 (17\%) CON were postmenopausal. Eleven (50\%) PE had chronic hypertension compared with none in the control group.

Table 2 lists the clinical variables measured in PE and CON. PE differed from $\mathrm{CON}$ by higher mean values for blood pressure, fasting insulin and HOMA-IR, and a higher incidence of hyperinsulinemia $(23 \%$ vs. $0 \%, \mathrm{p}<0.01)$. Both groups were comparable with respect to fasting glucose, total -, HDL- and LDL-cholesterol, triglycerides and CRP.

\begin{tabular}{|c|c|c|c|}
\hline & $\operatorname{PE}(n=22)$ & $\operatorname{CON}(n=29)$ & p-value \\
\hline \multicolumn{4}{|l|}{ Dorsal site } \\
\hline Mean basal flow (PU) & $21(7-46)$ & $16(6-42)$ & 0.91 \\
\hline Max flow (PU) & $81(66-112)$ & $84(69-139)$ & 0.51 \\
\hline Ratio max/basal & $4.6(2.4-12.8)$ & $5.8(2.2-11.8)$ & 0.87 \\
\hline Time hyperemia (s) & $156(122-209)$ & $149(95-192)$ & 0.25 \\
\hline Time max (s) & $16(10-20)$ & $15(12-21)$ & 0.72 \\
\hline AUC-total (PU) & 7778 (3910-10259) & $5523(3395-9546)$ & 0.28 \\
\hline AUC-1min (PU) & $3736(2533-4953)$ & $3435(2557-5328)$ & 0.83 \\
\hline \multicolumn{4}{|l|}{ Ventral site } \\
\hline Mean basal flow (PU) & $102(34-192)$ & $87(33-204)$ & 0.99 \\
\hline Max flow (PU) & $230(172-273)$ & $252(195-328)$ & 0.28 \\
\hline Ratio max/basal & $2.9(0.9-7.3)$ & $4.1(1.2-8.9)$ & 0.52 \\
\hline Time hyperemia (s) & $196(150-257)$ & $185(109-268)$ & 0.49 \\
\hline Time max (s) & $34(14-58)$ & $39(16-71)$ & 0.41 \\
\hline AUC-total (PU) & $28493(15192-37518)$ & $26615(15985-52401)$ & 0.69 \\
\hline AUC-1min (PU) & 9585 (6917-12458) & $10135(6761-13962)$ & 0.52 \\
\hline
\end{tabular}


Table 3 shows that the PORH response was comparable in PE and CON. No differences between groups were found for the maximum flow, time to maximum and period of hyperemia. The AUC-total tended to be higher and the ratio max/basal to be lower in PE compared with $\mathrm{CON}$, although this was not significant. Three control women did not exhibit a post-occlusion response at the ventral side of the finger, possibly due to an incorrect position of the ventral probe. They had the same characteristics as the whole population and were not included in the data-analysis of the ventral PORH response.

In a univariate analysis (table 4) we tested the correlation between the AUC-total and several cardiovascular risk factors. In CON, the AUC did not correlate with any of the risk factors. In contrast, in PE, the AUC correlated with plasma insulin and HOMA-IR at both sites, with triglycerides and $\mathrm{BMI}$ at the dorsal, and with CRP at the ventral site of the finger.

Table 4: Univariate correlation between several clinical variables and AUC-total on the dorsal and ventral site of the finger in formerly preeclamptic women (PE) and controls $(\mathrm{CON})$.

\begin{tabular}{|c|c|c|c|c|}
\hline & \multicolumn{2}{|c|}{$\operatorname{PE}(n=22)$} & \multicolumn{2}{|c|}{ CON $(n=29)$} \\
\hline & $\mathbf{r}$ & p-value & $\mathbf{r}$ & p-value \\
\hline \multicolumn{5}{|l|}{ AUC dorsal } \\
\hline $\operatorname{BMI}\left(\mathrm{kg} / \mathrm{m}^{2}\right)$ & -0.49 & 0.02 & -0.08 & 0.67 \\
\hline MAP (mmHg) & -0.22 & 0.32 & 0.15 & 0.45 \\
\hline Insulin (mU/l) & -0.55 & $<0.01$ & 0.03 & 0.88 \\
\hline HOMA-IR & -0.56 & $<0.01$ & -0.06 & 0.78 \\
\hline HDL-cholesterol (mmol/l) & 0.29 & 0.19 & 0.23 & 0.24 \\
\hline Triglycerides $(\mathrm{mmol} / \mathrm{l})$ & -0.43 & 0.04 & 0.14 & 0.47 \\
\hline $\mathrm{CRP}(\mathrm{mg} / \mathrm{l})$ & -0.36 & 0.10 & 0.01 & 0.97 \\
\hline \multicolumn{5}{|l|}{ AUC ventral } \\
\hline BMI $\left(\mathrm{kg} / \mathrm{m}^{2}\right)$ & -0.42 & 0.05 & -0.14 & 0.50 \\
\hline MAP (mmHg) & -0.04 & 0.85 & -0.07 & 0.74 \\
\hline Insulin (mU/l) & -0.43 & 0.05 & -0.06 & 0.76 \\
\hline HOMA-IR & -0.45 & 0.04 & -0.07 & 0.73 \\
\hline HDL-cholesterol (mmol/l) & 0.29 & 0.18 & 0.02 & 0.91 \\
\hline Triglycerides $(\mathrm{mmol} / \mathrm{l})$ & -0.32 & 0.15 & 0.30 & 0.14 \\
\hline $\mathrm{CRP}(\mathrm{mg} / \mathrm{l})$ & -0.48 & 0.03 & 0.13 & 0.53 \\
\hline
\end{tabular}

Figures 1 and 2 illustrate that in PE, but not in CON, AUC-total correlated inversely with HOMA-IR both at the dorsal $(b=-38.8$, $p=0.009)$ and the ventral side $(b=-47.9, p=0.039)$ of the finger. The latter relationship, in the PE subgroup, persisted after adjustment for chronic hypertension, postmenopausal state and smoking in a multiple regression analysis $(b=-41.2, p=0.013$ and $b=-55.4, p=0.029$, respectively).

a. Dorsal

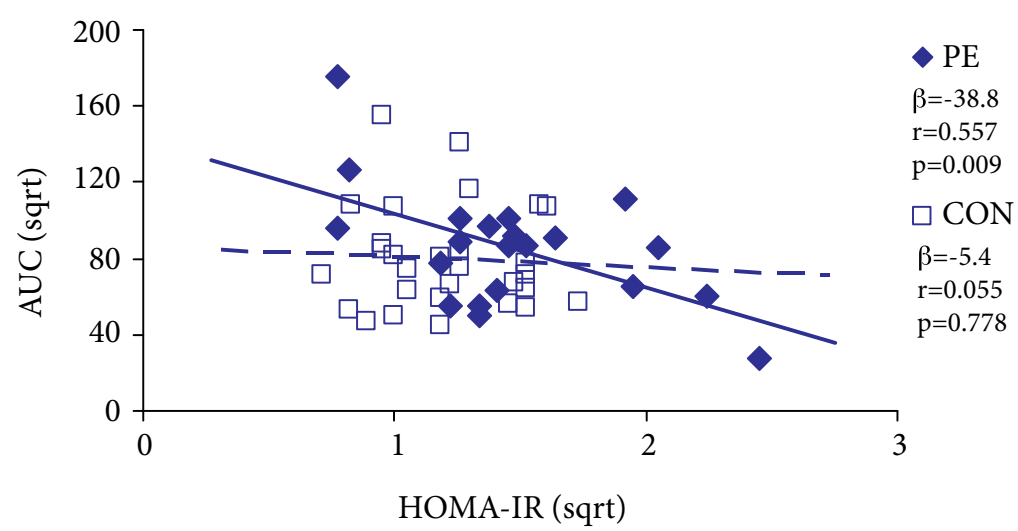

b. Ventral

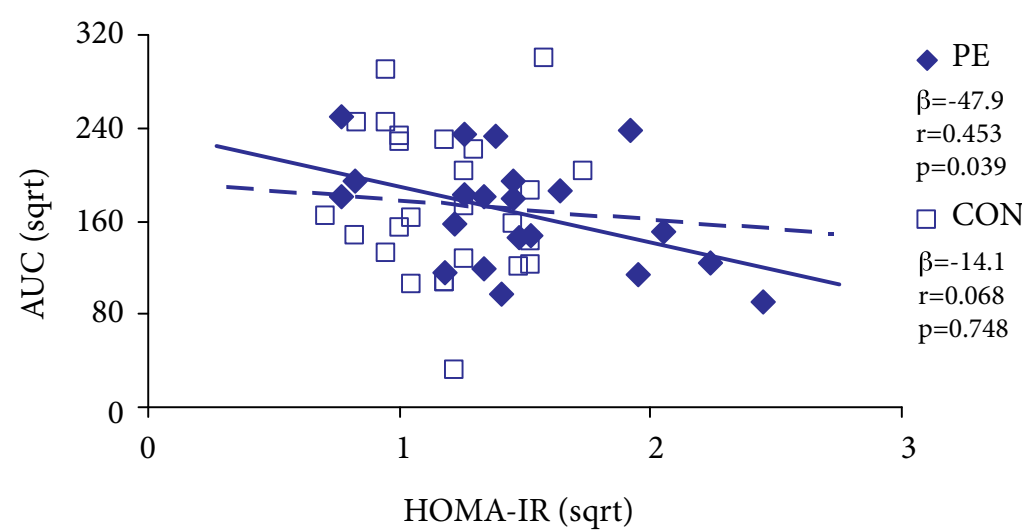

Figure 2: Correlation between the area under the curve (AUC-total) and HOMA-IR at the dorsal (a) and ventral (b) site of the finger in formerly preeclamptic women $(\mathrm{PE})$ and controls $(\mathrm{CON})$. 
Discussion

The microvascular hyperemic response did not differ between women with a history of preeclampsia and controls. Notably, this vasodilator response did correlate with several cardiovascular risk factors in the group of formerly preeclamptic women. This suggests that classical cardiovascular risk factors are associated with reduced microvascular reactivity in women with a history of preeclampsia.

Endothelial function can be investigated by measuring the response of a vascular bed to pharmacological or physiological stimuli. ${ }^{15}$ Several studies focused on large vessel reactivity in women with a history of preeclampsia and observed an attenuated vasodilatory response measured by flow-mediated dilatation or venous occlusion plethysmography. $8,9,16$ Just one study evaluated microvascular function several years after preeclampsia, observing a lower response to both endothelium-dependent and independent vasodilatation using laser Doppler imaging of the forearm 20 years after preeclampsia. ${ }^{10}$ In contrast, in our study we did not observe a difference in microcirculatory blood flow between PE and controls. To obtain a vasodilatory response we did not use a strong pharmacological stimulus, but used a post-occlusion test instead to induce hyperemia, which may have been less sensitive. The PORH response is mediated by both endothelium-dependent and independent vasodilatation. This mixed response may not have been able to discriminate between both groups.

Our study confirms that classical cardiovascular risk factors, such as $\mathrm{BMI}$, triglycerides and CRP correlate with the PORH response in the group of women with a history of preeclampsia. A large prospective cohort study in healthy females showed that the presence of cardiovascular risk factors coincides with impaired postischemic skin reactive hyperemia. ${ }^{12}$ Moreover, the number of cardiovascular risk factors can be related to the degree of vascular impairment. ${ }^{12,17}$ We hypothesized that middle-aged women with a history of preeclampsia have a chronically impaired microvascular function due to persistence of endothelial dysfunction. However, we do realize that in this crosssectional study we measured women about 23 years after pregnancy and several unidentified confounders may have influenced endothelial health in both groups. Another limitation of this study is that we had no complete data on the clinical management of these women throughout their pregnancies.
We observed a relationship between insulin resistance and the microvascular PORH response. Insulin resistance has been shown to correlate with impaired microvascular function in subjects with mild hypertension or a family history of diabetes. ${ }^{18-20}$ Physiologically, acute exposure of a microvascular bed to insulin triggers vasodilatation by stimulating the endothelial release of nitric oxide. ${ }^{21}$ This vasodilator effect of insulin is important for the regulation of blood flow in the microvessels. On the other hand, insulin resistance is related to impaired insulin-mediated nitric oxide release. ${ }^{22,23}$ For example, healthy obese women differ from women with a normal weight by an impaired microvascular vasodilator response to directly administrated insulin. ${ }^{24}$

In our study, the hyperemic response of the skin microvasculature correlated inversely with insulin resistance in formerly preeclamptic women only and not in controls. Similarly, others showed an impaired vasodilator response in relation to insulin resistance in brachial artery of women with a history of preeclampsia and not in controls. ${ }^{25}$ These observations suggest that this relationship observed in our study is not confined to the small arterioles, but applies to the conductance vessels as well. Apparently, already a marginally raised HOMA-IR, as observed in our PE subgroup, is associated with reduced microvascular reactivity.

Possibly, the presence of hypertension may have contributed to the observed negative effect of insulin resistance on the microvascular vasodilator response, as half of the women in our PE group had chronic hypertension. However, adjustment for the presence of chronic hypertension in a multivariate analysis did not modify this relationship. The antihypertensive drugs were discontinued two weeks prior to measurement, which may have been too short to completely eliminate the pharmacologic effect, however, this may have only attenuated the observed correlations.

To sum up, women with a history of preeclampsia are at increased risk of cardiovascular disease. It is generally thought that endothelial dysfunction precedes the onset of overt cardiovascular disease. ${ }^{26}$ Endothelial dysfunction - considered to be responsible for most clinical symptoms during preeclampsia - has been reported to persist post partum, even though the disorder seems completely resolved. In this study we did not observe a difference in the microvascular hyperemic 
response between women with a history of preeclampsia and controls 23 years after pregnancy. However, this study did reveal that in a group of middle-aged women with a history of preeclampsia, classical cardiovascular risk factors correlate closely with the microvascular vasodilator response to arterial occlusion. This effect is not observed in control women with uncomplicated pregnancies. In conclusion, the results of our study provide evidence for the concept that insulin resistance and other cardiovascular risk factors are associated with reduced microvascular reactivity in women with a history of preeclampsia.

\section{References}

1. Report of the National High Blood Pressure Education Program Working Group on High Blood Pressure in Pregnancy. Am J Obstet Gynecol. 2000;183:S1-S22.

2. Bellamy L, Casas JP, Hingorani AD, Williams DJ. Pre-eclampsia and risk of cardiovascular disease and cancer in later life: systematic review and meta-analysis. Bmj. 2007;335:974.

3. Rodie VA, Freeman DJ, Sattar N, Greer IA. Pre-eclampsia and cardiovascular disease: metabolic syndrome of pregnancy? Atherosclerosis. 2004;175:189-202.

4. Sattar N, Ramsay J, Crawford L, Cheyne H, Greer IA. Classic and novel risk factor parameters in women with a history of preeclampsia. Hypertension. 2003;42:39-42.

5. Smith GN, Walker MC, Liu A, et al. A history of preeclampsia identifies women who have underlying cardiovascular risk factors. Am J Obstet Gynecol. 2009;200:58.e1-8.

6. Garovic VD, Hayman SR. Hypertension in pregnancy: an emerging risk factor for cardiovascular disease. Nat Clin Pract Nephrol. 2007;3:613-22.

7. Harskamp RE, Zeeman GG. Preeclampsia: at risk for remote cardiovascular disease. Am J Med Sci. 2007;334:291-5

8. Chambers IC, Fusi L, Malik IS, Haskard DO, De Swiet M, Kooner IS. Association of maternal endotheli dysfunction with preeclampsia. Jama. 2001;285:1607-12

9. Lampinen KH, Ronnback M, Kaaja RJ, Groop PH. Impaired vascular dilatation in women with a history f pre-eclampsia. J Hypertens. 2006;24:751-6.

10. Ramsay JE, Stewart F, Greer IA, Sattar N. Microvascular dysfunction: a link between pre-eclampsia and maternal coronary heart disease. Bjog. 2003;110:1029-31.

11. Spaan JJ, Ekhart T, Spaanderman ME, Peeters LL. Remote Hemodynamics and Renal Function in Formerly Preeclamptic Women. Obstet Gynecol. 2009;113:853-9.

12. Vuilleumier P, Decosterd D, Maillard M, Burnier M, Hayoz D. Postischemic forearm skin reactive hyper-

13. Houben AJ, Slaaf DW, Huvers FC, de Leeuw PW, Nieuwenhuijzen Kruseman AC, Schaper NC Diurnal variations in total forearm and skin microcirculatory blood flow in man. Scand J Clin Lab Invest. 1994;54:161-8.

95.

15. Kuvin JT, Karas RH. Clinical utility of endothelial function testing: ready for prime time? Circulation. 2003;107:3243-7.

16. Agatisa PK, Ness RB, Roberts JM, Costantino JP, Kuller LH, McLaughlin MK. Impairment of endothelia function in women with a history of preeclampsia: an indicator of cardiovascular risk. Am J Physiol Hear Circ Physiol. 2004;286:1389-93.

17. Ishibashi $\mathrm{Y}$, Takahashi $\mathrm{N}$, Shimada $\mathrm{T}$, et al. Short duration of reactive hyperemia in the forearm of subjects with multiple cardiovascular risk factors. Circ J. 2006;70:115-23.

18. Caballero AE, Arora S, Saouaf R, et al. Microvascular and macrovascular reactivity is reduced in subjects th risk for type 2 diabetes. Diabetes. 1999:48:1856-62.

19. Nazzaro P, Vulpis V, Schirosi G, et al. Microvascular impairment is associated with insulin resistance in euglycemic mild hypertensives. Am J Hypertens. 2008;21:432-7.

20. Serne EH, Stehouwer CD, ter Maaten JC, et al. Microvascular function relates to insulin sensitivity and blood pressure in normal subjects. Circulation. 1999;99:896-902. 
22. Jonk AM, Houben AJ, de Jongh RT, Serne EH, Schaper NC, Stehouwer CD. Microvascular dysfunction in obesity: a potential mechanism in the pathogenesis of obesity-associated insulin resistance and hypertension. Physiology (Bethesda). 2007;22:252-60.

23. Kim JA, Montagnani M, Koh KK, Quon MJ. Reciprocal relationships between insulin resistance and endothelial dysfunction: molecular and pathophysiological mechanisms. Circulation. 2006;113:1888-904.

24. de Jongh RT, Serne EH, RG IJ, Jorstad HT, Stehouwer CD. Impaired local microvascular vasodilatory effects of insulin and reduced skin microvascular vasomotion in obese women. Microvasc Res. 2008;75:256-62

25. Lampinen KH, Ronnback M, Groop PH, Kaaja RJ. A relationship between insulin sensitivity and vasodilation in women with a history of preeclamptic pregnancy. Hypertension. 2008;52:394-401.

26. Celermajer DS, Sorensen KE, Gooch VM, et al. Non-invasive detection of endothelial dysfunction in children and adults at risk of atherosclerosis. Lancet. 1992;340:1111-5. 


\section{Chapter 5}

\section{Reduced renal function after preeclampsia does not result from accelerated age-dependent renal function loss}

Julia Spaan, Timo Ekhart, Marc Spaanderman M, Louis Peeters Acta Obstetricia et Gynecologica Scandinavica 2010;89:1202-5

Preeclampsia is associated with later kidney disease. This study tested the hypothesis that the normal decline in renal function with age is more rapid in formerly preeclamptic women than in controls. Four groups were compared cross-sectionally; young women with a history of preeclampsia $(n=34)$, young controls $(n=12)$, middle-aged women with a history of preeclampsia $(n=22)$ and middle-aged controls $(n=29)$. We measured blood pressure (semi-automatic device), effective renal plasma flow (ERPF, para-aminohippurate clearance), glomerular filtration rate (GFR, creatinine clearance) and cardiac output (Doppler echocardiography). ERPF was lower in both young and middle-aged women with a history of preeclampsia relative to controls. The decrease in both GFR and ERPF with age was comparable in both groups. In conclusion, the lower renal function in middleaged formerly preeclamptic women does not result from accelerated age-dependent renal function loss, but from an already reduced renal function relative to parous controls at young age. 


\section{Introduction}

Preeclampsia is a hypertensive disorder of pregnancy, characterized by new-onset hypertension and proteinuria. Women with a history of preeclampsia have a five-fold higher risk of end-stage renal disease. ${ }^{1}$ Probably, preeclampsia is associated with accelerated renal function loss with age. However, data on long-term follow-up of renal function after preeclampsia are scarce. ${ }^{2-4}$ Recently, we found a $15 \%$ lower effective renal plasma flow (ERPF) and a 30\% higher renal vascular resistance (RVR) in women with a history of preeclampsia more than 20 years ago relative to age-matched parous controls. ${ }^{5}$

In preeclampsia, the kidneys display so-called 'glomerular endotheliosis', a typical histological abnormality consisting of swelling and hypertrophy of glomerular endothelial and mesangial cells. This has been reported to resolve within 3 months post partum. ${ }^{6}$ However, the presence of microalbuminuria and a reduced renal function several years after preeclampsia may indicate persistence of glomerular injury. ${ }^{2,3,5}$

A gradual loss of renal function is observed by a decrease in glomerular filtration rate (GFR) with $1 \mathrm{ml} / \mathrm{min} /$ year from 30 years onward in the general population, which can be more pronounced in certain risk groups. ${ }^{7}$ The aim of this study was to test the hypothesis that the normal decline in renal function with age is more rapid in formerly preeclamptic women than in controls. To this end, we compared renal function between a group of young and middle-aged formerly preeclamptic women and two age-matched parous control groups.

\section{Material and methods}

In order to study the effect of age, this cross-sectional study combined two previous studies in formerly preeclamptic and control women at different time intervals post partum. Thus, part of the data have been previously published. One study, performed between 2001 and 2008, included women who were studied about 23 years post partum at an age ranging from 40 to 60 years. ${ }^{5}$ The other study, performed between 1996 and 1999, examined women about 1 year post partum at an age ranging from 20 to 40 years. ${ }^{8}$ For the latter study, we only selected those formerly preeclamptic women $(n=34)$ who were normotensive at post partum follow up. Preeclampsia was defined as new onset hypertension (bloodpressure $\geq 140 / 90 \mathrm{mmHg}$ ) and proteinuria after 20 weeks of gestation. The present study involved four groups: young women with a history of preeclampsia $(n=34)$, young controls $(n=12)$, middle-aged women with a history of preeclampsia $(n=22)$ and middle-aged controls $(n=29)$.

Since 1996 we have used the same standardized protocol for renal studies, described in more detail elsewhere. ${ }^{5,8}$ In short, participants used a standardized sodium diet (100 mmol sodium/day) for 1 week and refrained from smoking and coffee drinking at least 10 hours prior to the measurements. Antihypertensive drugs were discontinued 2 weeks beforehand. Measurements were performed in the mid-follicular phase of the menstrual cycle or randomly when postmenopausal. All subjects collected a 24-hour urine sample. Blood pressure was recorded using a semi-automated device (Dinamap Vital Signs Monitor 1846, Critikon, Tampa, FL, USA). Para-aminohippurate sodium (PAH, MSD, West Point, PA, USA) was administered using a constant-infusion technique. At least 2 hours after the start of the infusion we collected blood samples for the measurement of plasma levels of PAH. We determined the ERPF from clearance of PAH. Effective renal blood flow (ERBF) was obtained by dividing the ERPF by (1-hematocrit). RVR was estimated by $80 \times 103$ times mean arterial pressure (MAP) divided by ERBF. We used creatinine clearance to estimate GFR, because inulin was not available owing to manufactural problems during the second study period. Doppler echocardiography was performed to estimate stroke volume as described previously. ${ }^{8}$ Cardiac output (CO) was calculated by multiplying stroke volume by heart rate. Total peripheral vascular resistance (TPVR) was calculated by 80 times MAP divided by CO. Arterial compliance was estimated by stroke volume divided by pulse pressure.

Statistical analysis

The distribution of data was evaluated by histograms and the Kolmogorov-Smirnov test for normality. Groups were compared using analysis of variance (ANOVA) followed by Gabriel's post-hoc test for pairwise comparisons. The presence of interaction (group $\mathrm{x}$ age-category) was tested by linear regression analysis. To estimate the effect of group- and age-category on the dependent variable, we used multiple linear regression analysis including postmenopausal state as a confounder. In this analysis the intercept represents the group mean for the reference group (young controls). The effects of groupand age-category in percent are derived from the $\beta$ divided by the intercept. A p-value of $<.05$ was considered significant. 


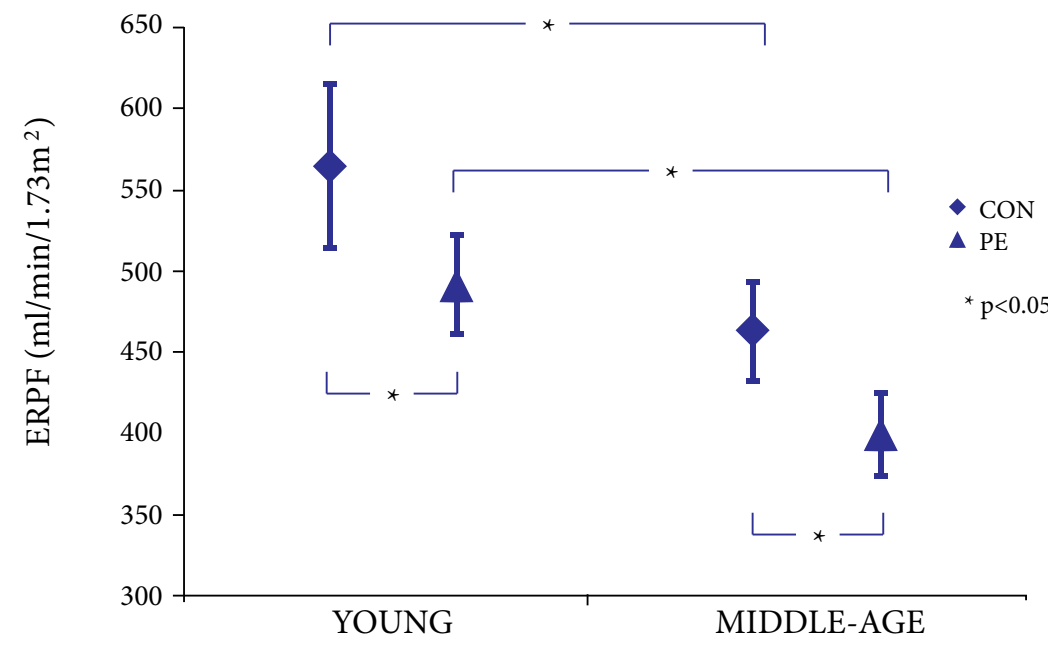

Figure 1: Effective renal plasma flow.

Table 1: Demographics, cardiovascular and renal function in formerly preeclamptic women and controls.

\begin{tabular}{|c|c|c|c|c|}
\hline & $\begin{array}{l}\text { Young } \\
\text { controls } \\
(\mathrm{n}=12)\end{array}$ & $\begin{array}{l}\text { Young } \\
\text { preeclampsia } \\
(\mathrm{n}=34)\end{array}$ & $\begin{array}{l}\text { Middle-aged } \\
\text { controls } \\
(\mathrm{n}=29)\end{array}$ & $\begin{array}{l}\text { Middle-aged } \\
\text { preeclampsia } \\
(\mathrm{n}=22)\end{array}$ \\
\hline Age at measurement (y) & $31.8 \pm 2.2$ & $31.0 \pm 3.4$ & $49.8 \pm 3.9$ & $48.9 \pm 3.9$ \\
\hline Age at delivery (y) & $30.3 \pm 2.4$ & $30.2 \pm 3.4$ & $27.2 \pm 3.8$ & $26.7 \pm 3.6$ \\
\hline BMI $\left(\mathrm{kg} / \mathrm{m}^{2}\right)$ & $22.2 \pm 2.7$ & $24.2 \pm 4.3$ & $25.5 \pm 3.5$ & $25.0 \pm 3.6$ \\
\hline Sys BP (mmHg) & $111 \pm 7$ & $117 \pm 12$ & $117 \pm 15$ & $132 \pm 17^{* \dagger}$ \\
\hline Dias BP (mmHg) & $69 \pm 5$ & $71 \pm 9$ & $72 \pm 9$ & $80 \pm 12^{\dagger}$ \\
\hline MAP (mmHg) & $82 \pm 7$ & $84 \pm 10$ & $88 \pm 10$ & $100 \pm 12^{* \dagger}$ \\
\hline $\mathrm{CO}(\mathrm{L} / \mathrm{min})$ & $4.8 \pm 0.7$ & $5.3 \pm 0.7$ & $5.0 \pm 0.7$ & $4.8 \pm 0.7$ \\
\hline $\begin{array}{l}\text { TPVR } \\
\left(.100 \text { dyne.s } / \mathrm{cm}^{5}\right)\end{array}$ & $14.3 \pm 2.3$ & $13.5 \pm 2.2$ & $14.6 \pm 1.9$ & $17.5 \pm 2.5^{\star \dagger}$ \\
\hline $\begin{array}{l}\text { Arterial compliance } \\
(\mathrm{mL} / \mathrm{mmHg})\end{array}$ & $1.6 \pm 0.2$ & $1.6 \pm 0.2$ & $1.6 \pm 0.3$ & $1.3 \pm 0.3^{* \dagger}$ \\
\hline $\begin{array}{l}\text { GFR CrCl } \\
\left(\mathrm{mL} / \mathrm{min} / 1.73 \mathrm{~m}^{2}\right)\end{array}$ & $118 \pm 19$ & $106 \pm 23$ & $100 \pm 19^{\dagger}$ & $88 \pm 15^{\dagger}$ \\
\hline $\begin{array}{l}\text { ERPF } \\
\left(\mathrm{mL} / \mathrm{min} / 1.73 \mathrm{~m}^{2}\right)\end{array}$ & $565 \pm 87$ & $491 \pm 90^{*}$ & $463 \pm 83^{\dagger}$ & $399 \pm 61^{\star \dagger}$ \\
\hline $\begin{array}{l}\text { ERBF } \\
\left(\mathrm{mL} / \mathrm{min} / 1.73 \mathrm{~m}^{2}\right)\end{array}$ & $875 \pm 139$ & $778 \pm 146$ & $768 \pm 138$ & $675 \pm 103^{\dagger}$ \\
\hline $\begin{array}{l}\text { RVR } \\
\left(.100 \text { dyne.s } / \mathrm{cm}^{5} / 1.73 \mathrm{~m}^{2}\right)\end{array}$ & $76.2 \pm 14.9$ & $89.4 \pm 20.8$ & $94.9 \pm 19.5$ & $121.7 \pm 27.9^{* \dagger}$ \\
\hline \multicolumn{5}{|c|}{$\begin{array}{l}\text { BMI, body mass index; Sys BP, systolic blood pressure; Dias BP, diastolic blood pressure; } \\
M A P, \text { mean arterial pressure; CO, cardiac output; TPVR, total peripheral vascular resist- } \\
\text { ance; GFR, glomerular filtration rate based on creatinine clearance (CrCl); ERPF, effective } \\
\text { renal plasma flow; ERBF, effective renal blood flow; RVR, renal vascular resistance. } \\
{ }^{*} p<.05 \text { compared with control group. }{ }^{\dagger} p<.05 \text { compared with young group. }\end{array}$} \\
\hline
\end{tabular}

Results

At the time of measurement, eight (36\%) formerly preeclamptic women and five (17\%) controls were postmenopausal and twelve (55\%) formerly preeclamptic women and two (7\%) controls were hypertensive in the middle-aged groups. Table 1 lists the general characteristics and variables measured. Body mass index did not differ between groups. Although young women with a history of preeclampsia and young controls were comparable with respect to blood pressure, TPVR and arterial compliance, the former had a lower ERPF. Middle-aged formerly preeclamptic women differed from both middle-aged controls and young formerly preeclamptic women by a higher blood pressure, TPVR and RVR; and a lower arterial compliance, ERPF and ERBF. Agecategory had a different effect in women with a history of preeclampsia than in controls for MAP, TPVR and arterial compliance (interaction $\mathrm{p}=.049, \mathrm{p}<.001$ and $\mathrm{p}=.015$, respectively). This interaction was not significant for GFR, ERPF, ERBF and RVR (figure 1, interaction $p=.958$, $\mathrm{p}=.797, \mathrm{p}=.740$ and $\mathrm{p}=.157$, respectively). Middle-aged women with a history of preeclampsia and middle-aged controls had a lower GFR and ERPF than their respective young groups.

Table 2: The effect of group- and age-category on renal function in a multiple regression analysis adjusted for postmenopausal state.

\begin{tabular}{|l|l|l|l|l|l|}
\hline Dependent variable & Independent variable & b & Error & $95 \%-C I$ & p-value \\
\hline GFR CrCl & Intercept & 117 & 4 & $109-126$ & \\
\hline & Preeclampsia & -11 & 4 & $-19--2$ & 0.013 \\
\hline & Middle-aged & -16 & 5 & $-25--6$ & $<0.001$ \\
\hline ERPF & Postmenopausal & -8 & 6 & $-21-4$ & 0.191 \\
\hline & Intercept & 557 & 18 & $522-592$ & \\
\hline & Preeclampsia & -63 & 18 & $-98--28$ & 0.001 \\
\hline & Middle-aged & -82 & 19 & $-119--44$ & $<0.001$ \\
\hline ERBF & Postmenopausal & -50 & 26 & $-102-2$ & 0.057 \\
\hline & Intercept & 866 & 29 & $809-924$ & \\
\hline & Preeclampsia & -86 & 29 & $-143--28$ & 0.004 \\
\hline RVR & Middle-aged & -82 & 31 & $-143--20$ & 0.010 \\
\hline & Postmenopausal & -79 & 43 & $-164-6$ & 0.069 \\
\hline & Intercept & 71.6 & 4.7 & $62.3-80.9$ & \\
\hline & Preeclampsia & 19.4 & 4.7 & $10.1-28.7$ & $<0.001$ \\
\hline & Middle-aged & 22.5 & 5.0 & $12.6-32.4$ & $<0.001$ \\
\hline & Postmenopausal & 15.6 & 7.0 & $1.8-29.4$ & 0.027 \\
\hline
\end{tabular}

GFR: glomerular filtration rate based on creatinine clearance (CrCl), ERPF: effective renal plasma flow, ERBF: effective renal blood flow, RVR: renal vascular resistance. The intercept represents the group mean for young controls. 
Table 2 provides an estimate for the effect of group- and age-category on renal function adjusted for postmenopausal state. Compared with young controls, the GFR was $9 \%$ lower $(b=-11, p=.013)$ when a history of preeclampsia was present, $14 \%$ lower $(b=-16, p=.001)$ when women were middle-aged, and $23 \%$ lower when both factors were present. The presence of a history of preeclampsia lowered ERPF by $11 \%(b=-63, p=.001)$, lowered ERBF by $10 \%(b=-86, p=.004)$ and raised RVR by $27 \%(\mathrm{~b}=19.4, \mathrm{p}<.001)$. The factor middle-aged lowered ERPF by $15 \%(b=-82, p<.001)$, lowered ERBF by $9 \%(b=-82$, $\mathrm{p}=.010)$ and raised RVR by $31 \%(\mathrm{~b}=22.5, \mathrm{p}<.001)$.

\section{Discussion}

This study shows that the decline in renal function with age is comparable in formerly preeclamptic women and parous controls. In formerly preeclamptic women, renal function is lower at young as well as at middle-age.

The only other study reporting on GFR several years after preeclampsia, did not find a difference in creatinine clearance 5 years post partum. ${ }^{4}$ To our knowledge, no previous studies reported on the effect of age on renal function after preeclampsia. We do realize that our findings should be interpreted cautiously. Firstly, we used crosssectional and not longitudinal data in this study, comparing two different populations with small participant numbers. Secondly, data on medical history obtained more than 20 years after preeclampsia are likely to be incomplete, particularly regarding data on postpartum blood pressure. Thirdly, during the two periods obstetrical management and guidelines have been modified, which may have reduced the comparability of the groups. Therefore, it is important to emphasize that the results of this study require confirmation in a larger population and preferably using a longitudinal study design.

Renal aging leads to a gradual loss of renal function due to glomerulosclerosis and, subsequently, a reduction in nephron number. ${ }^{7}$ Several diseases, such as hypertension and diabetes, can aggravate glomerulosclerosis and the associated loss of renal function. ${ }^{7}$ By contrast, about one third of normal healthy subjects were found to have no decrease in renal function at all with age. ${ }^{9}$ Our study provides indirect evidence for a comparable effect of aging on renal function in formerly preeclamptic and control women. Although about half of the formerly preeclamptic women were hypertensive at middle-age, the presence of hypertension did not seem to have accelerated the age-dependent decrease in renal function The absence of an anticipated effect on renal function loss related to the development of hypertension may be due to our cross-sectional study design and may only be solidly answerable in a longitudinal study design. Other factors, such as insulin resistance or hyperlipidemia, might have influenced our data in both groups.

The lower renal function, observed in both young and middle-aged formerly preeclamptic women, may be consistent with either a reduced renal function already present before pregnancy or persistence of glomerular injury after preeclamptic pregnancy. The observation that preeclampsia but not pregnancy-induced hypertension is associated with later diabetic nephropathy in type 1 diabetes supports the latter option. ${ }^{10}$ Conversely, women with a history of preeclampsia may have a reduced renal function throughout their lives due to a low initial nephron number. At birth, the number of nephrons varies widely (from 250.000 to 2.000.000), and a low nephron number at birth, as seen in association with low birth weight, predisposes to hypertension later in life. ${ }^{11}$

In this study, we found a higher TPVR and a lower arterial compliance in middle-aged formerly preeclamptic women exclusively. This observation indicates that the systemic vascular stiffness increased with age only in formerly preeclamptic women. Vascular stiffness is a hallmark of vascular aging and an independent predictor of cardiovascular disease. Presumably, hypertension and vascular stiffness developed secondary to the reduced renal function in formerly preeclamptic women. ${ }^{12}$

In conclusion, these findings suggest that the lower renal function in middle-aged women with a history of preeclampsia does not result from accelerated age-dependent renal function loss, but from an already reduced renal function relative to parous controls at young age. 
1. Vikse BE, Irgens LM, Leivestad T, Skjaerven R, Iversen BM. Preeclampsia and the risk of end-stage renal disease. N Engl I Med. 2008;359:800-9.

2. Bar J, Kaplan B, Wittenberg C, et al. Microalbuminuria after pregnancy complicated by pre-eclampsia. Nephrol Dial Transplant. 1999;14:1129-32

3. Nisell H, Lintu H, Lunell NO, Mollerstrom G, Pettersson E. Blood pressure and renal function seven years after pregnancy complicated by hypertension. Br J Obstet Gynaecol. 1995;102:876-81.

4. Lampinen KH, Ronnback M, Groop PH, Kaaja RJ. Renal and vascular function in women with previous preeclampsia: a comparison of low- and high-degree proteinuria. Kidney Int. 2006;70:1818-22.

5. Spaan JJ, Ekhart T, Spaanderman ME, Peeters LL. Remote Hemodynamics and Renal Function in Formerly Preeclamptic Women. Obstet Gynecol. 2009;113:853-9.

6. Hladunewich MA, Myers BD, Derby GC, et al. Course of preeclamptic glomerular injury after delivery. Am J Physiol Renal Physiol. 2008;294:F614-20.

7. Zhou XJ, Rakheja D, Yu X, Saxena R, Vaziri ND, Silva FG. The aging kidney. Kidney Int. 2008;74:710-20.

8. Spaanderman ME, Ekhart TH, van Eyck J, Cheriex EC, de Leeuw PW, Peeters LL. Latent hemodynamic abnormalities in symptom-free women with a history of preeclampsia. Am J Obstet Gynecol. 2000;182:101-7.

9. Lindeman RD, Tobin J, Shock NW. Longitudinal studies on the rate of decline in renal function with age. J Am Geriatr Soc. 1985;33:278-85.

10. Gordin D, Hiilesmaa V, Fagerudd J, et al. Pre-eclampsia but not pregnancy-induced hypertension is a risk factor for diabetic nephropathy in type 1 diabetic women. Diabetologia. 2007;50:516-22.

11. Zandi-Nejad K, Luyckx VA, Brenner BM. Adult hypertension and kidney disease: the role of fetal programming. Hypertension. 2006;47:502-8.

12. Johnson RJ, Herrera-Acosta J, Schreiner GF, Rodriguez-Iturbe B. Subtle acquired renal injury as a mechanism of salt-sensitive hypertension. $\mathrm{N}$ Engl J Med. 2002;346:913-23.

\section{Chapter 6}

\section{Renal function after preeclampsia; a longitudinal pilot study}

Julia Spaan, Timo Ekhart, Marc Spaanderman, Louis Peeters Nephron Clinical Practice Nephron 2012;120:156-161 
Background: Women with a history of preeclampsia are at increased risk to develop end-stage renal disease. In this longitudinal study, we evaluated renal function in women with a history of severe pree-

clampsia and parous controls over a period of 14 years.

Methods: Renal function was measured 1 and again 14 years postpartum by para-aminohippurate and inulin clearances in 20 women with a history of severe preeclampsia and 8 parous controls.

Results: The difference in glomerular filtration rate 1 year postpartum between women with a history of preeclampsia and parous controls $\left(112 \pm 10\right.$ and $\left.125 \pm 8 \mathrm{ml} / \mathrm{min} / 1.73 \mathrm{~m}^{2}, \mathrm{p}<.01\right)$ had disappeared 14 years postpartum $\left(104 \pm 10\right.$ and $\left.109 \pm 13 \mathrm{ml} / \mathrm{min} / 1.73 \mathrm{~m}^{2}, \mathrm{p}=.37\right)$. There was a consistent trend for a lower effective renal plasma flow both 1 and 14 years postpartum (477 \pm 90 and $543 \pm 92, \mathrm{p}=.09$ and $473 \pm 85$ and $\left.543 \pm 98 \mathrm{ml} / \mathrm{min} / 1.73 \mathrm{~m}^{2}, \mathrm{p}=.07\right)$.

Conclusion: This explorative study suggests no accelerated renal function loss in the first decade after preeclampsia.

\section{Introduction}

Preeclampsia, a hypertensive disorder of pregnancy, predisposes to premature cardiovascular and renal disease. ${ }^{1,2}$ The risk of developing end-stage renal disease is 3 times higher in women with a history of one preeclamptic pregnancy and 6 to 15 times higher in women with a history of recurrent preeclampsia. ${ }^{3}$ Microalbuminuria, an important risk marker for cardiovascular disease, ${ }^{4,5}$ is present in about $30 \%$ of the women with a history of preeclampsia approximately 5 years postpartum, ${ }^{6}$ a figure comparable to the prevalence observed in type 1 diabetes. $^{7}$

It is still unclear whether renal disease in women with a history of preeclampsia is pre-existent, induced directly by preeclampsia or evolves later, secondary to aging or hypertension. Histological findings suggest that the glomerular endotheliosis of preeclampsia resolves shortly postpartum, in concert with rapid improvement of the glomerular filtration capacity. ${ }^{8,9}$ However, long term follow-up data on renal function after preeclampsia are scarce and show conflicting results. A few studies evaluating kidney function 3-6 years postpartum indicated no difference in creatinine clearance between women with a history of preeclampsia and controls..$^{8,10,11}$ In contrast, we previously found evidence for a lower creatinine clearance, lower renal blood flow and higher renal vascular resistance 23 years postpartum comparing women with a history of preeclampsia and parous controls. ${ }^{12}$ Therefore, the aim of this study is to evaluate renal function longitudinally over a 14 years period in women with a history of preeclampsia and parous controls.

\section{Methods}

In this explorative longitudinal pilot study we measured renal function in women with a history of preeclampsia and parous controls approximately 1 and 14 years postpartum. Women who participated in a previous study on renal function in the period between 1996 and 1999 were invited to participate in this follow-up study. ${ }^{13}$ At that time, women with a history of preeclampsia were recruited at the outpatient clinic at postpartum follow-up. Most of them experienced a severe form of preeclampsia, either early-onset preeclampsia $(<34$ weeks of gestation) or preeclampsia complicated by fetal growth restriction or fetal demise. Controls were recruited by advertisement. Women with pre-existing renal disease or pre-existing hypertension (before pregnancy) were excluded $(n=6)$. We invited 33 women with 
a history of preeclampsia and 10 controls to participate once more 14 years postpartum. No recent address was available from 3 women, one woman died as a consequence of pulmonary embolism and one woman was currently undergoing treatment with chemotherapeutic drugs. Eight (29\%) women with a history of preeclampsia and $2(20 \%)$ controls declined participation, because of lack of time and/or emotional strain. Eventually, 20 women with a history of preeclampsia and 8 controls were enrolled in this study. All women gave informed consent to participate. The study protocol was approved by the Medical Ethical Committee board of Maastricht University Medical Center (MEC 08-2-130)

Preeclampsia was defined as new-onset hypertension (after 20 weeks of gestation) accompanied by new-onset proteinuria ( $\geq 300 \mathrm{mg} / 24 \mathrm{hr}$ ), according to the criteria of the International Society for the Study of Hypertension in Pregnancy. ${ }^{14}$ Hypertension was defined as blood pressure $\geq 140$ and/or $90 \mathrm{mmHg}$ during the measurement session or current use of antihypertensive drugs. We defined early-onset preeclampsia as preeclampsia diagnosed before 34 weeks of gestation. Small for gestational age was defined as a birth weight below the 5th percentile according to the birth weight reference curves of the Perinatal Registry in the Netherlands. ${ }^{15}$

Both measurement sessions at 1 and 14 years postpartum were performed by the same research technician using a standardized protocol for renal studies, as detailed previously. ${ }^{13}$ The research technician performing the measurements was aware of the clinical diagnosis of the participants. All measurements were performed at least 4 months postpartum. We standardized the external conditions as much as possible, with respect to menstrual cycle, medication use and environmental influences. None of the women were breastfeeding or using oral contraceptive pills. Antihypertensive drugs were discontinued 2 weeks before the measurement.

Arterial blood pressure was measured after an acclimatization period of 30 minutes using a semi-automatic oscillometric device (Dinamap Vital Signs Monitor 1846, Critikon, Tampa, FL). Renal function was derived from the clearances of para-aminohippurate sodium (PAH; MSD, West Point, PA) and inulin (first period Inutest, Fresenius AG, Bad Homburg, Germany; second period Inutest 25\%, Fresenius Kabi, Austria) using the constant-infusion technique. ${ }^{16}$ Effective renal plasma flow (ERPF) and glomerular filtration rate were corrected for body surface area and expressed in $\mathrm{ml} / \mathrm{min} / 1.73 \mathrm{~m}^{2}$. Renal vascular resistance (dyne. $\mathrm{s} / \mathrm{cm}^{5} / 1.73 \mathrm{~m}^{2}$ ) was obtained by dividing mean arterial pressure by ERPF/(1-hematocrit). The filtration fraction was calculated dividing glomerular filtration rate by ERPF x 100\%. Participants collected a 24-h urine sample and completeness was evaluated by creatinine concentration (at least $6.0 \mathrm{mmol} / \mathrm{l}$ if volume less than $1000 \mathrm{ml}) \cdot{ }^{17}$ Creatinine clearance was calculated based on the timed urine collection. The degree of microalbuminuria was evaluated 1 year postpartum by turbidimetry (Cobas Bio centrifugal analyzer) and 14 years postpartum by nephelometry (BN ProSpec, Siemens Healthcare Diagnostics, Deerfield, IL). The presence of microalbuminuria was defined as a urinary albumin excretion rate $\geq 3.5$ $\mathrm{g} / \mathrm{mol}$ creatinine. All laboratory tests were performed at the time of measurement and data were stored in a database.

Data are presented as mean with standard deviation, unless stated otherwise. Differences between groups were examined using the independent Student's t-test or Mann-Whitney U-test where applicable. Paired differences were tested by the paired t-test. Categorical data were tested using Chi-square test. Multivariable analysis was performed using repeated-measures ANOVA. We considered a p-value below .05 as statistically significant. To detect a difference between groups at 14 years postpartum with respect to glomerular filtration rate, based on the available data 1 year postpartum, we needed at least 8 women in each group $(\mu 1=125, \sigma=10, \mu 2=112, \sigma=8, \alpha=0.05$, $\beta=0.8){ }^{13}$

\section{Results}

Table 1 shows the characteristics of the study population. Measurements were performed approximately 1 and 14 years postpartum. Groups did not differ with respect to age, BMI and smoking. Hypertension was present in $3(15 \%)$ and 7 (35\%) women with a history of preeclampsia at 1 and 14 years postpartum, respectively. All women with hypertension were using antihypertensive drugs. The index pregnancy was complicated by early preeclampsia in $65 \%$, by fetal demise in $25 \%$ and/or by small for gestational age in $25 \%$ of women with a history of preeclampsia. In almost half of the women with a history of preeclampsia (8 out of 17 ) the subsequent pregnancy was complicated by either gestational hypertension or preeclampsia. During the period of follow-up, one formerly preeclamptic woman 


\begin{tabular}{|c|c|c|c|}
\hline & & $\begin{array}{l}\text { Preeclampsia } \\
(\mathrm{n}=20)\end{array}$ & $\begin{array}{l}\text { Controls } \\
(\mathrm{n}=8)\end{array}$ \\
\hline $\begin{array}{l}\text { Follow-up time } \\
\text { (years) }\end{array}$ & $\begin{array}{l}1 \text { year postpartum } \\
14 \text { years postpartum }\end{array}$ & $\begin{array}{l}1.2 \pm 0.8 \\
13.7 \pm 1.0\end{array}$ & $\begin{array}{l}1.8 \pm 0.9 \\
14.3 \pm 1.0\end{array}$ \\
\hline Age (years) & $\begin{array}{l}1 \text { year postpartum } \\
14 \text { years postpartum }\end{array}$ & $\begin{array}{l}31.2 \pm 2.6 \\
43.6 \pm 2.8\end{array}$ & $\begin{array}{l}32.7 \pm 1.7 \\
45.3 \pm 1.8\end{array}$ \\
\hline BMI $\left(\mathrm{kg} / \mathrm{m}^{2}\right)$ & $\begin{array}{l}1 \text { year postpartum } \\
14 \text { years postpartum }\end{array}$ & $\begin{array}{l}23.1 \pm 4.1 \\
25.6 \pm 4.6\end{array}$ & $\begin{array}{l}21.7 \pm 3.0 \\
23.3 \pm 3.7\end{array}$ \\
\hline Smoking, n(\%) & $\begin{array}{l}1 \text { year postpartum } \\
14 \text { years postpartum }\end{array}$ & $\begin{array}{l}2(10) \\
1(5)\end{array}$ & $\begin{array}{l}1(13) \\
3(38)\end{array}$ \\
\hline $\begin{array}{l}\text { Hypertension, } \\
\mathrm{n}(\%)\end{array}$ & $\begin{array}{l}1 \text { year postpartum } \\
14 \text { years postpartum }\end{array}$ & $\begin{array}{l}3(15) \\
7(35) \\
\end{array}$ & $\begin{array}{l}0(0) \\
1(13)\end{array}$ \\
\hline Parity & $\begin{array}{l}1 \text { year postpartum } \\
14 \text { years postpartum }\end{array}$ & $\begin{array}{l}1.0(1-2) \\
2.0(1-4)\end{array}$ & $\begin{array}{l}1.5(1-2) \\
2.5(2-4)\end{array}$ \\
\hline \multirow[t]{5}{*}{ Index pregnancy } & GA delivery (weeks) & $314 / 7(27-36)^{\star}$ & $395 / 7(38-42)$ \\
\hline & Birth weight (g) & $1600(850-2630)^{*}$ & $3360(2800-3645)$ \\
\hline & SGA <p5, n(\%) & $5(25)$ & $0(0)$ \\
\hline & Early preeclampsia, n(\%) & $13(65)$ & $\mathrm{n} / \mathrm{a}$ \\
\hline & Fetal demise, $\mathrm{n}(\%)$ & $5(25)$ & $0(0)$ \\
\hline $\begin{array}{l}\text { Subsequent } \\
\text { pregnancy }\end{array}$ & $\begin{array}{l}\text { None } \\
\text { Uncomplicated } \\
\text { Gestational hypertension } \\
\text { Preeclampsia }\end{array}$ & $\begin{array}{l}3 \\
9 \\
4 \\
4\end{array}$ & $\begin{array}{l}1 \\
7 \\
0 \\
0\end{array}$ \\
\hline
\end{tabular}

Data presented are mean \pm standard deviation or median (min-max), unless stated otherwise. BMI: body mass index, GA: gestational age, SGA: small for gestational age, n/a: not applicable.

${ }^{*} p<0.05$ compared with controls

had had an ischemic cardiac event and another a deep venous thrombosis. None of the women developed diabetes mellitus during this period. All women were premenopausal at the time of the second measurement session.

Table 2 lists the renal function in both groups comparing the measurements 1 and 14 years postpartum. We observed a comparable increase over time in mean arterial pressure. One year postpartum, the glomerular filtration rate in women with a history of preeclampsia was about $10 \%$ lower than in controls, a difference that had disappeared 14 years postpartum. The glomerular filtration rate decreased over time in both groups to a similar extent. The ERPF did not change over time, but tended to be consistently lower in women with a history of preeclampsia both 1 and 14 years postpartum $(\mathrm{p}=0.09$ and $p=0.07$, respectively). The RVR increased over time in women with a history of preeclampsia but not in controls; however,

\begin{tabular}{|c|c|c|c|c|}
\hline & & $\begin{array}{l}\text { Preeclampsia } \\
(n=20)\end{array}$ & $\begin{array}{l}\text { Controls } \\
(\mathrm{n}=8)\end{array}$ & p-value \\
\hline $\begin{array}{l}\text { MAP } \\
(\mathrm{mmHg})\end{array}$ & $\begin{array}{l}1 \text { year postpartum } \\
14 \text { years postpartum } \\
\Delta\end{array}$ & $\begin{array}{l}83 \pm 10 \\
94 \pm 15 \\
11(7,15)^{*}\end{array}$ & $\begin{array}{l}83 \pm 8 \\
91 \pm 12 \\
8(1,14)^{*}\end{array}$ & $\begin{array}{l}0.98 \\
0.56 \\
0.38\end{array}$ \\
\hline $\begin{array}{l}\text { Serum creatinine } \\
(\mu \mathrm{mol} / \mathrm{l})\end{array}$ & $\begin{array}{l}1 \text { year postpartum } \\
14 \text { years postpartum } \\
\Delta\end{array}$ & $\begin{array}{l}70 \pm 9 \\
77 \pm 9 \\
7(4,10)^{\star}\end{array}$ & $\begin{array}{l}64 \pm 6 \\
74 \pm 13 \\
10(3,18)^{\star}\end{array}$ & $\begin{array}{l}0.07 \\
0.45 \\
0.33\end{array}$ \\
\hline $\begin{array}{l}\text { Creatinine clearance } \\
\left(\mathrm{ml} / \mathrm{min} / 1.73 \mathrm{~m}^{2}\right)\end{array}$ & $\begin{array}{l}1 \text { year postpartum } \\
14 \text { years postpartum } \\
\Delta\end{array}$ & $\begin{array}{l}101 \pm 20 \\
99 \pm 19 \\
-2(-13,9)\end{array}$ & $\begin{array}{l}124 \pm 18 \\
104 \pm 29 \\
-20(-44,4)\end{array}$ & $\begin{array}{l}<0.05 \\
0.61 \\
0.09\end{array}$ \\
\hline $\begin{array}{l}\text { GFR } \\
\left(\mathrm{ml} / \mathrm{min} / 1.73 \mathrm{~m}^{2}\right)\end{array}$ & $\begin{array}{l}1 \text { year postpartum } \\
14 \text { years postpartum } \\
\Delta\end{array}$ & $\begin{array}{l}112 \pm 10 \\
104 \pm 10 \\
-8(-14,-2)^{*}\end{array}$ & $\begin{array}{l}125 \pm 8 \\
109 \pm 13 \\
-16(-27,-6)^{*}\end{array}$ & $\begin{array}{l}<0.01 \\
0.37 \\
0.11\end{array}$ \\
\hline $\begin{array}{l}\text { ERPF } \\
\left(\mathrm{ml} / \mathrm{min} / 1.73 \mathrm{~m}^{2}\right)\end{array}$ & $\begin{array}{l}1 \text { year postpartum } \\
14 \text { years postpartum } \\
\Delta\end{array}$ & $\begin{array}{l}477 \pm 90 \\
473 \pm 85 \\
-4(-34,26)\end{array}$ & $\begin{array}{l}543 \pm 92 \\
543 \pm 98 \\
0(-34,33)\end{array}$ & $\begin{array}{l}0.09 \\
0.07 \\
0.86\end{array}$ \\
\hline $\begin{array}{l}\text { RVR } \\
\left(.100 \text { dyne } \cdot \mathrm{s} / \mathrm{cm} 5 / 1.73 \mathrm{~m}^{2}\right)\end{array}$ & $\begin{array}{l}1 \text { year postpartum } \\
14 \text { years postpartum } \\
\Delta\end{array}$ & $\begin{array}{l}91.7 \pm 25.2 \\
99.2 \pm 26.5 \\
7.6(0.6,14.5)^{*}\end{array}$ & $\begin{array}{l}79.5 \pm 15.9 \\
84.0 \pm 18.4 \\
4.5(-7.5,16.5)\end{array}$ & $\begin{array}{l}0.22 \\
0.15 \\
0.63\end{array}$ \\
\hline $\begin{array}{l}\text { FF } \\
(\%)\end{array}$ & $\begin{array}{l}1 \text { year postpartum } \\
14 \text { years postpartum } \\
\Delta\end{array}$ & $\begin{array}{l}24.2 \pm 4.1 \\
22.6 \pm 3.5 \\
-1.6(-3.1,-0.2)^{*}\end{array}$ & $\begin{array}{l}24.1 \pm 2.2 \\
20.4 \pm 2.8 \\
-3.8(-5.9,-1.5)^{*}\end{array}$ & $\begin{array}{l}0.99 \\
0.13 \\
0.10\end{array}$ \\
\hline $\begin{array}{l}\text { Microalbuminuria } \\
\mathrm{n}(\%)\end{array}$ & $\begin{array}{l}1 \text { year postpartum } \\
14 \text { years postpartum }\end{array}$ & $\begin{array}{l}4(20) \\
2(10)\end{array}$ & $\begin{array}{l}- \\
- \\
-\end{array}$ & \\
\hline \multicolumn{5}{|c|}{$\begin{array}{l}\text { Data presented are mean } \pm \text { standard deviation or mean ( } 95 \% \text { confidence interval), } \\
\text { unless stated otherwise. MAP: mean arterial pressure, GFR: glomerular filtration } \\
\text { rate, ERPF: effective renal plasma flow, ERBF: effective renal blood flow, RVR: } \\
\text { renal vascular resistance, FF: filtration fraction. } \\
\triangle \text { Paired difference, }{ }^{*} p<0.05\end{array}$} \\
\hline
\end{tabular}

the magnitude of the rise did not differ statistically between both groups. Microalbuminuria persisted at 14 years postpartum in $2(10 \%)$ out of $4(20 \%)$ women with a history of preeclampsia.

Figure 1 presents a comparison with reference data from a healthy group of potential kidney donors, showing that women with a history of preeclampsia have a normal glomerular filtration rate, lower ERPF and higher filtration fraction at both time points when compared with females of similar age. 


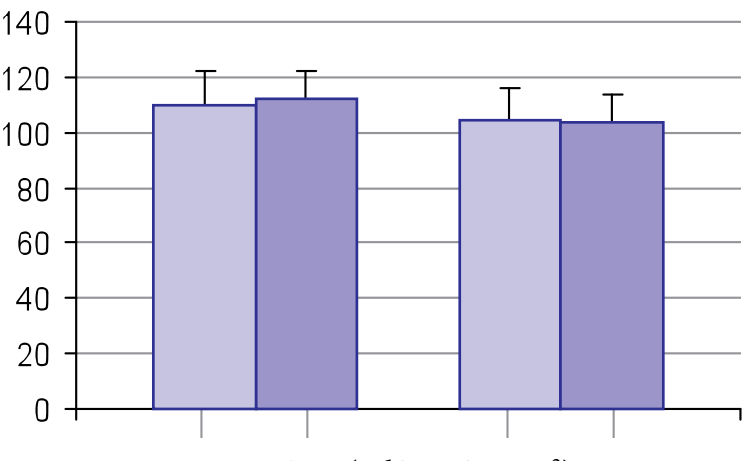

GFR $\left(\mathrm{ml} / \mathrm{min} / 1.73 \mathrm{~m}^{2}\right)$
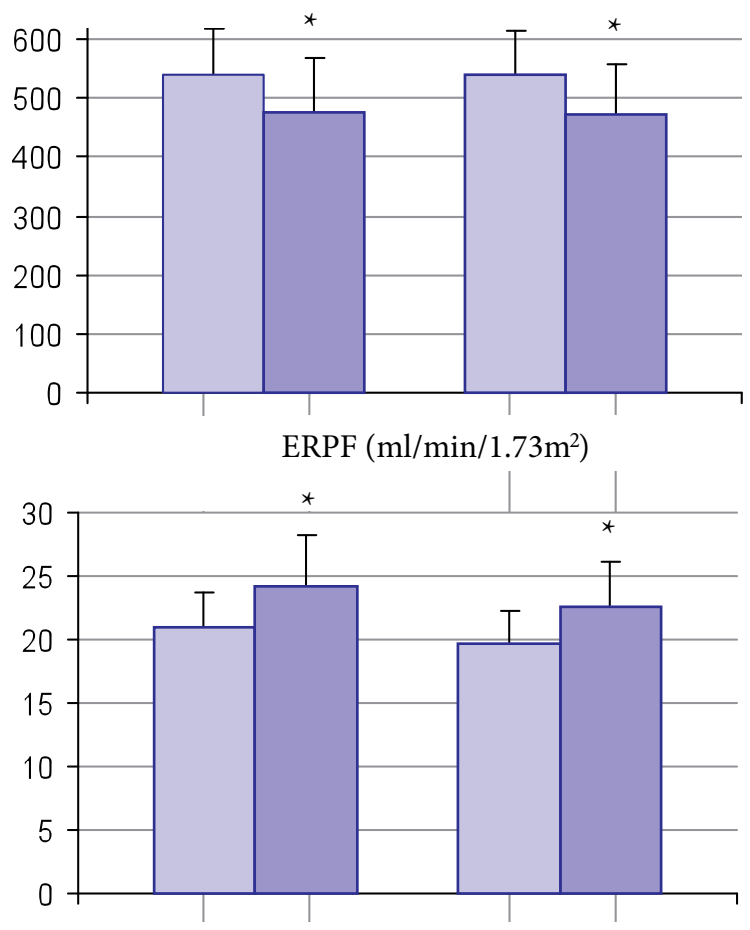

$\mathrm{FF}(\%)$

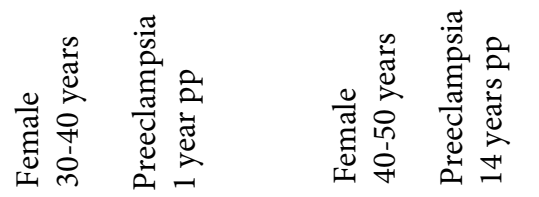

Figure 1: Comparison of renal function in women with a history of preeclampsia 1 and 14 years postpartum (black boxes) with reference data from a group of

potential female kidney donors of similar age (grey boxes).
Adapted from Berg et al ${ }^{18}$ reprinted with permission Nature Publishing Group.
In a multivariable sub analysis we studied the effect of follow-up time, group and hypertension on renal function. The presence of hypertension related to a higher MAP at 14 years postpartum (interaction $\mathrm{p}=0.02$ ) and a higher RVR and filtration fraction at both time points $(\mathrm{p}<0.01$ and $\mathrm{p}=0.02$, respectively) without a significant effect on ERPF $(\mathrm{p}=0.19), \operatorname{ERBF}(\mathrm{p}=0.11)$ or GFR $(\mathrm{p}=0.67)$.

\section{Discussion}

This explorative study gives some directions to the question whether women with a history of preeclampsia will have accelerated renal function loss in the years after their complicated pregnancy. Most importantly, this study showed that the lower renal function at 1 year postpartum did not persist or worsen in the first decade ahead. Instead, the glomerular filtration rate 14 years postpartum was comparable in women with a history of preeclampsia and parous controls. Microalbuminuria in women with a history of preeclampsia seemed to decrease, rather than to increase in this period. Although these data seem reassuring, we did observe a trend for a lower renal blood flow in women with a history of preeclampsia that persisted over the years. This observation was confirmed when our data were compared with a reference group of potential female kidney donors of similar age. $^{18}$

The strength of this study is the longitudinal design and the accuracy of the methods used to assess renal function in a group of women with mostly severe preeclampsia and without known pre-existing hypertension or kidney disease. The most important limitation of our study is the modest size of the control group precluding firm conclusions. It may be possible that we observed a relatively higher glomerular filtration rate in the controls 1 year postpartum, instead of a reduced rate in women with a history of preeclampsia. Actually, 14 years postpartum the observed values in the controls showed large similarities with an external reference group. Another limitation of this study is the presence of hypertension as a confounding factor, which did influence blood pressure, renal vascular resistance and filtration fraction.

The renovascular profile observed in women with a history of preeclampsia (figure 1) of a lower renal blood flow in combination with a higher filtration fraction suggests renal hyperfiltration. This compensatory mechanism in the kidneys is a well described phenomenon 
in early kidney disease, in which hyperfiltration of the remaining nephrons is present. ${ }^{19-21}$ Our observations show similarities with the renovascular profile observed in chronic hypertension of an in-

creased renal vascular resistance, normal glomerular filtration rate, reduced renal blood flow and increased filtration fraction. ${ }^{22,23}$ This altered renovascular profile may already be present before hypertension becomes clinically evident. ${ }^{22}$ Whether this profile observed after preeclampsia is present independent of hypertension requires further investigation. Later in life, due to ageing or after the menopause, it is possible that a decline in glomerular filtration rate may become evident, as suggested by previous observations in women with a history of preeclampsia 23 years postpartum. ${ }^{12}$

In conclusion, large epidemiological studies have shown that women with a history of preeclampsia have an increased risk of developing end-stage renal disease. ${ }^{3}$ Although our study does not support accelerated renal function loss in the first decade after preeclampsia, our data did suggest a possible role for renal hyperfiltration. Larger studies are necessary to confirm this. Moreover, functional tests to determine the renal reserve capacity by for example a protein load may increase our insight in the renovascular function of women with a history of preeclampsia.

\section{References}

1. Sattar N, Greer IA. Pregnancy complications and maternal cardiovascular risk: opportunities for intervention and screening? Bmj. 2002;325:157-60.

2. Bellamy L, Casas JP, Hingorani AD, Williams DJ. Pre-eclampsia and risk of cardiovascular disease and cancer in later life: systematic review and meta-analysis. Bmj. 2007;335:974.

3. Vikse BE, Irgens LM, Leivestad T, Skjaerven R, Iversen BM. Preeclampsia and the risk of end-stage renal disease. N Engl J Med. 2008:359:800-9.

4. Romundstad S, Holmen J, Hallan H, Kvenild K, Ellekjaer H. Microalbuminuria and all-cause mortality in treated hypertensive individuals: does sex matter? The Nord-Trondelag Health Study (HUNT), Norway. Circulation. 2003;108:2783-9.

5. Hillege HL, Fidler V, Diercks GF, et al. Urinary albumin excretion predicts cardiovascular and noncardiovascular mortality in general population. Circulation. 2002;106:1777-82.

6. McDonald SD, Han Z, Walsh MW, Gerstein HC, Devereaux PJ. Kidney disease after preeclampsia: a systematic review and meta-analysis. Am J Kidney Dis. 2010;55:1026-39.

7. de Boer IH, Rue TC, Cleary PA, et al. Long-term renal outcomes of patients with type 1 diabetes mellitus and microalbuminuria: an analysis of the Diabetes Control and Complications Trial/Epidemiology of Diabetes Interventions and Complications cohort. Arch Intern Med. 2011;171:412-20.

8. Bar J, Kaplan B, Wittenberg C, et al. Microalbuminuria after pregnancy complicated by pre-eclampsia. Nephrol Dial Transplant. 1999;14:1129-32

9. Lampinen KH, Ronnback M, Groop PH, Kaaja RJ. Renal and vascular function in women with previous preeclampsia: a comparison of low- and high-degree proteinuria. Kidney Int. 2006;70:1818-22.

10. Mangos GJ, Spaan JJ, Pirabhahar S, Brown MA. Markers of cardiovascular disease risk after hypertension in pregnancy. J Hypertens. 2012;30:351-8.

1. Nisell H, Lintu H, Lunell NO, Mollerstrom G, Pettersson E. Blood pressure and renal function seven years after pregnancy complicated by hypertension. Br J Obstet Gynaecol. 1995;102:876-81.

12. Spaan JJ, Ekhart T, Spaanderman ME, Peeters LL. Remote Hemodynamics and Renal Function in Formerly Preeclamptic Women. Obstet Gynecol. 2009;113:853-9.

13. Spaanderman ME, Van Beek E, Ekhart TH, et al. Changes in hemodynamic parameters and volume homeostasis with the menstrual cycle among women with a history of preeclampsia. Am J Obstet Gynecol. 2000;182:1127-34.

14. Perry IJ, Beevers DG. The definition of pre-eclampsia. Br J Obstet Gynaecol. 1994;101:587-91.

15. The Netherlands Perinatal Registry. PRN-foundation. (Accessed at www.perinatreg.nl.)

16. Cole BR, Giangiacomo J, Ingelfinger JR, Robson AM. Measurement of renal function without urine colection. A critical evaluation of the constant-infusion technic for determination of inulin and para-aminohippurate. N Engl J Med. 1972;287:1109-14

17. Laatikainen T, Pietinen P, Valsta L, Sundvall J, Reinivuo H, Tuomilehto J. Sodium in the Finnish diet: 20year trends in urinary sodium excretion among the adult population. Eur J Clin Nutr. 2006;60:965-70.

18. Berg UB. Differences in decline in GFR with age between males and females. Reference data on clearances of inulin and PAH in potential kidney donors. Nephrol Dial Transplant. 2006;21:2577-82.

19. Meijer E, Rook M, Tent H, et al. Early renal abnormalities in autosomal dominant polycystic kidney disease. Clin I Am Soc Nephrol. 2010:5:1091-8.

2. Livi R, Guiducci S, Perfetto F, et al. Lack of activation of renal functional reserve predicts the risk of significant renal involvement in systemic sclerosis. Ann Rheum Dis. 2011;70:1963-7. 


\section{PART III}

22. Ruilope LM, Lahera V, Rodicio JL, Carlos Romero J. Are renal hemodynamics a key factor in the development and maintenance of arterial hypertension in humans? Hypertension. 1994;23:3-9.

23. Gabbai FB. Renal reserve in patients with high blood pressure. Semin Nephrol. 1995;15:482-7.

\section{Cardiovascular risk management}




\section{Chapter 7}

\section{Cardiovascular risk management following a hypertensive disorder of pregnancy: a review}

Julia Spaan, Louis Peeters, Marc Spaanderman, Mark Brown Accepted Hypertension

\section{Abstract}

Women with a history of a hypertensive disorder of pregnancy have an increased risk of later cardiovascular disease. Although this offers opportunities for primary prevention of cardiovascular disease in young women, there appears to be no guidelines or consensus on how to screen or treat these women. This review identifies current barriers and opportunities for cardiovascular risk management following a hypertensive disorder of pregnancy, and suggests a practical approach for risk management. 


\section{Introduction}

Awareness of cardiovascular disease in women is increasing and currently a main topic of the Heart Associations and Foundations worldwide. Although several guidelines underscore gender differences in clinical presentation, treatment and prognosis, almost no attention is given to a unique risk marker in women: the obstetric history. Large epidemiological studies have confirmed the association between a hypertensive disorder of pregnancy and the risk of future cardiovascular disease. Despite this, physician's awareness of a hypertensive disorder of pregnancy as a risk factor for cardiovascular disease is limited. There appears to be no structured follow-up of women after a hypertensive disorder of pregnancy and guidelines on cardiovascular risk management following a hypertensive disorder of pregnancy are lacking. It is time to incorporate this easily identifiable risk marker into cardiovascular risk management in women.

The purpose of this review is to identify current barriers and opportunities for cardiovascular risk management following a hypertensive disorder of pregnancy, and to suggest a practical approach for risk management.

Why does current risk prediction fail in young women? More women die of cardiovascular disease than of any other cause. ${ }^{1}$ During the last decade the focus of primary prevention has widened from individuals with the highest risk and largest short-term benefit (usually older people with previous cardiovascular events) to include individuals at an earlier stage of disease to prevent target organ damage. Young women have a low absolute risk of cardiovascular disease and premenopausal women are in general protected. Few women below 65 years of age will be considered high risk with traditional risk prediction models for cardiovascular disease, such as the Framingham risk score, SCORE and QRISK. ${ }^{2-4}$ Still, women have a lifetime risk of cardiovascular disease of $30-40 \%$ at 50 years of age. ${ }^{5,6}$ Using a 30 -year prediction model, women with multiple risk factors (unfavourable lipids, hypertension and smoking) had a $12 \%$ predicted risk of cardiovascular disease at 25 years of age, increasing to $42 \%$ at 45 years of age. 7 The obstetric history offers a unique risk marker to identify young women at risk for future cardiovascular disease.

What is the risk of cardiovascular disease after a hypertensive disorder of pregnancy?

Preeclampsia occurs in 3-5\% of all pregnancies; ${ }^{8}$ a figure comparable to the prevalence of diabetes mellitus at reproductive age, a well accepted risk marker for cardiovascular disease. ${ }^{9}$ The prevalence of any hypertensive disorder of pregnancy is up to 5-10\% of all pregnancies and rising with the epidemic of obesity. ${ }^{8}$ Women with a history of preeclampsia have a doubled risk of stroke, cardiac ischemia or venous thrombosis within 10-20 years after pregnancy. ${ }^{10,11}$ Moreover, they have a four-fold higher risk of chronic hypertension and a three-fold higher risk of type 2 diabetes mellitus. ${ }^{10,12}$ These comorbidities are observed at a relatively young age in mostly premenopausal women. Comparable risk estimates are found in women with a history of gestational hypertension only. ${ }^{13-16}$ The risk of cardiovascular disease is further increased in combination with other risk factors of the obstetric history, such as preterm birth or fetal growth restriction. For example, preterm birth and preeclampsia is associated with an 8-10 fold higher cardiovascular mortality, instead of a 2 fold higher cardiovascular mortality after term preeclampsia compared with term normotensive pregnancies. ${ }^{17-19}$

Which cardiovascular risk factors are present postpartum? Risk factors that have been observed postpartum in women who had a hypertensive disorder of pregnancy show large overlap with traditional risk factors for cardiovascular disease. Consistent findings after a hypertensive disorder of pregnancy are the presence of an elevated blood pressure, body mass index and insulin resistance. ${ }^{20-26}$ An unfavourable lipid profile is frequently observed postpartum; low HDLcholesterol $(\leq 1.29 \mathrm{mmol} / \mathrm{l})$ is present in approximately $40 \%$ and high triglycerides $(\geq 1.7 \mathrm{mmol} / \mathrm{l})$ in approximately $20 \%$ of all women with a history of early-onset preeclampsia. ${ }^{27,28}$ Although lipid abnormalities are frequently present; $;^{20,29}$ several studies did not find appreciable differences compared with women with previous normotensive pregnancies. ${ }^{21,22,24,31,32}$ A wide range of other cardiovascular risk markers have been identified in case-control studies, such as raised circulating CRP, TNF- $\alpha, V C A M / I C A M$, adiponectin, attenuated flow-mediated dilatation and increased intima-media thickness. ${ }^{20,21,33,34}$

A significant consideration is that several measures in women with a history of a hypertensive disorder of pregnancy may still fall within a so-called 'normal' range. Blood pressure abnormalities may not be detectable by routine blood pressure checks but only by use of 24-hour ambulatory blood pressure measurement; even then these blood pressure average levels will still appear to be 'normal' though 
they are higher than in women who had had normal pregnancy. ${ }^{25}$ The same holds true for other cardiovascular risk markers. The key message is that we need to define what is normal for blood pressure, lipids and insulin resistance measures in young women at reproductive age.

What is the current clinical practice?

The obstetric clinic is often the first clinic where a woman's blood pressure is measured. ${ }^{35}$ For many years, preeclampsia was considered a syndrome of pregnancy that completely resolves after pregnancy and women are generally referred back to their general practitioner. Nowadays, the risk of cardiovascular disease may be communicated to the women at discharge shortly after delivery or at a 6 weeks postpartum evaluation at the obstetric outpatient clinic. After that, if cardiovascular risk counselling is given later in life, the history of a hypertensive disorder of pregnancy is often not taken into account. Most guidelines and textbooks on prevention of cardiovascular disease in women do not mention the obstetric history as a risk factor. In a hospital survey, only $5 \%$ of all internists asked about preeclampsia when taking the medical history of a woman. ${ }^{36}$ The development of chronic hypertension after preeclampsia is frequently not adequately monitored; 21 years after preeclampsia about one third of the women was hypertensive, but this was only diagnosed in half of them. ${ }^{37}$

\section{Table 1: Unanswered questions}

Further research should answer whether a hypertensive disorder of pregnancy is an independent risk factor for cardiovascular disease.

There are no tools available to make an individualised risk estimate of cardiovascular disease that includes the obstetric history.

We do not know the optimal timing and frequency to test for traditional cardiovascular risk markers after a hypertensive disorder of pregnancy.

It is unclear whether to use traditional cut-off levels for blood pressure, glucose and lipids to define abnormalities or if normal ranges for young women with previous normal pregnancies should be developed.

The role of screening for additional cardiovascular risk markers or target organ damage to predict future cardiovascular disease should be clarified in this specific group of women.

At present there are no randomised controlled trials in young people unequivocally demonstrating the benefit of antihypertensive or lipid lowering medication on cardiovascular disease risk.

Upcoming trials should prove the efficacy of lifestyle interventions in the reproductive age on the next pregnancy outcome and long-term cardiovascular health.
Recently, the latest guideline of the American Heart Association for the prevention of cardiovascular disease in women has included a hypertensive disorder of pregnancy as a major risk factor for cardiovascular disease. ${ }^{1}$ They recommend postpartum referral by the obstetrician to a primary care physician or cardiologist, so that in the years after pregnancy risk factors can be carefully monitored and controlled without further specification. Up until now, it has been clinic- or even clinician-dependent whether and how cardiovascular risk assessment is performed after a hypertensive disorder of pregnancy. A few clinics have started with postpartum cardiovascular risk counselling in a structured manner about 3-6 months postpartum, usually in a multidisciplinary setting involving obstetricians, internal medicine specialists and cardiologists. ${ }^{38}$

What are barriers to include the obstetric history in cardiovascular risk counselling for women?

Currently, it is unclear whether a hypertensive disorder of pregnancy is an independent risk factor for cardiovascular disease or whether this is all explained by traditional cardiovascular risk factors. Tools are lacking to give an individualised risk estimate of cardiovascular disease after a hypertensive disorder of pregnancy. A possible strategy is to overcome the latter is to use a classical risk prediction model, but to calculate the risk as if the woman was 60 years of age; ${ }^{39}$ or to use a 30 -year or lifetime risk prediction model. ${ }^{6,7}$ However, this does not take the obstetric history into account. Most guidelines will use classical risk score models to identify high-risk women that need an intervention or treatment. We do not know whether criteria for treatment should be more strict for these women, as for those with diabetes. Despite these uncertainties (table 1), the least we can do is to offer cardiovascular risk management based on existing guidelines about cardiovascular risk counselling in asymptomatic people in the postpartum period.

What opportunities does a structured postpartum cardiovascular screening program has to offer?

A structured cardiovascular screening program, as proposed in table 2, ensures adequate follow-up after a hypertensive disorder of pregnancy. It creates a moment to explain and discuss in detail the increased risk of cardiovascular disease. Such a screening will identify 


\begin{tabular}{|c|c|c|c|}
\hline Time & Specialty & Measurements & Care \\
\hline $\begin{array}{l}6 \text { weeks } \\
\text { postpartum }\end{array}$ & Obstetrician & Blood pressure & $\begin{array}{l}\text { - Counselling about cardiovas- } \\
\text { cular risk. } \\
\text { - Referral for screening 3-6 } \\
\text { months postpartum. }\end{array}$ \\
\hline \multirow[t]{3}{*}{$\begin{array}{l}3-6 \text { months } \\
\text { postpartum }\end{array}$} & $\begin{array}{l}\text { Multidisci- } \\
\text { plinary team } \\
\text { preferred }\end{array}$ & $\begin{array}{l}\text { 1. Blood pressure, } \\
\text { preferably includ- } \\
\text { ing } 24 \text {-hr ABPM } \\
\text { or automated } \\
\text { home blood } \\
\text { pressure } \\
\text { 2. Screening for } \\
\text { metabolic abnor- } \\
\text { malities; body } \\
\text { mass index, fast- } \\
\text { ing glucose, lipid } \\
\text { profile } \\
\text { 3. Dipstick for } \\
\text { albuminuria and } \\
\text { proteinuria }\end{array}$ & $\begin{array}{l}\text { - Estimate cardiovascular risk } \\
\text { based on obstetric history } \\
\text { (gestational hypertension, ges- } \\
\text { tational diabetes, preeclamp- } \\
\text { sia, preterm birth, fetal growth } \\
\text { restriction) and concomitant } \\
\text { risk factors (smoking, family } \\
\text { history, hypertension, meta- } \\
\text { bolic abnormalities). } \\
\text { - Individualised lifestyle advices } \\
\text { for all women; family-centred; } \\
\text { consider local lifestyle inter- } \\
\text { vention programs. } \\
\text { - Individualised advice about } \\
\text { next pregnancy; possible } \\
\text { benefit of a healthy lifestyle on } \\
\text { recurrence risk. } \\
\text { - Pharmacological treatment of } \\
\text { high blood pressure is indi- } \\
\text { cated; treatment of lipid ab- } \\
\text { normalities can be considered. }\end{array}$ \\
\hline & $\begin{array}{l}\text { Referral to } \\
\text { specialist }\end{array}$ & $\begin{array}{l}\text { 1. In case of signs } \\
\text { suggestive of } \\
\text { secondary } \\
\text { hypertension }\end{array}$ & $\begin{array}{l}\text { - Screening for underlying } \\
\text { secondary hypertension. }\end{array}$ \\
\hline & & $\begin{array}{l}\text { 2. In case of persis- } \\
\text { tent albuminuria }\end{array}$ & $\begin{array}{l}\text { - Screening for underlying renal } \\
\text { disease. }\end{array}$ \\
\hline $\begin{array}{l}\text { Ongoing } \\
\text { care }\end{array}$ & $\begin{array}{l}\text { General } \\
\text { practitioner }\end{array}$ & $\begin{array}{l}\text { 1. Yearly weight and } \\
\text { blood pressure } \\
\text { 2. Every other year } \\
\text { glucose and } \\
\text { cholesterol }\end{array}$ & $\begin{array}{l}\text { - Lifestyle counselling. } \\
\text { - Weight management. } \\
\text { a Detection of the development } \\
\text { of chronic hypertension, type } 2 \\
\text { diabetes or dyslipidemias. }\end{array}$ \\
\hline
\end{tabular}

women with comorbidities such as hypertension, obesity, type 2 diabetes and hyperlipidaemias. Moreover, it allows adequate referral of women with signs suggestive of underlying disease, such as persistent proteinuria or secondary hypertension. Most importantly, it gives the opportunity for primary prevention of cardiovascular disease by promoting a healthy lifestyle and offering tailored lifestyle interventions.
Table 3: Motivational factors for a healthy lifestyle after a hypertensive disorder of pregnancy

The hypertensive disorder of pregnancy is a wake-up call.

A healthy lifestyle reduces the risk of future cardiovascular disease.

A next pregnancy is likely to benefit from a healthy lifestyle as it may reduce the recurrence of a hypertensive disorder of pregnancy.

All family members are likely to benefit from a healthy lifestyle, which is particularly important for an infant born premature or small for gestational age.

Motivational factors for a healthy lifestyle

Several factors unique to this specific group of women are present to motivate them to adopt a healthy lifestyle (table 3). Group interviews revealed that women are more aware of the importance of health after a complicated pregnancy and are motivated to adjust their lifestyle. ${ }^{40}$ A healthy lifestyle is not only beneficial for their own future health,

but may also improve the outcome of future pregnancies and the lifestyle of her partner and children. This is especially relevant as women with a hypertensive disorder of pregnancy give often birth to small for gestational age babies, who themselves have a higher risk of later cardiovascular disease. ${ }^{41,42}$

Women gain on average $2 \mathrm{~kg}$ of weight after each pregnancy and this is even more after a hypertensive disorder of pregnancy. ${ }^{43,44}$ Interpregnancy weight gain is associated with a doubled risk of gestational hypertension, gestational diabetes or preeclampsia during the next pregnancy. ${ }^{45}$ Therefore, the postpartum period should be an important target for weight management and lifestyle counselling.

What is the benefit of a healthy lifestyle?

Lifestyle interventions during reproductive age have potentially a large effect on future cardiovascular health. The benefit of a healthy lifestyle is evident from large epidemiological studies such as the INTERHEART study. ${ }^{46}$ The adverse effect of hypertension, smoking and diabetes on cardiovascular disease was larger in women and young people than in men and elderly people. ${ }^{46-48}$ In a cohort of young women, a favourable cardiovascular risk profile (low blood pressure, low cholesterol, non-smoking and non-diabetic) was associated with $80 \%$ lower cardiovascular mortality than in women with more than two of these risk factors. ${ }^{49}$ The lifetime risk of cardiovascular disease at 50 years of age in women with optimal risk factors was only $8 \%$, in contrast to a $50 \%$ risk in women with more than 2 risk factors based on long-term follow-up of the Framingham cohort. ${ }^{5}$ 
What is the effectiveness of postpartum lifestyle interventions? Several lifestyle intervention trials specifically designed for women with a history of a hypertensive disorder of pregnancy are currently listed in clinical trial registries. Some preliminary reports indicate that women after preeclampsia are willing to participate in such an intervention program and will have improved weight, lipid profile and vascular function after three months. ${ }^{50,51}$ However, in general the effectiveness of lifestyle interventions is often disappointing. Even in structured programs with frequent contact moments for support, the effect on for example weight loss is usually modest and difficult to pursue on the long term. Lifestyle interventions in the postpartum period failed to show a positive effect in about one third of the trials reported in a meta-analysis. ${ }^{52}$ On the other hand, other lifestyle interventions have proven to be effective, especially for clinical outcome variables such as blood pressure, glucose or lipid control. ${ }^{53,54}$ Such outcomes can be used as motivational tools to convince and motivate women to adhere to their new lifestyle. The potential effect of lifestyle change on the next pregnancy is evident from a study in obese women that had bariatric surgery as intervention, showing impressive reductions in the recurrence of hypertensive disorders in pregnancy. ${ }^{55}$ Upcoming research should prove the (cost)effectiveness of postpartum lifestyle interventions in women with a history of a hypertensive disorder of pregnancy on the outcome of a subsequent pregnancy and long-term cardiovascular health. ${ }^{52}$

What are indications for pharmacological treatment?

Blood pressure lowering treatment

One in four women will develop chronic hypertension after a hypertensive disorder of pregnancy. ${ }^{10}$ Still, there is no consensus about the management of hypertension in the immediate postpartum period and as a consequence when to discontinue or pursue the adopted management. ${ }^{56,57}$ Long-term blood pressure lowering aims to reduce the risk of cardiovascular disease, but this effect has not been unequivocally proven in young people. In the general population, systolic blood pressure lowering of $10 \mathrm{mmHg}$ reduces the risk of stroke by $40 \%$ and of coronary heart disease by $20 \%$ in both primary and secondary prevention. ${ }^{58}$ The European Society of Hypertension and the Joint National Committee (JNC7) recommend the treatment of a blood pressure $\geq 140 / 90 \mathrm{mmHg}$ in adolescents. ${ }^{59,60}$ In line with this, following a hypertensive disorder of pregnancy blood pressure lowering treatment is recommended above this threshold. The pos- sible benefit of treatment of a high normal blood pressure should first be evaluated in clinical research. ${ }^{61}$

Lipid lowering treatment

According to the Third Adult Treatment Panel, pharmacologi-

cal treatment is indicated in all women when LDL $>4.9 \mathrm{mmol} / \mathrm{l}$, in women with 2 or more cardiovascular risk factors when LDL $>4.1$ $\mathrm{mmol} / \mathrm{l}$, lowering this threshold in women with a 10 -year cardiovascular disease risk $>10 \%$ to LDL $>3.4 \mathrm{mmol} / 1.62$ Accordingly, less than $5 \%$ of all women with a history of early-onset preeclampsia will fulfil the criteria for lipid lowering medication. ${ }^{28}$ Meanwhile, the American Heart Association recommends treatment of $\mathrm{LDL}>4.1 \mathrm{mmol} / \mathrm{l}$ already when only one major cardiovascular risk factor is present, including a hypertensive disorder of pregnancy. ${ }^{1}$ In the general population there remains debate about the efficacy of lipid lowering treatment for primary prevention of cardiovascular disease ${ }^{63,64}$ Hence, more research is necessary to decide on which cut-off level to use for treatment in this specific group of women. For now, lipid lowering treatment can be considered following a hypertensive disorder of pregnancy if one of the above criteria are fulfilled.

\section{Glucose control}

About one in seven women will develop type 2 diabetes in the years after a hypertensive disorder of pregnancy. ${ }^{65}$ Pharmacological treatment of overt type 2 diabetes is indicated. However, there is no consensus with respect to how prediabetes (impaired fasting glucose or glucose intolerance) is to be managed. A recent meta-analysis indicates that lifestyle interventions seem more effective than pharmacological interventions in preventing diabetes. ${ }^{66}$

What about aspirin for stroke prevention?

The Women's Health Study provided evidence for the efficacy of aspirin in the primary prevention of stroke in women, though the largest benefit was for women $>65$ years of age. ${ }^{67}$ Possible benefits of aspirin use should be carefully balanced against the increased risk of gastro-intestinal bleeding. Future research should explore the possible benefit of aspirin for primary prevention in this specific group of women. 
Table 4: Summary points

There appears to be no structured follow-up of women following a hypertensive

disorder of pregnancy and guidelines on cardiovascular risk management following a hypertensive disorder of pregnancy are lacking.

Currently used 10 year-risk prediction models for cardiovascular disease are likely to underestimate the risk of cardiovascular disease in this group of young women. Any physician performing cardiovascular risk counselling in women should be aware of the importance of obstetric risk factors for later cardiovascular health. A postpartum cardiovascular risk screening should be based on guidelines for cardiovascular risk assessment in asymptomatic people.

Lifestyle interventions in the reproductive age may reduce prolonged exposure to cardiovascular risk factors, may positively influence a next pregnancy and contribute to a healthy lifestyle for her partner and children.

In summary, we recommend a postpartum cardiovascular risk assessment for all women with a hypertensive disorder of pregnancy in order to give these women the best possible long-term outcomes. We do realize that more research is needed to give definitive answers about the timing of screening, the markers to be tested and the costeffectiveness of such a program. Moreover, the development and implementation of effective lifestyle intervention programs in the postpartum period is crucial. For now, cardiovascular risk management following a hypertensive disorder of pregnancy should be based on guidelines for cardiovascular risk assessment in asymptomatic people. Key points of this review are presented in table 4. We hope that this review encourages obstetric units to develop a clearly defined local protocol concerning postpartum cardiovascular screening in conjunction with local general practices.

\section{References}

. Mosca L, Benjamin EJ, Berra K, et al. Effectiveness-based guidelines for the prevention of cardiovascula disease in women--2011 update: A guideline from the american heart association. Circulation. 2011;123:1243-62

2. Anderson KM, Odell PM, Wilson PW, Kannel WB. Cardiovascular disease risk profiles. Am Heart J. $1991 ; 121: 293-8$

3. Conroy RM, Pyorala K, Fitzgerald AP, et al. Estimation of ten-year risk of fatal cardiovascular disease in europe: The score project. Eur Heart J. 2003;24:987-1003.

4. Hippisley-Cox J, Coupland C, Vinogradova Y, et al. Derivation and validation of qrisk, a new cardiovascular disease risk score for the united kingdom: Prospective open cohort study. BMJ. 2007;335:136.

5. Lloyd-Jones DM, Leip EP, Larson MG, et al. Prediction of lifetime risk for cardiovascular disease by risk factor burden at 50 years of age. Circulation. 2006;113:791-8.

6. Hippisley-Cox J, Coupland C, Robson J, Brindle P. Derivation, validation, and evaluation of a new qrisk model to estimate lifetime risk of cardiovascular disease: Cohort study using qresearch database. BM). 2010;341:c6624.

7. Pencina MJ, D’Agostino RB, Sr., Larson MG, Massaro JM, Vasan RS. Predicting the 30-year risk of cardiovascular disease: The framingham heart study. Circulation. 2009;119:3078-84.

8. Hutcheon JA, Lisonkova S, Joseph KS. Epidemiology of pre-eclampsia and the other hypertensive disorders of pregnancy. Best Pract Res Clin Obstet Gynaecol. 2011:25:391-403.

9. Wild S, Roglic G, Green A, Sicree R, King H. Global prevalence of diabetes: Estimates for the year 2000 and projections for 2030. Diabetes Care. 2004:27:1047-53.

10. Bellamy L Casas JP Hingorani AD, Williams DJ. Pre-eclampsia and risk of cardiovascular disease and cancer in later life: Systematic review and meta-analysis. Bmj. 2007;335:974.

11. McDonald SD, Malinowski A, Zhou Q, Yusuf S, Devereaux PJ. Cardiovascular sequelae of preeclampsia

12. Lykke JA, Langhoff-Roos J, Sibai BM, et al. Hypertensive pregnancy disorders and subsequent cardiovascular morbidity and type 2 diabetes mellitus in the mother. Hypertension. 2009;53:944-51.

13. Wilson BJ, Watson MS, Prescott GJ, et al. Hypertensive diseases of pregnancy and risk of hypertension and stroke in later life: Results from cohort study. BMJ. 2003;326:845.

14. Kestenbaum B, Seliger SL, Easterling TR, et al. Cardiovascular and thromboembolic events following hypertensive pregnancy. Am J Kidney Dis. 2003;42:982-9.

5. Arnadottir GA, Geirsson RT, Arngrimsson R, Jonsdottir LS, Olafsson O. Cardiovascular death in women who had hypertension in pregnancy: A case-control study. Bjog. 2005;112:286-92.

16. Wikstrom AK, Haglund B, Olovsson M, Lindeberg SN. The risk of maternal ischaemic heart disease after gestational hypertensive disease. Bjog. 2005;112:1486-91

17. Irgens HU, Reisaeter L, Irgens LM, Lie RT. Long term mortality of mothers and fathers after pre-eclampsia: Population based cohort study. Bmi. 2001;323:1213-7.

18. Mongraw-Chaffin ML, Cirillo PM, Cohn BA. Preeclampsia and cardiovascular disease death: Prospective evidence from the child health and development studies cohort. Hypertension. 2010;56:166-71.

19. Smith GC, Pell JP, Walsh D. Pregnancy complications and maternal risk of ischaemic heart disease: A retrospective cohort study of 129,290 births. Lancet. 2001:357:2002-6.

. Girouard J, Giguere Y, Moutquin JM, Forest JC. Previous hypertensive disease of pregnancy is associated with alterations of markers of insulin resistance. Hypertension. 2007;49:1056-62 
21. Sattar N, Ramsay I, Crawford L, Cheyne H, Greer IA. Classic and novel risk factor parameters in women with a history of preeclampsia. Hypertension. 2003;42:39-42.

22. Laivuori H, Tikkanen MJ, Ylikorkala O. Hyperinsulinemia 17 years after preeclamptic first pregnancy.J Clin Endocrinol Metab. 1996;81:2908-11.

23. Wolf M, Hubel CA, Lam C, et al. Preeclampsia and future cardiovascular disease: Potential role of altered angiogenesis and insulin resistance. J Clin Endocrinol Metab. 2004:89:6239-43.

24. Spaan JJ, Houben AJ, Musella A, et al. Insulin resistance relates to microvascular reactivity 23 years after preeclampsia. Microvasc Res. 2010;80:417-21

25. Mangos GJ, Spaan JJ, Pirabhahar S, Brown MA. Markers of cardiovascular disease risk after hypertension in pregnancy. Journal of hypertension. 2012;30:351-8.

26. Smith GN, Walker MC, Liu A, et al. A history of preeclampsia identifies women who have underlying cardiovascular risk factors. American journal of obstetrics and gynecology. 2009;200:58 e1-8.

27. Stekkinger E, Zandstra M, Peeters LL, Spaanderman ME. Early-onset preeclampsia and the prevalence of postpartum metabolic syndrome. Obstet Gynecol. 2009;114:1076-84.

28. Veltman-Verhulst SM, van Rijn BB, Westerveld HE, et al. Polycystic ovary syndrome and early-onset preeclampsia: Reproductive manifestations of increased cardiovascular risk. Menopause. 2010;17:990-6.

29. Barden AE, Beilin LJ, Ritchie J, Walters BN, Michael C. Does a predisposition to the metabolic syndrome sensitize women to develop pre-eclampsia? J Hypertens. 1999;17:1307-15

30. Magnussen EB, Vatten LJ, Smith GD, Romundstad PR. Hypertensive disorders in pregnancy and subsequently measured cardiovascular risk factors. Obstet Gynecol. 2009;114:961-70.

1. Berends AL, de Groot CJ, Sijbrands EJ, et al. Shared constitutional risks for maternal vascular-related pregnancy complications and future cardiovascular disease. Hypertension. 2008;51:1034-41.

32. Mangos GJ, Spaan JJ, Pirabhahar S, Brown MA. Markers of cardiovascular disease risk after hypertension in pregnancy. J Hypertens. 2012:30:351-8.

33. Blaauw J, van Pampus MG, Van Doormaal JJ, et al. Increased intima-media thickness after early-onset preeclampsia. Obstet Gynecol. 2006;107:1345-51.

34. Germain AM, Romanik MC, Guerra I, et al. Endothelial dysfunction: A link among preeclampsia, recurrent pregnancy loss, and future cardiovascular events? Hypertension. 2007;49:90-5.

35. Schmittdiel J, Selby JV, Swain B, et al. Missed opportunities in cardiovascular disease prevention?: Low

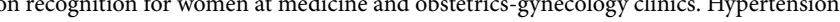
2011;57:717-22.

36. Young B, Hacker MR, Rana S. Physicians' knowledge of future vascular disease in women with preeclampsia. Hypertension in pregnancy : official journal of the International Society for the Study of Hypertension in Pregnancy. 2012;31:50-8.

37. Callaway LK, David McIntyre H, Williams GM, et al. Diagnosis and treatment of hypertension 21 year after a hypertensive disorder of pregnancy. Aust N Z J Obstet Gynaecol. 2011;51:437-40.

38. Sia WW, Montgomery-Fajic E, Germaine D, et al. The postpartum preeclampsia clinic (pppec) - an interdisciplinary clinic for cardiovascular risk reduction for women with preeclampsia. Abstract ISSHP World Congress. 2012.

39. Hermes W, Franx A, van Pampus MG, et al. 10-year cardiovascular event risks for women who experienced hypertensive disorders in late pregnancy: The hyras study. BMC Pregnancy Childbirth. 2010;10:28.

. Hoedjes M, Berks D, Vogel I, et al. Motivators and barriers to a healthy postpartum lifestyle in women increased cardiovascular and metabolic risk: A focus-group study. Hypertension in pregnancy : official journal of the International Society for the Study of Hypertension in Pregnancy 2012:31:147-55.
41. Barker DJ. Fetal origins of coronary heart disease. Bmj. 1995;311:171-4.

42. Geelhoed JJ, Fraser A, Tilling K, et al. Preeclampsia and gestational hypertension are associated with childhood blood pressure independently of family adiposity measures: The avon longitudinal study of parents and children Circulation. 2010:122:1192-9.

43. Gunderson EP. Childbearing and obesity in women: Weight before, during, and after pregnancy. Obstet Gynecol Clin North Am. 2009;36:317-32, ix.

44. Callaway $\mathrm{LK}$, McIntyre $\mathrm{HD}$, O'Callaghan M, et al. The association of hypertensive disorders of pregnancy with weight gain over the subsequent 21 years: Findings from a prospective cohort study. Am J Epidemiol. 2007;166:421-8.

45. Villamor E, Cnattingius S. Interpregnancy weight change and risk of adverse pregnancy outcomes: A population-based study. Lancet. 2006;368:1164-70.

46. Yusuf S, Hawken S, Ounpuu S, et al. Effect of potentially modifiable risk factors associated with myocardial infarction in 52 countries (the interheart study): Case-control study. Lancet. 2004;364:937-52.

47. Levit RD, Reynolds HR, Hochman JS. Cardiovascular disease in young women: A population at risk Cardiol Rev. 2011;19:60-5.

48. Andersen KK, Andersen ZJ, Olsen TS. Age- and gender-specific prevalence of cardiovascular risk factors in 40,102 patients with first-ever ischemic stroke: A nationwide danish study. Stroke. 2010;41:2768-74.

49. Daviglus ML, Stamler J, Pirzada A, et al. Favorable cardiovascular risk profile in young women and long-term risk of cardiovascular and all-cause mortality. Jama. 2004:292:1588-92.

50. Berks D, Hoedjes M, Franx A, et al. Lifestyle interventions after complicated pregnancy successfully improves cardiovascular and metabolic health; results of the pro-active study. Abstract ISSHP World Congress. improves 2012.

51. Scholten R, Thijssen D, Lotgering F, Hopman M, Spaanderman M. Vascular adaptations to 12-week cycling training in formerly preeclamptic women. Abstract sgi, san diego, USA. Reprod Sci. 2012;19:220A.

52. Hoedjes M, Berks D, Vogel I, et al. Effect of postpartum lifestyle interventions on weight loss, smoking cessation, and prevention of smoking relapse: A systematic review. Obstet Gynecol Surv. 2010;65:631-52.

53. Wing RR. Long-term effects of a lifestyle intervention on weight and cardiovascular risk factors in individuals with type 2 diabetes mellitus: Four-year results of the look ahead trial. Archives of internal medicine. 2010;170:1566-75

54. Roumen C, Corpeleijn E, Feskens EJ, et al. Impact of 3-year lifestyle intervention on postprandial glucose metabolism: The slim study. Diabet Med. 2008;25:597-605.

55. Lapolla A, Marangon M, Dalfra MG, et al. Pregnancy outcome in morbidly obese women before and after laparoscopic gastric banding. Obes Surg. 2010;20:1251-7.

56. Magee L, Sadeghi S, Von Dadelszen P. Prevention and treatment of postpartum hypertension [cochrane review]. Cochrane Database of systematic reviews. 2009

57. Firoz T, Melnik T. Postpartum evaluation and long term implications. Best Pract Res Clin Obstet Gynaecol. 2011:25:549-61.

58. Law MR, Morris JK, Wald NJ. Use of blood pressure lowering drugs in the prevention of cardiovascular disease: Meta-analysis of 147 randomised trials in the context of expectations from prospective epidemiological studies. BMJ. 2009;338:b1665

59. Lurbe E Cifkova R. Cruickshank JK, et al Management of high blood pressure in children and adolescents: Recommendations of the european society of hypertension. J Hypertens. 2009;27:1719-42.

60. Chobanian AV, Bakris GL, Black HR, et al Seventh report of the joint national committee on prevention, detection, evaluation, and treatment of high blood pressure. Hypertension. 2003;42:1206-52.

61. Lewington S, Clarke R, Qizilbash N, Peto R, Collins R. Age-specific relevance of usual blood pressure to 


\section{Chapter 8}

62. Third report of the national cholesterol education program (ncep) expert panel on detection, evaluation and treatment of high blood cholesterol in adults (adult treatment panel iii) final report. Circulation.

2002;106:3143-421.

63. Ray KK, Seshasai SR, Erqou S, et al. Statins and all-cause mortality in high-risk primary prevention: A meta-analysis of 11 randomized controlled trials involving 65,229 participants. Arch Intern Med. 2010;170:1024-31.

The metabolic syndrome as a 64. Mora S, Glynn RJ, Hsia J, et al. Statins for the primary prevention of cardiovascular events in women with
elevated high-sensitivity c-reactive protein or dyslipidemia: Results from the justification for the use of statins in prevention: An intervention trial evaluating rosuvastatin (jupiter) and meta-analysis of women from primary prevention trials. Circulation. 2010;121:1069-77.

65. Callaway LK, Lawlor DA, O'Callaghan M, et al. Diabetes mellitus in the 21 years after a pregnancy that was complicated by hypertension: Findings from a prospective cohort study. Am J Obstet Gynecol.

2007;197:492 el-7.

66. Hopper I, Billah B, Skiba M, Krum H. Prevention of diabetes and reduction in major cardiovascular events in studies of subjects with prediabetes: Meta-analysis of randomised controlled clinical trials. Eur Cardiovasc Prev Rehabil. 2011;18:813-23.

67. Ridker PM, Cook NR, Lee IM, et al. A randomized trial of low-dose aspirin in the primary prevention of cardiovascular disease in women. N Engl I Med. 2005;352:1293-304.

\section{risk factor for hypertension after preeclampsia}

Julia Spaan, Veronica Lopes van Balen, Simone Sep, Marc Spaanderman, Louis Peeters

Obstetrics \& Gynecology 2012;120:311-7 
Objective: To identify metabolic and obstetric risk factors associated with hypertension after preeclampsia.

Methods: We analyzed demographic and clinical data from a postpartum screening (blood pressure, microalbuminuria and fasting plasma levels of glucose, insulin and lipid profile) from 683 primiparous women with a history of preeclampsia. We excluded women with pre-existing hypertension, kidney disease or diabetes mellitus. In the group of women that were normotensive at postpartum screening, we evaluated the risk of developing chronic hypertension in the following years using questionnaires.

Results: Hypertension at postpartum screening ( $\mathrm{n}=107,17 \%$ of all cases) was related to obesity (OR 1.9, 95\% CI 1.1-3.2), elevated fasting levels of insulin (OR 1.7, 95\% CI 1.0-2.9), low-density |lipoprotein (OR 1.6, 95\% CI 1.1-2.6), microalbuminuria (OR 2.3, 95\%-CI 1.3-4.0), family history of hypertension

(OR 1.8, 95\% CI 1.1-2.8) and delivery before 34 weeks of gestation (OR 2.5, 95\% CI 1.6-4.0). We identified 27 cases of hypertension within 2095 person-years during a median 6 year follow-up in the group of women normotensive at postpartum screening. The hazard rate for the development of hypertension was 2.9 (95\% CI 1.2-7.5) and 8.1 (95\% CI 2.8-22.9), respectively, when 2 and $\geq 3$ components of the metabolic syndrome were present; 3.7 (95\% CI 1.4-10.0) for family history of hypertension and 4.3 (95\% CI 1.6-11.5) for recurrence of a hypertensive disorder in pregnancy.

Conclusion: Several metabolic and obstetric risk factors related to hypertension postpartum in the short term and predisposed to the subsequent development of chronic hypertension after preeclampsia in initially normotensive women.

\section{Introduction}

Preeclampsia identifies women at risk of cardiovascular disease at young age, making them eligible for preventive strategies. The risk of ischemic heart disease, thrombosis and stroke is doubled in women with a history of preeclampsia. ${ }^{1}$ The presence of one or more metabolic risk factors, including obesity, hypertension, insulin resistance, dyslipidemia and microalbuminuria, is frequently observed postpartum in women with a history of preeclampsia. ${ }^{2-4}$ This suggests that these women may benefit from life style interventions aimed to reduce their risk of cardiovascular disease. However, to our knowledge there are no reports supporting a direct correlation between the postpartum presence of metabolic risk factors and later cardiovascular disease in women with a history of preeclampsia.

Hypertension itself is a major predictor of cardiovascular disease in the general population, with an attributable risk to myocardial infarction of about $30 \%$ in women. ${ }^{5}$ Chronic hypertension may be an important mediator for the development of cardiovascular disease in women with a history of preeclampsia. About $25 \%$ develops hypertension after preeclampsia in contrast to only $7 \%$ after uncomplicated pregnancies. ${ }^{1}$ We postulate that metabolic and obstetric risk factors are associated with the development of hypertension after preeclampsia. This study aims to identify risk factors that coincide with hypertension at postpartum screening and predispose to the development of hypertension during a median follow-up period of 6 years in a cohort of primiparous women with a history of mainly early-onset preeclampsia.

\section{Material and methods}

In Maastricht University Medical Center (MUMC), we routinely screen women with a recent history of preeclampsia for underlying disorders to increase the efficacy of counseling with respect to a possible future pregnancy and cardiovascular health. For this study, we analyzed the data of all primiparous women with a history of preeclampsia $(n=683)$ that have visited this clinic between 1996 and 2010. These women mainly had early-onset preeclampsia (before 37 weeks of gestation) or preeclampsia complicated by fetal growth restriction or fetal demise. All women were Caucasian and participated at least 4 months postpartum after they ceased breastfeeding. Oral contraceptives were discontinued 4 weeks before the measurement. Exclusion criteria were pre-existing hypertension, kidney disease or diabetes 
mellitus. The Medical Ethical Committee board of MUMC approved this study (MEC 0-4-049).

At the postpartum screening we recorded blood pressure for a period of 30 minutes using a semi-automatic oscillometric device in halfsitting position (Dinamap Vital Signs Monitor 1846, Critikon, Tampa, FL, USA) and median values were used for analysis. Blood was collected for fasting plasma lipid profile, glucose and insulin. We determined fasting triglycerides, total cholesterol, high-density lipoprotein (HDL)-cholesterol and glucose using standard automated laboratory techniques (Beckman Coulter LX20 PRO, Fullerton, USA). Low-density lipoprotein (LDL)-cholesterol was calculated by the Friedewald equation. Plasma insulin concentrations were measured using AutoDelfia time-resolved fluoroimmunoassay. We estimated insulin resistance based on the homeostasis model assessment of insulin resistance (HOMA-IR), using the following formula: HOMA-IR $=[$ fasting serum insulin $(\mathrm{mU} / \mathrm{l}) \times$ fasting plasma glucose (mmol/l)] / 22.5. ${ }^{6}$ Microalbuminuria was measured by turbidometry (Cobas Bio centrifugal analyzer) and since 2007 by nephelometry (BN ProSpec, Siemens Healthcare Diagnostics, Deerfield, IL).

Preeclampsia was defined according to the criteria of the Report of the National High Blood Pressure Education Program Working Group on High Blood Pressure in Pregnancy. ${ }^{7}$ Small for gestational age was defined as a birth weight below the 10th percentile according to the birth weight reference curves of the Perinatal Registry in the Netherlands. Family history was evaluated using a standard form and for this analysis only first-degree relatives were taken into account. The metabolic score consisted of components of the metabolic syndrome as defined by the Third Adult Treatment Panel (updated version) and included, elevated glucose, low HDL-cholesterol and elevated triglycerides. ${ }^{8}$ A high-normal blood pressure was defined as a blood pressure of 130-139 $\mathrm{mmHg}$ systolic and/or $85-89 \mathrm{mmHg}$ diastolic; ${ }^{9}$ and was only used to predict the development of hypertension at follow-up. Cut-off values for other metabolic risk factors as total cholesterol, LDL-cholesterol and microalbuminuria were defined according to the criteria of the European Society of Hypertension; ${ }^{9}$ for plasma insulin and HOMA-IR we used the 75th percentile in our population as cut-off point.
The main outcome measure of this study was hypertension after preeclampsia, which was evaluated at postpartum screening and during follow-up. We considered women hypertensive at postpartum screening, when automated blood pressures were $\geq 140 \mathrm{mmHg}$ systolic and/or $\geq 90 \mathrm{mmHg}$ diastolic or when using antihypertensive drugs. We evaluated the development of hypertension by a short health questionnaire sent out every 2 years to all women who had had a diagnostic work-up at least 18 months ago. We used self-reported antihypertensive treatment to define hypertension at follow-up.

\section{Statistical analysis}

Data are presented as mean \pm standard deviation or median with interquartile range. The rate of missing data ranged from 1 to $8 \%$. Differences between groups were tested using independent t-test or Mann-Whitney U-test. Proportions were compared by chi-square test. We used logistic regression analysis to test the association between several risk factors and the presence of hypertension at postpartum screening. Cox proportional hazard analysis was used to estimate the hazard to develop hypertension during follow-up. The event was occurrence of hypertension during follow-up (yes/no). Time-to-event was calculated by the time elapsed between year of postpartum screening and the year of initiating antihypertensive drugs (16 events) or,

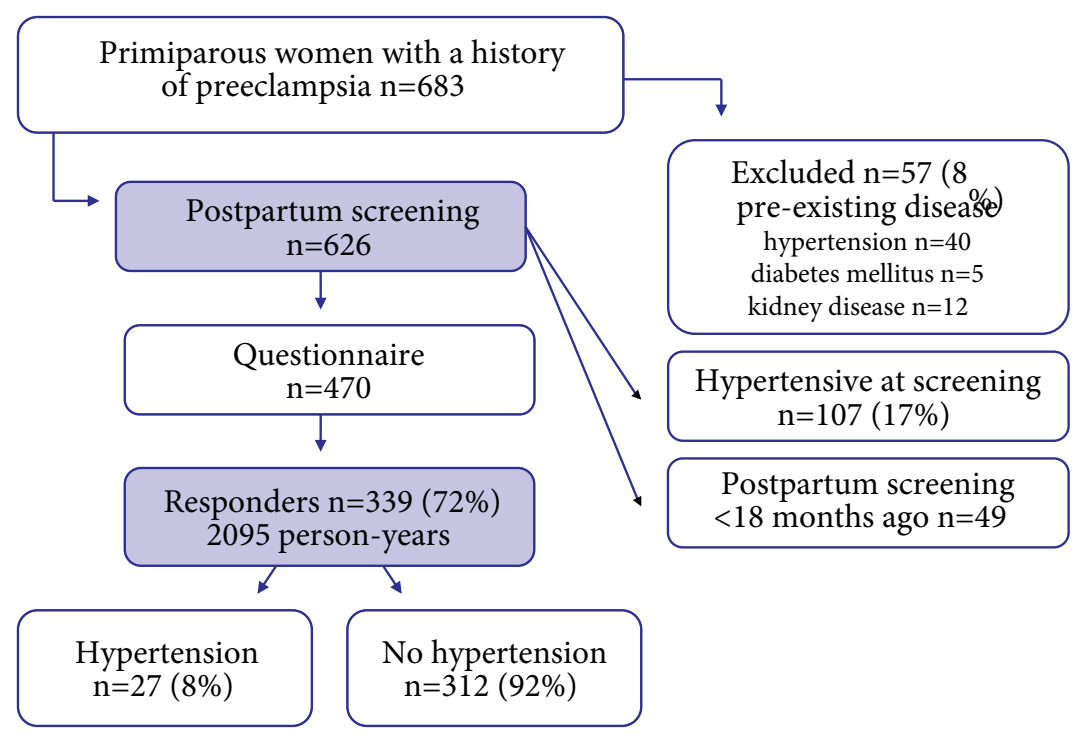

Figure 1: Selection of study population. 
Table 1: Characteristics and clinical variables at postpartum screening in primiparous women with a history of preeclampsia $(n=626)$.

\begin{tabular}{|l|l|l|l|} 
& $\begin{array}{l}\text { Hypertensive } \\
(\mathbf{n}=107)\end{array}$ & $\begin{array}{l}\text { Normotensive } \\
(\mathbf{n}=519)\end{array}$ & $\begin{array}{l}\mathbf{p}- \\
\text { value }\end{array}$ \\
\hline Postpartum interval (months) & $8(6-18)$ & $10(6-19)$ & 0.06 \\
\hline Age (years) & $31.4 \pm 4.1$ & $30.7 \pm 4.3$ & 0.16 \\
\hline Smoking (n,\%) & $19(18)$ & $75(15)$ & 0.39 \\
\hline BMI (kg/m²) & $26.5 \pm 5.7$ & $25.1 \pm 4.6$ & 0.01 \\
\hline Family hypertension (n,\%) & $69(66)$ & $266(52)$ & $<0.01$ \\
\hline Family cardiovascular disease (n,\%) & $55(52)$ & $269(53)$ & 0.95 \\
\hline GA delivery (weeks) & $320 / 7(29-34)$ & $334 / 7(30-36)$ & $<0.01$ \\
\hline Birth weight (g) & $1398(945-1806)$ & $1725(1090-2450)$ & $<0.01$ \\
\hline Fetal demise (n, \%) & $11(10)$ & $30(6)$ & 0.22 \\
\hline $\begin{array}{l}\text { Glucose (mmol/l) } \\
\text { Insulin (mmol/l) }\end{array}$ & $5.1 \pm 0.6$ & $5.1 \pm 0.5$ & 0.59 \\
\hline HOMA-IR & $11.0(7.4-16.0)$ & $9.2(6.6-13.0)$ & $<0.01$ \\
\hline Total-cholesterol (mmol/l) & $2.6(1.6-3.4)$ & $2.1(1.4-3.1)$ & 0.02 \\
\hline HDL-cholesterol (mmol/l) & $5.2 \pm 1.0$ & $4.8 \pm 0.9$ & $<0.01$ \\
\hline LDL-cholesterol (mmol/l) & $1.4 \pm 0.3$ & $1.4 \pm 0.9$ & 0.88 \\
\hline Triglycerides (mmol/l) & $3.3 \pm 0.9$ & $3.1 \pm 0.8$ & $<0.01$ \\
\hline $\begin{array}{l}\text { Microalbuminuria }>3.5 \mathrm{~g} / \mathrm{mol} \text { creat } \\
\text { (n, \%) }\end{array}$ & $1.01(0.71-1.30)$ & $0.80(0.56-1.15)$ & $<0.01$ \\
\hline $\begin{array}{l}\text { Data are presented as mean } \pm \text { standard deviation or median (interquartile range), } \\
\text { unless stated otherwise. BMI, body mass index; HOMA-IR, homeostatic model } \\
\text { insulin resistance; HDL, high-density lipoprotein; LDL, low-density lipoprotein; creat, } \\
\text { creatinine. }\end{array}$ & & & $<0.01$ \\
\hline
\end{tabular}

if not available, the year halfway the most recent follow-up interval (11 events). Data were censored for follow-up time if the event had not occurred. A following pregnancy was taken into account only when delivery preceded the event. As a rule of thumb we defined that we needed at least 5 cases for each independent variable in the model. ${ }^{10}$ A p-value below 0.05 was considered statistically significant.

\section{Results}

Figure 1 presents a flowchart of the selection of the study population. Exclusion for kidney disease included nine cases of systemic lupus erythematosus and one case of atrophic kidney, kidney aplasia and Fabry's syndrome. Of the 626 primiparous women with a history of preeclampsia, 107 (17\%) were hypertensive and 519 (83\%) were normotensive at postpartum screening. A total of 470 women received a follow-up questionnaire; they were all normotensive at the time of postpartum screening and had had at least 18 months of follow-up.
Of these women, $339(72 \%)$ responded to at least one questionnaire. During a median follow-up of 6 (IQR 4-9, min-max 1-14) years covering 2095 person-years, we identified 27 cases of new-onset hypertension, an incidence of 13 cases per 1000 person-years. Five women did develop type 2 diabetes during follow-up.

Table 1 lists the characteristics and clinical variables of the hypertensive and normotensive women with a history of preeclampsia at postpartum screening. The screening was performed about 8 (IQR 6-18, min-max 4-92) and 10 (IQR 6-19, min-max 4-166) months postpartum in the hypertensive and normotensive women, respectively. Groups were comparable with respect to age and smoking. Hypertensive women delivered at an earlier gestational age of an infant with a lower birth weight compared with normotensive women.

A family history of hypertension was more often present and hypertensive women had a higher body mass index (BMI) and elevated fasting plasma levels of insulin, total-, LDL-cholesterol and triglycerides compared with normotensive women. Microalbuminuria was present in $22 \%$ of hypertensive and in $12 \%$ of normotensive women with a history of preeclampsia $(\mathrm{p}<0.01)$.

Table 2 shows to what extent risk factors at postpartum screening coincided with hypertension after adjustment for maternal age, smoking and months postpartum, with and without adjustment for BMI. The presence of hypertension was associated with obesity

(OR 1.9, 95\%-CI 1.1-3.2), elevated levels of insulin (OR 2.2, 95\%-CI 1.4-3.5) and insulin resistance based on HOMA-IR (OR 1.7, 95\%-CI 1.0-2.7). Adjustment for BMI attenuated the associations with insulin and HOMA-IR (OR 1.7, 95\%-CI 1.0-2.9 and OR 1.2, 95\%-CI 0.7-2.1, respectively). Hypertension related to elevated levels of totaland LDL-cholesterol and microalbuminuria, independent of BMI (OR 1.6, 95\%-CI 1.0-2.4; OR 1.6, 95\%-CI 1.1-2.6 and OR 2.3, 95\%-CI 1.3-4.0, respectively). Hypertension was associated with a family history of hypertension and delivery before 34 weeks of gestation (OR 1.8, 95\%-CI 1.1-2.8 and OR 2.5, 95\%-CI 1.6-4.0, respectively) and not with the birth of a small for gestational age infant. 
Table 2: Risk factors associated with the presence of hypertension at postpartum screening in women with a history of preeclampsia $(n=626)$.

\begin{tabular}{|c|c|c|c|c|c|}
\hline & & $\begin{array}{l}\text { HT } \\
(n=107) \\
n(\%)\end{array}$ & $\begin{array}{l}\text { NT } \\
(n=519) \\
n(\%)\end{array}$ & $\begin{array}{l}\text { Model } 1 \\
\text { OR } \\
(95 \%-C I)\end{array}$ & $\begin{array}{l}\text { Model } 2 \\
\text { OR } \\
(95 \%-C I)\end{array}$ \\
\hline \multicolumn{6}{|l|}{ Metabolic variables } \\
\hline Metabolic score $^{\dagger}$ & $\begin{array}{l}<2 \text { components } \\
2 \text { components } \\
\geq 3 \text { components }\end{array}$ & $\begin{array}{l}78(76) \\
17(17) \\
8(8)\end{array}$ & $\begin{array}{l}402(83) \\
67(14) \\
24(5)\end{array}$ & $\begin{array}{l}1.0 \\
1.3(0.7-2.3) \\
1.8(0.8-4.1)\end{array}$ & $\begin{array}{l}- \\
- \\
-\end{array}$ \\
\hline${ }^{\dagger}$ Obesity & $\geq 30 \mathrm{~kg} / \mathrm{m}^{2}$ & $23(21)$ & $67(13)$ & $1.9(1.1-3.2)$ & - \\
\hline${ }^{\dagger}$ Glucose & $\geq 5.6 \mathrm{mmol} / \mathrm{l}$ & $16(16)$ & $73(15)$ & $1.0(0.6-1.8)$ & $1.0(0.6-1.8)$ \\
\hline${ }^{\dagger} \mathrm{HDL}$-cholesterol & $<1.29 \mathrm{mmol} / \mathrm{l}$ & $48(45)$ & $209(41)$ & $1.3(0.8-1.9)$ & $1.1(0.7-1.7)$ \\
\hline †Triglycerides & $\geq 1.7 \mathrm{mmol} / \mathrm{l}$ & $14(13)$ & $46(9)$ & $1.6(0.8-3.0)$ & $1.2(0.6-2.4)$ \\
\hline Total-cholesterol & $>5.0 \mathrm{mmol} / \mathrm{l}$ & $52(49)$ & $186(36)$ & $1.7(1.1-2.5)$ & $1.6(1.0-2.4)$ \\
\hline LDL-cholesterol & $>3.0 \mathrm{mmol} / \mathrm{l}$ & $65(62)$ & $239(47)$ & $1.8(1.1-2.7)$ & $1.6(1.1-2.6)$ \\
\hline Insulin & $\geq 14 \mathrm{mmol} / \mathrm{l}$ & $38(39)$ & $117(24)$ & $2.2(1.4-3.5)$ & $1.7(1.0-2.9)$ \\
\hline HOMA-IR & $\geq 3.2$ & $32(33)$ & $113(24)$ & $1.7(1.0-2.7)$ & $1.2(0.7-2.1)$ \\
\hline Microalbuminuria & $\geq 3.5 \mathrm{~g} / \mathrm{mol}$ creat & $22(22)$ & $58(12)$ & $2.3(1.3-4.0)$ & $2.3(1.3-4.0)$ \\
\hline \multicolumn{6}{|c|}{ Family history } \\
\hline Hypertension & 1st degree & $69(66)$ & $266(52)$ & $1.8(1.2$ & $1.8(1.1-2.8)$ \\
\hline CVD & 1st degree & $55(52)$ & $269(53)$ & $1.0(0.6-1.5)$ & $1.0(0.6-1.5)$ \\
\hline \multicolumn{6}{|l|}{ Obstetric history } \\
\hline SGA & $\leq \mathrm{p} 10$ & $24(24)$ & $126(25)$ & $0.9(0.5-1.4)$ & $0.9(0.5-1.4)$ \\
\hline GA delivery & $<34$ weeks & $78(74)$ & $266(52)$ & $2.6(1.6-4.2)$ & $2.5(1.6-4.0)$ \\
\hline \multicolumn{6}{|c|}{$\begin{array}{l}\text { Model 1: Adjusted for maternal age, smoking and months postpartum. } \\
\text { Model 2: Adjusted for maternal age, smoking, months postpartum, and BMI. } \\
{ }^{+} \text {Components of the metabolic score. OR, odds ratio; HT, hypertensive; NT, normo- } \\
\text { tensive; HDL, high-density lipoprotein; LDL, low-density lipoprotein; HOMA-IR, } \\
\text { homeostatic model insulin resistance; creat, creatinine; CVD, cardiovascular disease; } \\
\text { SGA, small for gestational age; p10, tenth percentile; GA, gestational age. }\end{array}$} \\
\hline
\end{tabular}

Table 3 shows to what extent risk factors at postpartum screening were associated with the development of hypertension during a median follow-up of 6 years after adjustment for maternal age, smoking and months postpartum, with and without adjustment for BMI. The hazard rate for the presence of 2 and $\geq 3$ components of the metabolic syndrome was 2.9 (95\%-CI 1.2-7.5) and 8.1 (95\%-CI 2.8-22.9), respectively (see figure 2 ). Obesity and high-normal blood pressure predisposed to the development of hypertension (HR 3.1, 95\%-CI 1.3-7.4 and HR 3.8, 95\%-CI 1.6-8.8, respectively). Associations of HDL-cholesterol and insulin with hypertension during follow-up disappeared after adjustment for BMI. Moreover, glucose, total- and
Table 3: Risk factors associated with the development of hypertension during a median 6 years follow-up of women with a history of preeclampsia who were normotensive at postpartum screening $(n=339)$.

\begin{tabular}{|c|c|c|c|}
\hline & & $\begin{array}{l}\text { Model } 1 \\
\text { HR (95\%-CI) }\end{array}$ & $\begin{array}{l}\text { Model } 2 \\
\text { HR (95\%-CI) }\end{array}$ \\
\hline \multicolumn{4}{|l|}{ Metabolic variables } \\
\hline Metabolic score $^{\dagger}$ & $\begin{array}{l}<2 \text { components } \\
2 \text { components } \\
\geq 3 \text { components }\end{array}$ & $\begin{array}{l}1.0 \\
2.9(1.2-7.5) \\
8.1(2.8-22.9)\end{array}$ & $\begin{array}{l}- \\
- \\
-\end{array}$ \\
\hline${ }^{\dagger}$ Obesity & $\geq 30 \mathrm{~kg} / \mathrm{m}^{2}$ & $3.1(1.3-7.4)$ & - \\
\hline${ }^{\dagger}$ Blood pressure & $130-139 / 85-89 \mathrm{mmHg}$ & $4.5(2.0-10.1)$ & $3.8(1.6-8.8)$ \\
\hline${ }^{\dagger}$ Glucose & $\geq 5.6 \mathrm{mmol} / \mathrm{l}$ & $1.6(0.6-4.0)$ & $1.2(0.4-3.2)$ \\
\hline${ }^{\dagger}$ HDL-cholesterol & $<1.29 \mathrm{mmol} / \mathrm{l}$ & $1.9(0.9-4.2)$ & $1.5(0.7-3.4)$ \\
\hline `Triglycerides & $\geq 1.7 \mathrm{mmol} / \mathrm{l}$ & $1.0(0.2-4.2)$ & $0.8(0.2-3.3)$ \\
\hline Total-cholesterol & $>5.0 \mathrm{mmol} / \mathrm{l}$ & $1.0(0.4-2.1)$ & $1.0(0.4-2.2)$ \\
\hline LDL-cholesterol & $>3.0 \mathrm{mmol} / \mathrm{l}$ & $1.3(0.6-2.9)$ & $1.2(0.6-2.7)$ \\
\hline Insulin & $\geq 14 \mathrm{mmol} / \mathrm{l}$ & $2.2(1.0-4.9)$ & $1.4(0.6-3.6)$ \\
\hline HOMA-IR & $\geq 3.2$ & $1.7(0.7-3.8)$ & $1.7(0.7-3.9)$ \\
\hline Microalbuminuria & $\geq 3.5 \mathrm{~g} / \mathrm{mol}$ creat & $1.1(0.3-3.8)$ & $1.3(0.4-4.4)$ \\
\hline \multicolumn{4}{|l|}{ Family history } \\
\hline Hypertension & 1st degree & $4.1(1.5-10.9)$ & $3.7(1.4-10.0)$ \\
\hline CVD & 1st degree & $1.8(0.8-4.2)$ & $1.7(0.7-4.0)$ \\
\hline \multicolumn{4}{|l|}{ Obstetric history } \\
\hline SGA & $\leq \mathrm{p} 10$ & $0.9(0.4-2.3)$ & $1.0(0.4-2.5)$ \\
\hline GA delivery & $<34$ weeks & $2.3(0.9-5.8)$ & $2.0(0.8-5.1)$ \\
\hline Following pregnancy & $\begin{array}{l}\text { None } \\
\text { Uncomplicated } \\
\text { PE/GH }\end{array}$ & $\begin{array}{l}1.4(0.4-4.7) \\
1.0 \\
4.5(1.7-11.8)\end{array}$ & $\begin{array}{l}1.3(0.4-4.3) \\
1.0 \\
4.3(1.6-11.5)\end{array}$ \\
\hline
\end{tabular}

27 cases for 2095 person-years.

Model 1: Adjusted for maternal age, smoking and months postpartum.

Model 2: Adjusted for maternal age, smoking, months postpartum, and BMI.

${ }^{+}$Components of the metabolic score. HR, hazard ratio; HDL, high-density lipoprotein; $L D L$, low-density lipoprotein; HOMA-IR, homeostatic model insulin resistance; creat, creatinine; $C V D$, cardiovascular disease; SGA, small for gestational age; $p 10$, tenth percentile; GA, gestational age; $P E$, preeclampsia; $G H$, gestational hypertension.

LDL-cholesterol, triglycerides and birth of a small for gestational age infant were not associated with hypertension during follow-up. A family history of hypertension and recurrence of a hypertensive disorder in the next pregnancy were independent of BMI related to the occurrence of hypertension during follow-up (HR 3.7, 95\%-CI 1.4-10.0 and HR 4.3, 95\%-CI 1.6-11.5, respectively). 


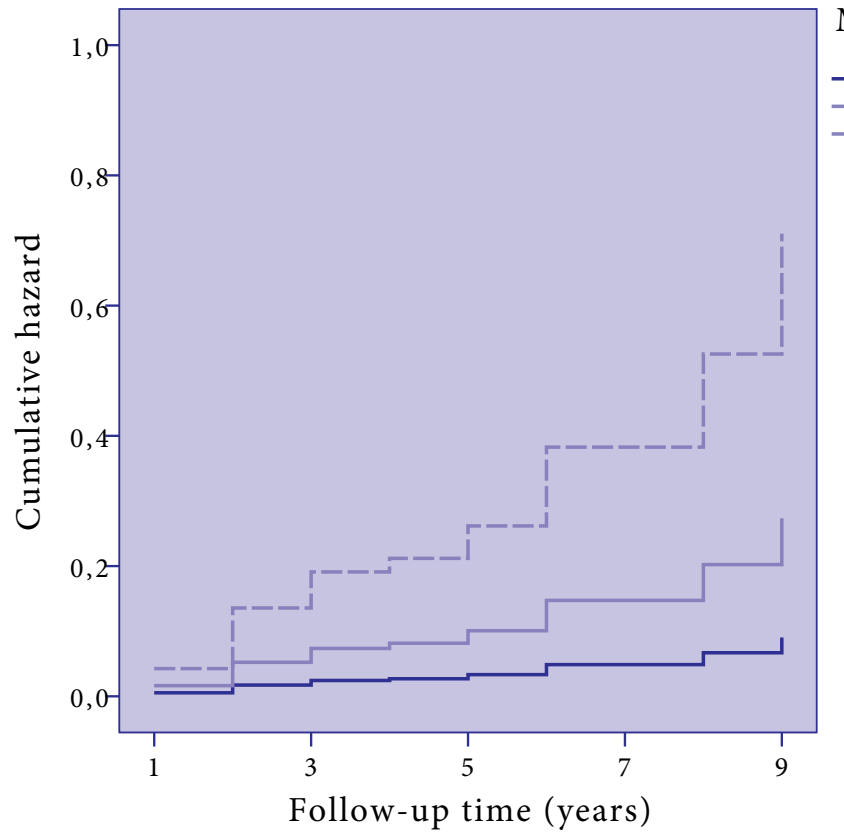

Figure 2: Cumulative hazard of hypertension stratified by metabolic score in women with a history of preeclampsia who were normotensive at postpartum screening.

\section{Discussion}

The presence of hypertension at postpartum screening related to modifiable risk factors such as obesity, hyperinsulinemia and dyslipidemia. The subsequent development of hypertension in women, who were normotensive at postpartum screening, was 3 times more likely when obesity was present and 4 times more likely when the blood pressure at postpartum screening was within the high-normal range. The risk of developing hypertension increased even more when 3 or more components of the metabolic syndrome were present. These findings support the view that women with a history of preeclampsia are likely to benefit from life-style interventions to reduce their longterm cardiovascular disease risk.

The total prevalence of chronic hypertension after preeclampsia in this study of about $25 \%$ was comparable to previous reports. ${ }^{1}$ This is higher than the expected prevalence of hypertension in the Dutch population of women of reproductive age of about $2.8-5.6 \% .{ }^{11} \mathrm{We}$ observed a relatively high proportion of hypertension directly at postpartum screening (17\%) and another $8 \%$ developed hypertension during a median 6 years follow-up. Hypertension in the early postpartum period may still normalize over the years, as 14 out of 74 women who were hypertensive at postpartum screening (and who filled out a questionnaire), did not indicate to use antihypertensive medication during follow-up. We used self-reported antihypertensive treatment to define hypertension during follow-up, as we intended to restrict our outcome to these women that have a confirmed diagnosis of hypertension. Self-reported hypertension underestimates the incidence of new-onset disease, but is reliable if reported to be present. ${ }^{12,13}$

The prevalence of metabolic abnormalities at postpartum screening was high in our study population, which is in line with others. ${ }^{3,4,14}$ Our study shows that these metabolic risk factors are associated with hypertension after preeclampsia. Whether or not the placental disorder itself contributes to this risk is still under debate. This study gives some direction to this question, suggesting a possible effect of disease severity as women with an earlier onset of preeclampsia (delivery before 34 weeks of gestation) had more often hypertension at postpartum screening. On the other hand, we could not confirm an association between small for gestational age and maternal hypertension.

This study gives further support for the current view that lifestyle interventions may be beneficial to these women. The benefit of a healthy lifestyle is clear from large epidemiological studies, ${ }^{5,15}$ but there is a strong need for trials proving the (cost)effectiveness of postpartum lifestyle interventions on long-term cardiovascular disease outcomes, such as stroke and myocardial infarction. ${ }^{16}$ Some preliminary reports suggest that women with a history of preeclampsia are willing to participate in such an intervention program and will have improved weight and lipid profile after three months. ${ }^{17,18}$ Several trials in women with gestational diabetes or obesity suggest that a postpartum lifestyle intervention is feasible. ${ }^{19,20}$

We want to emphasize that a high-normal blood pressure was a strong predictor for the development of hypertension in the following years. Recent evidence shows that there is a continuous relationship between blood pressure and cardiovascular disease risk; the cut-off level of 140/90 mmHg for hypertension seems arbitrarily. ${ }^{21,22}$ Some studies suggest that it may be beneficial to treat people with a highnormal blood pressure, especially if concomitant risk factors are present. 9, 23, 24 Whether this also applies to women with a history of preeclampsia requires further research. 
Table 4: Comparison of characteristics and clinical variables at postpartum screening in non-responders and responders $(n=470)$.

\begin{tabular}{|l|l|l|l|}
\hline & $\begin{array}{l}\text { Non-responders } \\
(\mathbf{n}=131)\end{array}$ & $\begin{array}{l}\text { Responders } \\
(\mathbf{n}=339)\end{array}$ & p-value \\
\hline Postpartum interval (months) & $9(6-17)$ & $10(7-20)$ & 0.14 \\
\hline Age (y) & $30.3 \pm 5.2$ & $31.0 \pm 3.8$ & 0.18 \\
\hline Smoking (n,\%) & $30(23)$ & $37(11)$ & $<0.01$ \\
\hline BMI (kg/m²) & $25.3 \pm 5.3$ & $24.9 \pm 4.4$ & 0.45 \\
\hline Family hypertension (n,\%) & $72(56)$ & $170(51)$ & 0.32 \\
\hline Family cardiovascular disease (n,\%) & $68(53)$ & $184(55)$ & 0.62 \\
\hline GA delivery (wks) & $350 / 7(32-37)$ & $330 / 7(30-36)$ & $<0.01$ \\
\hline Birth weight (g) & $1856(1162-2683)$ & $1615(1013-2319)$ & 0.02 \\
\hline Fetal demise (n, \%) & $11(8)$ & $16(5)$ & 0.13 \\
\hline Glucose (mmol/l) & $5.1 \pm 0.5$ & $5.1 \pm 0.5$ & 0.41 \\
\hline Insulin (mmol/l) & $9.3(5.9-15)$ & $9.4(6.7-13.0)$ & 0.61 \\
\hline HOMA-IR & $2.0(1.3-3.3)$ & $2.1(1.5-3.0)$ & 0.53 \\
\hline Total-cholesterol (mmol/l) & $4.7 \pm 1.0$ & $4.9 \pm 0.9$ & 0.16 \\
\hline $\begin{array}{l}\text { HDL-cholesterol (mmol/l) } \\
\text { LDL-cholesterol (mmol/l) }\end{array}$ & $1.3 \pm 0.3$ & $1.4 \pm 0.3$ & $<0.01$ \\
\hline $\begin{array}{l}\text { Triglycerides (mmol/l) } \\
\text { Microalbuminuria (>3.5 g/mol creat) }\end{array}$ & $0.9 \pm 1.0$ & $3.1 \pm 0.8$ & 0.59 \\
\hline $\begin{array}{l}\text { Data are presented as mean } \pm \text { standard deviation or median (interquartile range), } \\
\text { unless stated otherwise. BMI, body mass index; HOMA-IR, homeostatic model } \\
\text { insulin resistance; HDL, high density lipoprotein; LDL, low density lipoprotein; creat, } \\
\text { creatinine. }\end{array}$ & & $0.77(0.54-1.06)$ & 0.19 \\
\hline
\end{tabular}

There are several limitations of our study. Firstly, the study population consisted of Caucasian women only and women with mild preeclampsia were relatively underrepresented. Moreover, it would have been preferably to have a control group of women who had normotensive pregnancies. Secondly, we identified some differences in the risk profile of responders and non-responders to the questionnaire. A sub-analysis showed that non-responders delivered at a later gestational age, smoked more often and had a slightly less favorable lipid profile, without differences in BMI (table 4). Thirdly, first-trimester booking blood pressures of the index pregnancy were unfortunately not available. Some women with hypertension at postpartum screening may have had underlying secondary hypertension instead of essential hypertension, which is less likely to be related to metabolic risk factors and might have led to an underestimation of association estimates.
In conclusion, this study showed that several metabolic risk factors, such as obesity, insulin resistance and dyslipidemia, coincided or predisposed to hypertension after preeclampsia. Besides, this study identified several other clinical variables useful in postpartum cardiovascular risk stratification after preeclampsia, such as a family history of hypertension, a high-normal blood pressure and recurrence of a hypertensive disorder in the next pregnancy. 


\section{References}

1. Bellamy L, Casas JP, Hingorani AD, Williams DJ. Pre-eclampsia and risk of cardiovascular disease and cancer in later life: systematic review and meta-analysis. Bmj. 2007;335:974.

2. Sattar N, Ramsay J, Crawford L, Cheyne H, Greer IA. Classic and novel risk factor parameters in women with a history of preeclampsia. Hypertension. 2003;42:39-42.

3. Smith GN, Walker MC, Liu A, et al. A history of preeclampsia identifies women who have underlying cardiovascular risk factors. Am J Obstet Gynecol. 2008;200:58.e1- 8.

4. Stekkinger E, Zandstra M, Peeters LL, Spaanderman ME. Early-onset preeclampsia and the prevalence of postpartum metabolic syndrome. Obstet Gynecol. 2009;114:1076-84.

5. Yusuf S, Hawken S, Ounpuu S, et al. Effect of potentially modifiable risk factors associated with myocardial infarction in 52 countries (the INTERHEART study): case-control study. Lancet. 2004;364:937-52.

6. Matthews DR, Hosker JP, Rudenski AS, Naylor BA, Treacher DF, Turner RC. Homeostasis model assessment: insulin resistance and beta-cell function from fasting plasma glucose and insulin concentrations in man. Diabetologia. 1985;28:412-9.

7. Report of the National High Blood Pressure Education Program Working Group on High Blood Pressure in Pregnancy. Am J Obstet Gynecol. 2000;183:S1-S22.

8. Third Report of the National Cholesterol Education Program (NCEP) Expert Panel on Detection, Evaluation, and Treatment of High Blood Cholesterol in Adults (Adult Treatment Panel III) final report. Circulation. 2002:106:3143-421.

9. Mancia G, De Backer G, Dominiczak A, et al. 2007 Guidelines for the Management of Arterial Hypertension: The Task Force for the Management of Arterial Hypertension of the European Society of Hypertension (ESH) and of the European Society of Cardiology (ESC). J Hypertens. 2007;25:1105-87.

10. Vittinghoff $\mathrm{E}, \mathrm{McCulloch} \mathrm{CE}$. Relaxing the rule of ten events per variable in logistic and Cox regression. Am J Epidemiol. 2007;165:710-8.

11. Blokstra A, Smit H, Bueno de Mesquita H, Seidell J, Verschuren W. Monitoring Project on Chroni Disease Risk Factors (MORGEN-project) 1993-1997: prevalences and trends in lifestyle and risk Bilthoven: RIVM; 2005 .

12. Molenaar EA, Van Ameijden EJ, Grobbee DE, Numans ME. Comparison of routine care self-reported and biometrical data on hypertension and diabetes: results of the Utrecht Health Project. Eur J Public Health. 2007;17:199-205.

13. Oksanen T, Kivimaki M, Pentti J, Virtanen M, Klaukka T, Vahtera J. Self-report as an indicator of incident disease. Ann Epidemiol.20:547-54.

14. Lu J, Zhao YY, Qiao J, Zhang HJ, Ge L, Wei Y. A follow-up study of women with a history of severe preeclampsia: relationship between metabolic syndrome and preeclampsia. Chin Med J (Engl). 2011;124:775-9.

15. Daviglus ML, Stamler J, Pirzada A, et al. Favorable cardiovascular risk profile in young women and longterm risk of cardiovascular and all-cause mortality. JAMA. 2004;292:1588-92.

16. Hoedjes M, Berks D, Vogel I, et al. Effect of postpartum lifestyle interventions on weight loss, smoking cessation, and prevention of smoking relapse: a systematic review. Obstet Gynecol Surv. 2010;65:631-52.

17. Berks D, Hoedjes M, Franx A, et al. Postpartum lifestyle intervention after complicated pregnancy proves feasible. In: Abstract ISSHP World Congress. Melbourne, Australia; 2010.

18. Hoedjes M, Berks D, Vogel I, et al. Preferences for postpartum lifestyle counseling among women sharing an increased cardiovascular and metabolic risk: a focus group study Hypertens Pregnancy. 2011:30:83-92.
19. Ferrara A, Hedderson MM, Albright CL, et al. A pregnancy and postpartum lifestyle intervention in women with gestational diabetes mellitus reduces diabetes risk factors: a feasibility randomized control trial. Diabetes Care. 2011;34:1519-25.

20. Lombard CB, Deeks AA, Ball K, Jolley D, Teede HJ. Weight, physical activity and dietary behavior change in young mothers: short term results of the HeLP her cluster randomized controlled trial. Nutr I. 2009:8:17.

21. Lewington S, Clarke R, Qizilbash N, Peto R, Collins R. Age-specific relevance of usual blood pressure to vascular mortality: a meta-analysis of individual data for one million adults in 61 prospective studies. Lancet. 2002;360:1903-13.

2. Vasan RS, Larson MG, Leip EP, et al. Impact of high-normal blood pressure on the risk of cardiovascular disease. N Engl J Med. 2001;345:1291-7.

23. Chobanian AV, Bakris GL, Black HR, et al. The Seventh Report of the Joint National Committee on Prevention, Detection, Evaluation, and Treatment of High Blood Pressure: the JNC 7 report. JAMA. 2003;289:2560-72.

24. Julius S, Nesbitt SD, Egan BM, et al. Feasibility of treating prehypertension with an angiotensin-recepto blocker. N Engl J Med. 2006;354:1685-97. 


\section{Chapter 9}

Summary and general discussion

This thesis focuses on the question whether women with a history of preeclampsia will have impaired long-term cardiovascular health and renal function. Based on findings in this thesis we can conclude that several years after preeclampsia women have a higher blood pressure, increased vascular resistance, higher body mass index and more often insulin resistance compared with parous controls. This profile is often referred to as 'the metabolic syndrome' and the presence of one or more of these constituents increases their risk for chronic hypertension and cardiovascular disease. The presence of these modifiable risk factors suggests that women may benefit from lifestyle interventions to prevent cardiovascular disease. In order to give these women their best possible long term outcomes, a standardized cardiovascular risk assessment postpartum is recommended after a hypertensive disorder of pregnancy. The main findings of each chapter will be summarized below.

\section{Part I - Cardiovascular health}

The first part of this thesis describes the cardiovascular health of women with a history of preeclampsia. Chapter 2 describes a group of women 23 years postpartum. Half of the women with a history of preeclampsia had developed chronic hypertension. Notably, both normotensive and hypertensive women had increased (reno)vascular resistance and reduced renal blood flow compared with parous controls. Higher blood pressures were confirmed in chapter 3 by 24-h ambulatory blood pressure monitoring 4-6 years postpartum. This study suggests that a higher BMI and blood pressure may have been present already before pregnancy, but provided no evidence for differences in creatinine clearance, endothelial dysfunction or sympathetic activity. In chapter 4 , we found microvascular function after post-occlusion reactive hyperemia to be comparable between women with a history of preeclampsia and parous controls. Interestingly, insulin resistance did inversely relate to microvascular function only in women with a history of preeclampsia.

\section{Part II - Renal function}

The second part of this thesis focuses on renal function after preeclampsia. We tested the hypothesis that the normal decline in renal function with age is more pronounced in women with a history of preeclampsia. A comparison between two cross-sectional groups of young and middle-aged women in chapter 5 did not support this hy- 
blood flow is present after preeclampsia in both young and middleaged women. In chapter 6 , using inulin clearances in a longitudinal study design, we observed that the reduced glomerular filtration rate normalized at 14 years postpartum; however, there was a consistent trend for a lower renal blood flow in women with a history of preeclampsia.

\section{Part III - Cardiovascular risk management}

The third part of this thesis describes a strategy for cardiovascular risk management and explores possibilities for risk stratification. As proposed in Chapter 7, all women with a hypertensive disorder of pregnancy should receive postpartum a standardized cardiovascular risk assessment based on current guidelines for primary prevention in asymptomatic people. Chapter 8 outlines risk factors in a postpartum screening for the development of chronic hypertension after preeclampsia, such as a family history of hypertension, a high-normal blood pressure and the presence of constituents of the metabolic syndrome.

\section{General discussion}

Cardiovascular health: major risk profiles

This thesis identifies two major risk profiles for cardiovascular disease after preeclampsia: a hypertensive and a metabolic profile. A higher blood pressure is observed after preeclampsia, even in women that do not fulfil the clinical criteria for hypertension. This was confirmed during the day and night by findings of 24-h ambulatory blood pressure monitoring 4-6 years post partum. Subsequently, 23 years after preeclampsia half of the women had developed chronic hypertension. Chronic hypertension may cause end organ damage and is likely to be an important mediator in the development of cardiovascular disease in these women.

The metabolic syndrome is a well-known risk factor for preeclampsia and cardiovascular disease. In this thesis, we observed a higher body mass index and insulin resistance after preeclampsia, but we did not discern differences in lipid profile between women with a history of preeclampsia and parous controls. This is in line with previous reports; a higher body mass index, blood pressure and insulin resistance relative to parous controls are consistent findings, but several case-control studies were unable to demonstrate differences in lipid profile. ${ }^{1-5}$ Still, if present, lipid abnormalities may contribute to their risk for cardiovascular disease. Chapter 8 shows that the number of constituents of the metabolic syndrome present increases the risk to develop chronic hypertension after preeclampsia.

This does not implicate that women without metabolic risk factors are not at risk for cardiovascular disease. It is still unclear whether preeclampsia is an independent risk factor for cardiovascular disease. Research to explore this is preferably done in a large cohort of women from the general population, thereby overcoming the criticism that women with normotensive pregnancies may reflect a relatively healthy group with a reduced risk of cardiovascular disease. ${ }^{6}$

In this thesis we were unable to demonstrate differences in (micro) vascular reactivity, sympathetic activity and endothelial dysfunction between women with a history of preeclampsia and parous controls. It should be emphasized that this thesis focussed on vascular, metabolic and renal function after preeclampsia, which implies only modest appreciation for the possible contribution of other underlying pathways (trombophilic, immunologic or genetic) to the risk of cardiovascular disease after preeclampsia. ${ }^{7,8}$

\section{Pitfalls in the measurement of kidney function}

Data on kidney function after preeclampsia are conflicting. On the one hand, several case-control studies do not support a lower kidney function in the first decade after preeclampsia when measured by creatinine clearances. ${ }^{9,10}$ On the other hand, we know from a large cohort study that women with a history of preeclampsia have an established risk on end-stage renal disease. In this thesis we found a lower creatinine clearance in middle-aged, perimenopausal women 23 years postpartum. By evaluating the individual chapters on renal function after preeclampsia in this thesis, we observed a lower glomerular filtration rate at 1 and 23 years postpartum, but not at 4 and 14 years postpartum. Interestingly, there was a consistent trend for a lower renal blood flow in women with a history of preeclampsia compared with parous controls at all time periods. A lower renal blood flow together with a higher filtration fraction suggests renal hyperfiltration to preserve the glomerular filtration rate. This finding was confirmed when comparing our data with a reference group of female kidney donors of similar age. Based on these findings, we postulate that the first decade after preeclampsia glomerular hyperfiltration may mask a reduced kidney function for several years. At older age or after the 
menopause the glomerular filtration may fall, as suggested by our observations 23 years postpartum. However, this remains speculative for now and needs further investigation in larger groups.

Research on kidney function after preeclampsia is hampered by the low prevalence of end-stage renal disease of about 3.7/100.000, even though the relative risk in women with a history of preeclampsia is increased about 5 times. ${ }^{11}$ Moreover, both pre-existing kidney disease and the development of chronic hypertension may act as confounders. Our pilot study showed that it is feasible to collect longitudinal data using inulin clearances to determine kidney function. Still, even when accurate methods are used to determine glomerular filtration rate, this does not provide information about the filtration rate in a single nephron. As the measurement of single nephron glomerular filtration rate or nephron number is currently not feasible in humans, future research may focus on methods to determine renal reserve capacity. ${ }^{12,13}$

Postpartum cardiovascular screening: one step too far? The lack of solid data about a postpartum screening program after a hypertensive disorder currently hampers the implementation of postpartum cardiovascular screening in clinical practice. There is no consensus about cardiovascular screening following a hypertensive disorder of pregnancy. After all, screening of a population is only useful when an effective treatment is available. ${ }^{14}$ Randomized-controlled trials are needed to prove the (cost)effectiveness of postpartum lifestyle intervention programs. Moreover, we need more evidence to reach consensus about the frequency and content of a postpartum screening program. Based on these arguments, one reckons that it is too early to implement a cardiovascular risk assessment for this specific group of women.

However, with growing evidence supporting the risk of cardiovascular disease after a hypertensive disorder of pregnancy and the increasing awareness of cardiovascular disease in women, women who currently have their pregnancy complicated by a hypertensive disorder cannot be denied any strategy for cardiovascular risk management. There are widely accepted guidelines available describing cardiovascular risk management in asymptomatic people for primary prevention of cardiovascular disease. ${ }^{15-17}$ At least a screening based on these guidelines can be offered to women with a history of a hypertensive disorder of pregnancy, as suggested in chapter 7. For now, one could easily implement these guidelines to decide on what factors to screen for and when to treat in a postpartum screening program. Future research will have to prove the benefit of additional risk markers or specific interventions.

\section{Effectiveness of postpartum interventions}

The first trials on postpartum lifestyle interventions are currently in progress, not only in women with a history of a hypertensive disorder of pregnancy, but also in other subgroups such women who are obese or experienced gestational diabetes. ${ }^{20-22}$ These trials evaluate weight loss, improvement of physical activity and/or cardiovascular biomarkers over a relatively short interval of a few months to years. Preliminary results suggest that such a postpartum lifestyle intervention program is feasible, but more studies are necessary to assess the cost-effectiveness and long-term benefit. ${ }^{20}$ It remains a challenge in young people to demonstrate a reduction in hard cardiovascular disease (such as stroke, cardiac ischemia and thromboembolic events) as a result of any intervention, because of the low prevalence of cardiovascular disease at young age and the long follow-up period needed. The use of surrogate markers of cardiovascular disease could be helpful. Moreover, the next pregnancy is an important relatively short-term outcome that should be taken into account in future costeffectiveness studies.

Individualized risk counselling

Individualized risk stratification following a hypertensive disorder of pregnancy seems particularly relevant to determine the frequency of follow-up and the intensity of (lifestyle-)interventions. While counselling about a healthy lifestyle is recommended for all women with a hypertensive disorder of pregnancy, more frequent follow-up or intensive lifestyle interventions programs could be tailored to these women with the highest risk. In this thesis we identified risk factors for chronic hypertension after preeclampsia, showing that further risk stratification may be feasible. This is also suggested by epidemiological observations, in which women with a combination of obstetric risk factors (preeclampsia, preterm birth and fetal growth restriction) have the highest risk of cardiac disease. ${ }^{18}$ Currently, we do not know how to weigh these additional risk factors to give an individualized risk estimate for cardiovascular disease after preeclampsia. ${ }^{19}$ Further research should evaluate this. It may be possible that the strength of 
a model to predict cardiovascular disease risk in women increases by taking obstetric risk factors into account.

\section{Conclusion}

Women with a history of a hypertensive disorder of pregnancy have an increased risk to develop cardiovascular disease at relatively young age. Metabolic risk factors and the development of chronic hypertension are modifiable factors that contribute to their risk of cardiovascular disease. The challenge for the future is to develop a postpartum cardiovascular risk management strategy that will be effective to promote a healthy lifestyle, improve the outcome of subsequent pregnancies and reduce the risk of cardiovascular disease.

\section{References}

Sattar N, Ramsay J, Crawford L, Cheyne H, Greer IA. Classic and novel risk factor parameters in women with a history of preeclampsia. Hypertension. 2003;42:39-42.

2. Smith GN, Walker MC, Liu A, et al. A history of preeclampsia identifies women who have underlying cardiovascular risk factors. Am J Obstet Gynecol. 2008;200:58.e1- 8

3. Laivuori H, Tikkanen MJ, Ylikorkala O. Hyperinsulinemia 17 years after preeclamptic first pregnancy. J Clin Endocrinol Metab. 1996;81:2908-11.

4. Wolf M, Hubel CA, Lam C, et al. Preeclampsia and future cardiovascular disease: potential role of altered angiogenesis and insulin resistance. J Clin Endocrinol Metab. 2004;89:6239-43.

5. Berends AL, de Groot CJ, Sijbrands EJ, et al. Shared constitutional risks for maternal vascular-related pregnancy complications and future cardiovascular disease. Hypertension. 2008;51:1034-41

6. Fisher KA, Luger A, Spargo BH, Lindheimer MD. Hypertension in pregnancy: clinical-pathological correlations and remote prognosis. Medicine (Baltimore). 1981;60:267-76.

7. Spaanderman ME, Ekhart TH, van Eyck J, Cheriex EC, de Leeuw PW, Peeters LL. Latent hemodynamic abnormalities in symptom-free women with a history of preeclampsia. Am J Obstet Gynecol. 2000;182:101-7.

8. Verlohren S, Muller DN, Luft FC, Dechend R. Immunology in hypertension, preeclampsia, and targetorgan damage. Hypertension. 2009;54:439-43.

9. Nisell H, Lintu H, Lunell NO, Mollerstrom G, Pettersson E. Blood pressure and renal function seven years after pregnancy complicated by hypertension. Br J Obstet Gynaecol. 1995;102:876-81.

10. Bar J, Kaplan B, Wittenberg C, et al. Microalbuminuria after pregnancy complicated by pre-eclampsia. Nephrol Dial Transplant. 1999:14:1129-32.

11. Vikse BE, Irgens LM, Leivestad T, Skjaerven R, Iversen BM. Preeclampsia and the risk of end-stage rena disease. N Engl J Med. 2008;359:800-9.

12. Ruilope LM, Lahera V, Rodicio JL, Carlos Romero J. Are renal hemodynamics a key factor in the development and maintenance of arterial hypertension in humans? Hypertension. 1994;23:3-9.

13. Livi R, Guiducci S, Perfetto F, et al. Lack of activation of renal functional reserve predicts the risk of significant renal involvement in systemic sclerosis. Ann Rheum Dis. 2011;70:1963-7.

14. Wilson JM, Jungner YG. [Principles and practice of mass screening for disease]. Bol Oficina Sanit Panam. 1968;65:281-393.

15. Third Report of the National Cholesterol Education Program (NCEP) Expert Panel on Detection, Evaluation, and Treatment of High Blood Cholesterol in Adults (Adult Treatment Panel III) final report. Circulation. 2002;106:3143-421.

16. Graham I, Atar D, Borch-Johnsen K, et al. European guidelines on cardiovascular disease prevention in clinical practice: executive summary: Fourth Joint Task Force of the European Society of Cardiology and Other Societies on Cardiovascular Disease Prevention in Clinical Practice (Constituted by representatives of nine societies and by invited experts). Eur Heart J. 2007;28:2375-414

17. Mosca L, Benjamin EJ, Berra K, et al. Effectiveness-based guidelines for the prevention of cardiovascular disease in women--2011 update: a guideline from the american heart association. Circulation. 2011;123:1243-62.

18. Smith GC, Pell JP, Walsh D. Pregnancy complications and maternal risk of ischaemic heart disease: a retrospective cohort study of 129,290 births. Lancet. 2001:357:2002-6.

9. Kooter AJ, Kostense PJ, Groenewold J, Thiis A, Sattar N, Smulders YM. Integrating information from novel risk factors with calculated risks: the critical impact of risk factor prevalence. Circulation. 2011;124:741-5. 
20. Berks D, Hoedjes M, Franx A, et al. Postpartum lifestyle intervention after complicated pregnancy proves feasible. In: Abstract ISSHP World Congress. Melbourne, Australia; 2010.

\section{Chapter 10}

21. Ferrara A, Hedderson MM, Albright CL, et al. A pregnancy and postpartum lifestyle intervention in women with gestational diabetes mellitus reduces diabetes risk factors: a feasibility randomized control trial. Diabetes Care. 2011;34:1519-25.

22. Lombard CB, Deeks AA, Ball K, Jolley D, Teede HJ. Weight, physical activity and dietary behavior change in young mothers: short term results of the HeLP-her cluster randomized controlled trial. Nutr J. 2009;8:17.

Samenvatting 


\section{Samenvatting}

Dit proefschrift onderzoekt de langetermijngevolgen van het doormaken van een pre-eclampsie voor de cardiovasculaire gezondheid en nierfunctie van de vrouw. Op basis van dit proefschrift kunnen we concluderen dat er in de jaren na een pre-eclampsie sprake is van een verhoogde perifere vaatweerstand, body mass index en insuline resistentie in vergelijking met vrouwen die een ongecompliceerde zwangerschap hebben doorgemaakt. Dit profiel kan worden samengevat onder de noemer 'metabool syndroom' en de aanwezigheid van een of meer van deze factoren verhoogt het risico op het ontstaan van hypertensie en hart- en vaatziekten. De aanwezigheid van deze beïnvloedbare risicofactoren suggereert dat vrouwen met een preeclampsie in de voorgeschiedenis mogelijk gebaat zijn bij leefstijlinterventies met als doel hart- en vaatziekten te voorkomen. Om de gezondheid van deze vrouwen op de lange termijn te optimaliseren is naar onze mening een standaard cardiovasculaire risicoscreening na de bevalling geïndiceerd. De belangrijkste bevindingen van elk hoofdstuk worden hieronder samengevat.

\section{Deel I - Cardiovasculaire gezondheid}

Het eerste deel van dit proefschrift beschrijft de cardiovasculaire gezondheid van vrouwen met een pre-eclampsie in de voorge-

schiedenis. Hoofdstuk 2 beschrijft een groep vrouwen 23 jaar na de bevalling, waarin de helft van de vrouwen met een pre-eclampsie in de voorgeschiedenis chronische hypertensie heeft ontwikkeld. Zowel bij de normotensieve als hypertensieve vrouwen werd een verhoogde renale vaatweerstand en verminderde renale doorbloeding gevonden vergeleken met controle vrouwen. Een verhoogde bloeddruk werd ook in hoofdstuk 3 bij vrouwen 4-6 jaar postpartum geobserveerd middels 24-uurs bloeddrukmeting. Deze studie suggereert dat waarschijnlijk al voor de aanvang van de zwangerschap een hogere body mass index en bloeddruk aanwezig waren, maar vindt echter geen bewijs voor een verschil in kreatinine klaring, endotheel functie of sympatische activiteit. Hoofdstuk 4 vindt een vergelijkbare microvasculaire functie na post-occlussie reactieve hyperemie in vrouwen met een voorgeschiedenis van pre-eclampsie en controles. Echter, er was een negatieve relatie tussen insuline resistentie en de microvasculaire functie in vrouwen met een doorgemaakte pre-eclampsie.

\section{Deel II - Nierfunctie}

Het tweede deel van dit proefschrift gaat in op de nierfunctie van vrouwen met een eerdere pre-eclampsie. De volgende hypothese werd getoetst dat de normale leeftijdsgerelateerde afname in nierfunctie sterker is in vrouwen die een pre-eclampsie hebben doorgemaakt dan bij controle vrouwen. Een vergelijking in twee cross-sectionele groepen vrouwen van zowel jonge als middelbare leeftijd in hoofdstuk 5 bevestigde deze hypothese niet, maar suggereerde juist dat er een verminderde kreatinine klaring en nierdoorbloeding na preeclampsie aanwezig is in beide groepen. In hoofdstuk 6, gebruik makende van een nauwkeurige meetmethode van inuline klaringen in een longitudinale studie opzet, werd gevonden dat de glomerulaire filtratiesnelheid 14 jaar postpartum normaliseert; er was echter een consistente trend voor een lagere nierdoorbloeding in vrouwen met pre-eclampsie in de voorgeschiedenis. Een vergelijking met een groep vrouwelijke nierdonoren van vergelijkbare leeftijd liet een renovasculair profiel zien van een verlaagde nierdoorbloeding, normale glomerulaire filtratiesnelheid en verhoogde filtratiefractie.

\section{Deel III - Cardiovasculair risicomanagement}

Het derde deel van dit proefschrift zet een strategie uiteen voor cardiovasculair risicomanagement en verkent mogelijkheden voor risicostratificatie binnen deze groep. Zoals uitgewerkt in hoofdstuk 7 zouden alle vrouwen, die een hypertensieve zwangerschapscomplicatie hebben doorgemaakt, in aanmerking moeten komen voor een cardiovasculaire risicoscreening postpartum. Deze screening zou moeten uitgaan van huidige richtlijnen voor primaire preventie van hart- en vaatziekten in asymptomatische personen. Hoofdstuk 8 beschrijft welke risicofactoren tijdens een postpartum screening gerelateerd zijn aan het ontstaan van chronische hypertensie na preeclampsie, zoals een positieve familie-anamnese voor hypertensie, het herhaald optreden van een hypertensieve zwangerschapscomplicatie en de aanwezigheid van twee of meer factoren van het metabool syndroom.

Tot slot wordt in hoofdstuk 9 een algemene beschouwing gegeven van dit proefschrift. 


\section{Dankwoord}

Vele mensen hebben direct of indirect meegewerkt aan de totstandkoming van dit proefschrift. In het bijzonder wil ik bedanken:

\section{Dankwoord}

Louis - bedankt voor de kansen en verantwoordelijkheid die je mij gegeven hebt

Marc - zelfs op afstand altijd al heel betrokken en boordevol met ideeën Timo - zonder jouw metingen had ik niks kunnen analyseren Inez - bedankt voor het familiegevoel

Simone - jij was toch wel mijn grote voorbeeld als promovendus Carmen - ik heb me goed vermaakt met jou op de kamer Chahinda - koffie op de vierde verdieping was een erg goede gewoonte

Franziska - we had a wonderful time at and outside work and I miss our swimming

Veronika - ik denk met plezier terug aan onze brainstormen via skype Mark Brown and George - thanks for having me over at St George All the ladies from Chapel St - morning tea has never been so good Jerome - bedankt voor jouw trots

Mijn ouders - jullie hebben mij altijd mijn eigen weg laten kiezen

Mijn paranimfen, Nicole en Renske - bedankt dat jullie achter mij staan Milena - een mooi boekje dankzij jouw creativiteit 


\section{Chapter 12}

\section{Curriculum vitae}

\section{Curriculum Vitae}

Julia Spaan, geboren 7 juni 1982, is opgegroeid in Monnickendam en later in Sint-Pancras. Haar middelbare schooldiploma VWO-gymnasium heeft zij behaald aan de Christelijke Scholengemeenschap Jan Arentsz te Alkmaar. Zij is in eerste instantie Gezondheidswetenschappen gaan studeren aan de Universiteit van Maastricht en na 2 jaar overgestapt naar de opleiding Geneeskunde. Zowel het doctoraal als basisarts diploma heeft zij met het predicaat cum laude behaald. Tijdens haar studie was zij actief in verschillende commissies, onder andere bij 'the International Federation of Medical Students' Associations'.

Al tijdens haar studie is zij betrokken geraakt bij wetenschappelijk onderzoek. Na haar studie is aan haar het Kootstra Talent Fellowship van de faculteit Health Medicine and Life Sciences van de Universiteit Maastricht toegekend. Na een periode als basisarts in het Orbis Medisch Centrum te Sittard werkzaam te zijn geweest heeft zij het onderzoek voortgezet in een promotietraject. Een deel van haar promotie heeft zij tot uitvoering mogen brengen in het St. George Hospital, Kogarah, verbonden aan de Universiteit van New South Wales te Sydney, Australië. Zij heeft op het congres van de International Society for the Study of Hypertension in Pregnancy 2010 te Melbourne een Young Investigator Award ontvangen. Zij zal haar carrière voortzetten als arts in opleiding tot gynaecoloog. 


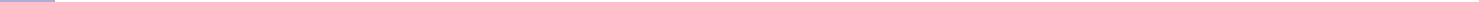




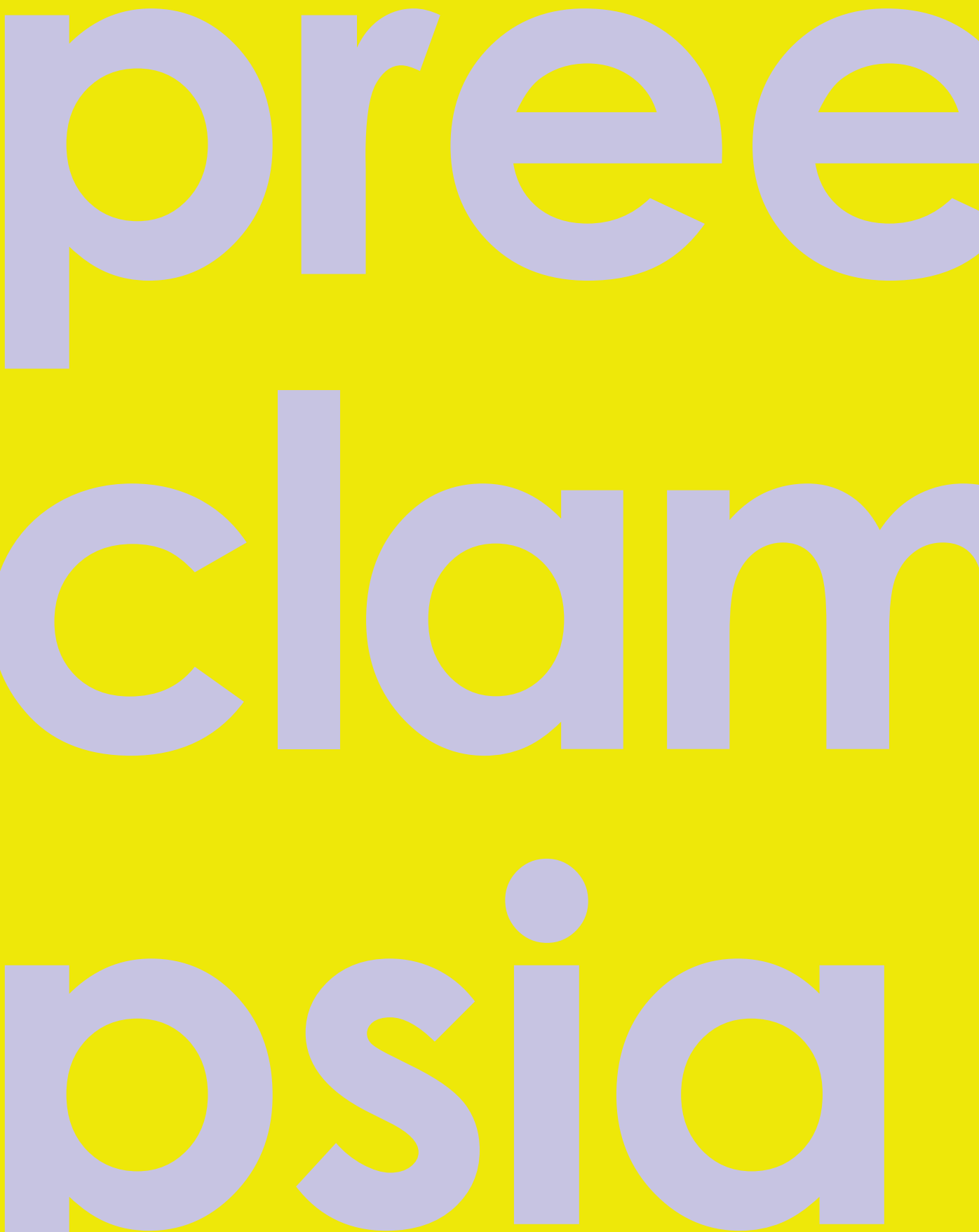